\title{
EFFECTS OF STAND DENSITY ON MITIGATION AND ADAPTABILITY TO CLIMATE CHANGE IN PINE AND HARDWOOD FORESTS OF MISSOURI
}

\author{
A Thesis \\ presented to \\ the Faculty of the Graduate School \\ at the University of Missouri-Columbia \\ In Partial Fulfillment \\ of the Requirements for the Degree \\ Master of Science

\begin{abstract}
by
SAMANTHA E. ANDERSON

Dr. Benjamin O. Knapp, Thesis Supervisor

May 2017
\end{abstract}


The undersigned, appointed by the dean of the Graduate School, have examined the thesis entitled

\section{EFFECTS OF STAND DENSITY ON MITIGATION AND ADAPTABILITY TO CLIMATE CHANGE IN PINE AND HARDWOOD FORESTS OF MISSOURI}

presented by Samantha E. Anderson, a candidate for the degree of Master of Science, and hereby certify that, in their opinion, it is worthy of acceptance.

\begin{tabular}{c}
\hline Benjamin O. Knapp, Ph.D. \\
\hline John M. Kabrick, Ph.D. \\
\hline Michael C. Stambaugh Ph.D. \\
\hline
\end{tabular}

Grant P. Elliott Ph.D 


\section{DEDICATION}

To my family, who have all truly perfected the 'smile and nod' when I start talking about trees, but support me $200 \%$ anyway. I love you guys!

To Jeffrey - whether we're 1,000 miles apart or living in the same crappy apartment, you've been my rock through it all. I can't wait to see where life takes us next! 


\section{ACKNOWLEDGEMENTS}

This project would not have been possible without the USDA Forest Service Northern Research Station and the decades of time and manpower put into these studies since 1950.

My technicians - 'The Davids' - David Dick and David Mann, Mike Rotondi, and Matt Easton, thank you all for dedicating your summers and free time to my project.

Ben- my tireless and unwavering advisor, who promised my study was well maintained and later listened patiently while I described the seemingly endless onslaught of problems I was encountering with my data - I don't think there are enough words to express how grateful I am for all your support and guidance.

Zim, my undergraduate advisor - thank you for pulling me aside and telling me flat-out I was going to go to graduate school, your faith in me has indescribably changed my life - my gratitude is boundless. 


\section{TABLE OF CONTENTS}

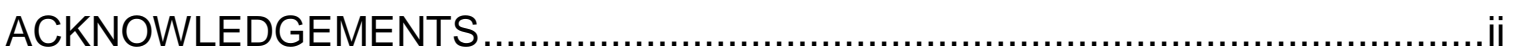

LIST OF TABLES …….........................................................................

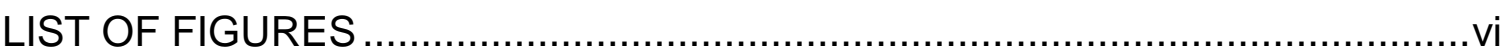

CHAPTER I: INTRODUCTION AND LITERATURE REVIEW .......................... 1

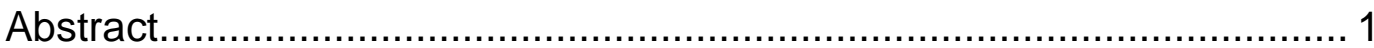

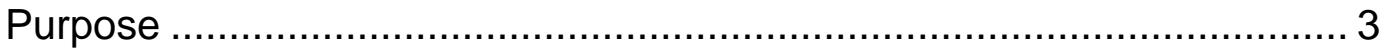

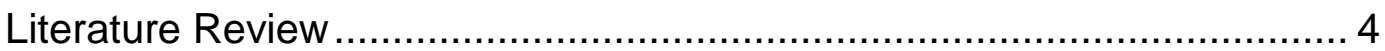

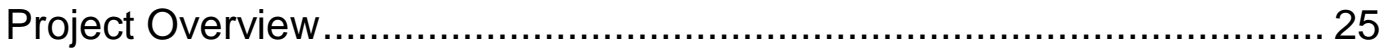

CHAPTER II: CARBON DYNAMICS OF TWO LONG-TERM THINNING STUDIES IN THE MISSOURI OZARKS ......................................................... 34

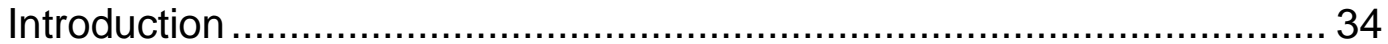

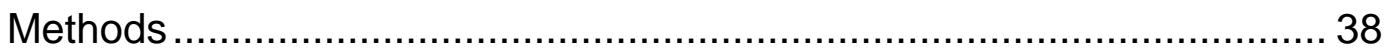

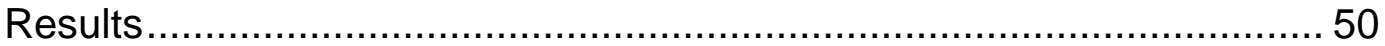

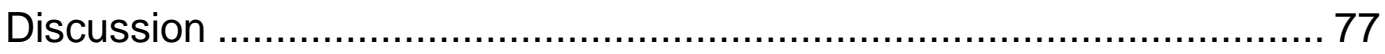

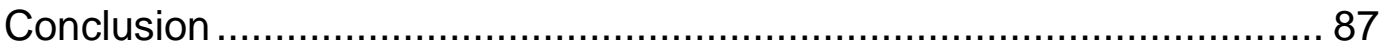

CHAPTER III: SHORT-TERM RESPONSE TO THINNING AT THE ONSET OF A SEVERE DROUGHT: A COMPARISON OF GROWTH MEASUREMENT

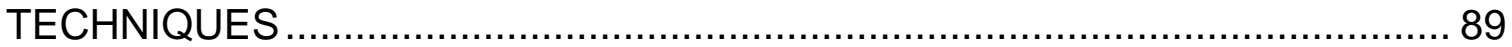

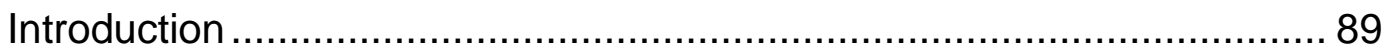

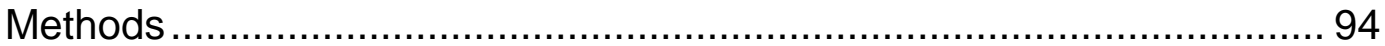

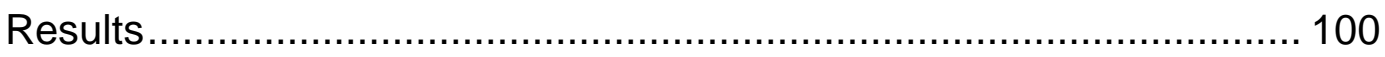

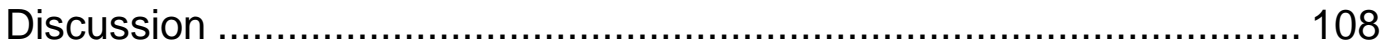

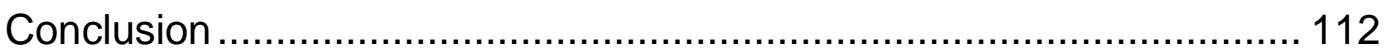

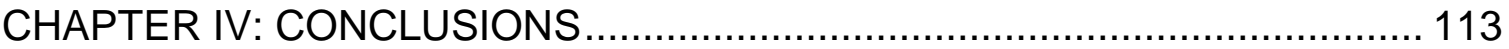

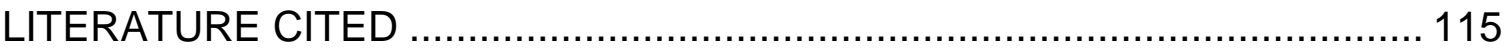

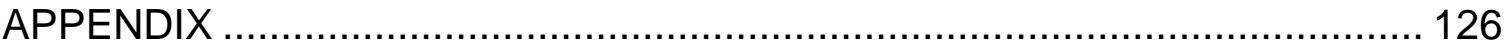




\section{LIST OF TABLES}

Table 1.1. Summary of 1952 Pine Stocking Study (PSS) treatments.

Table 1.2. Summary of 1961 Oak Stocking Study (OSS) treatments. 32

Table 2.1. Summary of PSS treatment groups. BA and \% stocking averaged across entire study period (1952-2007).

Table 2.2. Summary of OSS treatment groups. BA and \% stocking averaged across entire study period (1961-2001).

Table 2.3. Percent stocking equations for shortleaf pine developed by Rogers (1982).

Table 2.4. PSS variables, transformations, distributions, and analysis summary

Table 2.5. OSS variables, transformations, distributions, and analysis summary

Table 2.6. Stand description repeated measures ANOVA results for PSS and OSS. $P$ values represent significant effect at 0.05 level.

Table 2.7. Carbon dynamics repeated measures ANOVA results at stand and individual tree level for PSS and OSS. P values represent significant effect at 0.05 level.

Table 2.8. Gross carbon results of one-way ANOVA. Total gross carbon (TGC) for the PSS and study gross carbon (SGC) in overstory trees in the PSS and OSS. $P$ values represent a significant treatment effect at 0.05 level.

Table 2.9. OSS mortality repeated measures ANOVA results. $P$ values represent a significant effect at the 0.05 level. 
Table 2.10. Overstory species composition change 1961 to 2015. P values represent significant change in overstory species or group percentage at 0.05 level. * represents a significant loss in the species or group.

Table 2.11. Total species composition change 1961 to 2015. 2015 includes ingrowth $\geq 10 \mathrm{~cm} \mathrm{DBH}$. $\mathrm{P}$ values represent a significant change in total species composition at the 0.05 level. * represents a significant negative change in species or group composition. ^Spp in 'Other' category include (in order of abundance) Nyssa sylvatica, Ulmus spp., Acer rubrum, Sassafrass albidum, Prunus serotina, Cornus spp., Acer saccharum, Diospyros virginiana, and Morus spp.

Table 3.1. Treatment density growth response Pearson correlations with lagged treatment growth response. Bold $r$ values represent significant correlations at 0.05 significance level.

Table 3.2. Treatment density growth Pearson correlations with Palmer Drought Severity Index (PDSI) and lagged PDSI. Bold $r$ values represent significant correlations at 0.05 significance level.

Table 3.3. Drought influence and response to thinning paired t-test and ANOVA results. 105

Table 3.4. Drought influence on variance and response to thinning paired t-test and ANOVA results. 106 


\section{LIST OF FIGURES}

Figure 1.1. Sinkin Experimental Forest (SEF) map (Adams et al., 2004). 26

Figure 2.1. Descriptive stand metrics - trees per hectare (TPH) and quadratic mean diameter (QMD) for PSS (A-B) and OSS (C-D). Dashed line represents end of analysis and 2009 derecho.

Figure 2.2. Descriptive stand metrics - basal area and percent stocking for PSS (A-B) and OSS (C-D). Dashed line represents end of analysis and 2009 derecho.

Figure 2.3. QMD (A and $B)$ and basal area ( $C$ and $D)$ year and treatment effects in the OSS. Letters of significance represent treatment differences. Thinning application years are indicated by ' $\mathrm{T}$ '.

Figure 2.4. Total aboveground carbon storage and average tree aboveground carbon storage for the PSS (A \& B) and OSS (C \& D). T's represent thinning years. $T^{*}$ - only the High treatment was thinned. $T^{\wedge}$ - only High and Mid treatments thinned. Vertical line represents the final year included in the analysis before the 2009 derecho.

Figure 2.5. Individual tree carbon storage for the OSS including year and treatment effects. Letters of significance represent differences in treatment densities. Years of thinning application are indicated by ' $T$ '. Vertical line represents the final year included in the analysis before the 2009 derecho.

Figure 2.6. Stand and individual tree level carbon sequestration for the PSS (A\&B) and OSS (C\&D). T's represent thinning years. $T^{*}$ - only the High treatment was thinned. $T^{\wedge}$ - only High and Mid treatments thinned. Vertical line represents the final year included in the analysis before the 2009 derecho.

Figure 2.7. Stand-level carbon sequestration rate year and treatment effects for PSS (A and B) and OSS (C and D). Letters of significance indicate differences among treatment densities. Years of thinning application indicated with ' $\mathrm{T}^{\prime}$. $\mathrm{T}^{*}$ only the High treatment was thinned. $\mathrm{T}^{\wedge}$ - only High and Mid treatments thinned. Vertical line represents the final year included in the analysis before the 2009 derecho. 
Figure 2.8. Individual-tree carbon sequestration rate year and treatment effects for PSS (A and B) and OSS (C and D). Letters of significance indicate differences among treatment densities. Years of thinning application indicated with ' $T$ '. $T^{*}$ - only the High treatment was thinned. $\mathrm{T}^{\wedge}$ - only High and Mid treatments thinned. Vertical line represents the final year included in the analysis before the 2009 derecho. 64

Figure 2.9. Study gross carbon (SGC) for the PSS and OSS and total gross carbon (TGC) for the PSS. Letters represent significant differences among treatment densities with a visual comparison control plot. Pre-treatment data was unavailable to calculate TGC for the OSS.

Figure 2.10. Net change in aboveground carbon storage 1952-2007. Letters of significance indicate significant differences among treatment densities.

Figure 2.11. Sink v. Source. Comparison of growth and removal/mortality by treatment and growth period. Numbers below bars represent number of thins occurred in that treatment density in that period.

Figure 2.12. Sink v Source. Separated by treatment due to differences in thinning schedules. Letters of significance represent within treatment differences among treatment periods. * represents net change in carbon significantly different from 0 net change.

Figure 2.13. Merchantable volume by treatment density of the PSS in $2007 \ldots . . .70$

Figure 2.14. Carbon loss to mortality (Mg/ha) in OSS. Lowercase letters represent significant carbon loss due to mortality in the red oak group at 0.05 level. Uppercase letters represent significant carbon loss due to mortality in the white oak group at 0.05 level.

Figure 2.15. Red oak group carbon loss (Mg/ha). The effect of treatment on carbon loss was marginally significant between the 6.9 and 16.1 density treatments $(p=0.0596)$ in the red oak group.

Figure 2.16. Species composition of the OSS- 1961, 2001, and 2015. Graph A shows overstory composition only. Graph B shows overstory composition in 1961 and overstory plus ingrowth $\geq 10 \mathrm{~cm} \mathrm{DBH}$ in 2015. Letters show significant differences between years at 0.05 level. 
Figure 3.1. Average precipitation and temperature from 1920 - 2015 for the Missouri Ozark Region. Data supplied by the Salem weather station with gaps filled by Rolla and Berryman weather stations.

Figure 3.2. BAl from 1918 through 1971. Vertical dashed lines represent drought period; solid vertical line represents 1952 establishment thin. The CCC release is also visible as a small increase in BAI in 1934. 101

Figure 3.3. Basal area increment (BAI $\mathrm{mm}^{2}$ ) and Palmer Drought Severity Index (PDSI). BAI from 1918 through 1971 overlaid with PDSI averaged for Feb-Aug of each year. Note the very low PDSI value in 1954. 104

Figure 3.4. Change in growth (BAI) pre- drought to during-drought by treatment. Letters of significance represent one-way ANOVA results post-treatment. * designates paired t-tests showing a significant change in growth rates during the 1952-1956 drought. 106

Figure 3.5: Net BAI. Growth of thinned stands after removing control stand growth to reduce most of the influence of climate. Uppercase letters represent significant differences among treatments in one-way ANOVA results at 0.05 significance level pre-treatment (1931-1951). Lowercase letters indicate siginficant differenes among treatments based on one-way ANOVA results at 0.05 significance level post-treatment (1952-1971)..... 


\title{
CHAPTER I
}

\section{INTRODUCTION AND LITERATURE REVIEW}

\begin{abstract}
Understanding how forests respond to management practices in the context of climate change is increasingly important for developing multi-objective management strategies. In the Missouri Ozarks, the influence of long-term forest management on climate mitigation and adaptation potential is largely unknown. Using data from two long-term Missouri Ozark thinning studies, I determined the influence of stand density management on objectives relating to climate change mitigation and adaptability. First, carbon dynamics of even-aged shortleaf pine and upland oak forests were assessed to better understand the effects of stand density on storing and sequestering atmospheric $\mathrm{CO}_{2}$. Results from $>50$ years of management suggest that at the stand level, tree density influenced the amount of carbon stored and sequestered. At the individual-tree level, lower density stands produced merchantable trees earlier than more dense stands and stored more carbon per tree. Overall, carbon storage continued to increase through time and carbon sequestration rates did not show significant decline during the study. Second, a shortleaf pine tree ring-width chronology was developed to better understand the influence of thinning on tree-level growth during a severe drought. Decreased growth rates in response to a severe drought were apparent in unmanaged, overstocked stands. Thinned stands showed a range of responses from no change in growth in the lightest thinning treatment to more
\end{abstract}


than doubling pre-drought growth rates with heavy thinning during the drought period. Negative Pearson correlations between BAI and PDSI in the posttreatment period suggest that thinning increased shortleaf pine resistance and resilience to drought.

Results from this study offer valuable insight into the impacts of traditional forest management on emerging objectives related to climate change. This study illustrates: (1) stand- and individual tree-level trade-offs associated with managing for both increased carbon storage and merchantable volume; (2) the role of stand density in maintaining carbon sequestration rates through time; and (3) the role of thinning in increasing shortleaf pine adaptability to drought events. Results of this study will be beneficial for future management regarding the effects of stand density on mitigation and adaptation to climate change in upland oak and shortleaf pine forests of the Missouri Ozarks. 


\section{Purpose}

Many commonly used forest management practices were developed for the single objective of sustained yield. Recent interests in managing forests as complex ecosystems has shifted management interests from focus on a single objective toward a multi-resource approach, which includes emerging focus on climate change mitigation and adaptation objectives. Determining how forests respond to traditional management in the context of global climate change is critical for developing simple, effective management techniques that will foster healthy, productive forests into the future. In the Missouri Ozarks, the influence of long-term repeated thinning on climate change mitigation and adaptation potential is largely unknown.

Considering the implications of future climate change and increased global atmospheric $\mathrm{CO}_{2}$ levels, I first looked to determine the effects of repeated thinning in two long-term (>50 year) density management studies in the Missouri Ozarks on: (1) individual tree- and stand-level carbon storage and sequestration rates; (2) sink/source dynamics associated with thinning through the duration of the studies; (3) mortality and species composition changes in managed upland oak forests; and (4) trade-offs associated with managing for both volume and carbon storage in shortleaf pine stands. Using a shortleaf pine tree-ring chronology I next looked to determine: (1) the extent to which thinning influenced the effect of previous years' growth and PDSI on growth response, (2) the influence of the 1950s drought on growth of uncut stands, and (3) the influence of thinning on growth response during the 1950s drought. 


\section{Literature Review}

Forests represent one of the largest terrestrial sinks of atmospheric $\mathrm{CO}_{2}$ on Earth, storing over $80 \%$ of total global aboveground carbon as biomass (Fahey et al., 2010; Fu et al., 2015). Predicted effects of climate change, including increased ecosystem disturbances and altered water and carbon cycles, may compromise the ability of forests to maintain essential ecosystem functions into the future. Determining how forests respond to traditional management in the context of global climate change is important for developing simple, effective management techniques that will foster healthy, productive forests into the future.

Forest management objectives have expanded beyond traditional objectives related to production and volume yield toward addressing challenges surrounding climate change. A developing body of recent research has considered ways in which silviculture can address two such objectives: climate change mitigation and adaptation to new or future conditions (Cain and Shelton, 2003; Canadell and Raupach, 2008; Cescatti and Piutti, 1998; D’Amato et al., 2011; Duveneck et al., 2014; Hoover and Stout, 2007; Schaedel et al., 2017). Climate change mitigation is defined as the process of reducing emissions or enhancing sinks of greenhouse gases (Cain and Shelton, 2003; IPCC, 2014). Forests aid in climate change mitigation by sequestering carbon through photosynthesis, during which atmospheric $\mathrm{CO}_{2}$ and water are converted to biomass that is composed of approximately $50 \%$ carbon (Fu et al., 2015; Grigal and Ohmann, 1992). Carbon sequestration is the rate at which forests assimilate 
atmospheric $\mathrm{CO}_{2}$ into biomass, and carbon storage is the capacity of an ecosystem to maintain that biomass in trees, roots, soil, and forest floor debris for long periods of time. Effective climate change mitigation requires forests to serve as carbon sinks, defined as ecosystems that store more carbon than is lost to mortality or released into the atmosphere through respiration. Forest carbon sinks may become sources of atmospheric carbon if they experience a net loss of carbon through deforestation, mortality, decomposition, or tree removal for short-lived wood products such as fuel or paper (Birdsey, 1992).

Adaptation to climate change is defined as the ability of a forest or ecosystem to accommodate changes influenced by climate while continuing to provide ecosystem goods and services (Duveneck et al., 2014; Laurent et al., 2003). Forest adaptability has commonly been described and quantified in terms of resistance and resilience to disturbances. Resistance is the ability of an ecosystem to remain unchanged during a disturbance (D'Amato et al., 2013; Duveneck et al., 2014), while resilience allows systems to absorb some disturbance and reorganize while retaining essentially the same structure, function, identity, and feedbacks (DeRose and Long, 2015; Walker et al., 2004).

The application of forest management practices has been shown to promote both climate change mitigation and adaptation (D'Amato et al., 2011; Davis et al., 2009; Harmon and Marks, 2002; Hoover and Stout, 2007). Modified management strategies to achieve climate change mitigation and adaptation goals include extended rotation management, increasing structural and compositional complexity, supporting redundant functional species, patch 
harvesting, favoring future climate suitable species, and encouraging complementarity over competitive exclusion (D'Amato et al., 2011; Duveneck et al., 2014; Millar et al., 2007; Paquette and Messier, 2011). Thinning, an intermediate management treatment, is commonly used to manipulate forest structure and composition to achieve desirable future conditions. Due to uncertainties surrounding the effects of climate change, thinning may be a viable option for maintaining healthy forests capable of mitigating and adapting to a changing climate.

\section{Part I: Climate Change and Forests}

Climate change is a strong driver of ecological change and is associated with projected changes in global temperatures and water and carbon cycles in the foreseeable future. Climate change has been shown to be affected by human activities such as fossil fuel combustion, land use change, and agricultural and forestry practices. Concentrations of atmospheric greenhouse gasses (GHGs) have been increasing since 1750 , with GHG emissions peaking in the period from 2000 to 2010 (IPCC, 2014). Atmospheric carbon dioxide $\left(\mathrm{CO}_{2}\right)$ concentrations have shown a $40 \%$ increase since 1750 and continue to be a major contributor to anthropogenic greenhouse gas production ( $76 \%$ of total GHG emissions in 2010) (IPCC, 2014). Since 1970, $\mathrm{CO}_{2}$ emissions from fossil fuel combustion have more than tripled and emissions from land use practices, including agriculture and forestry, have increased by about $40 \%$. Based on the 2014 International Panel on Climate Change (IPCC) report, all but the least severe climate projection model, RCP2.6, will result in continued warming 
beyond the year 2100. Expected consequences of the more severe projections include the loss of ecosystems and biodiversity, species extinctions, and increased risks to food security and water availability.

Forests are one of the largest sinks of $\mathrm{CO}_{2}$ on Earth, but the complex effects of a changing climate, including increased global temperatures, drought events, insect and disease outbreaks, and wildfires, may threaten the capacity of forests to remain net $\mathrm{CO}_{2}$ sinks into the future (Chmura et al., 2011). To better understand the possible impacts of changes to ecosystem disturbances, researchers have begun to assess forest ecosystem response to past and current climate-related disturbances through observational studies.

Drought events are expected to result in vegetation range shifts, species composition changes, decreased regeneration success, slowed growth rates, and tree mortality (Adams et al., 2009; Breshears et al., 2009). Although future effects of drought-induced mortality remain uncertain, studies have addressed the topic in multiple ecosystems across the US. Based on their study of piñon pine (Pinus edulis), Adams et al. (2009) suggest that projected short, frequent droughts will cause widespread vegetation die-off in the southwest. Drought timing, another important factor, has been found to have differing impacts on tree growth. In a study conducted in an upland oak forest in Tennessee, Hanson et al. (2001) found that droughts occurring mid-growing season may inhibit height growth in many species while late-season droughts may slow diameter growth of mature trees and inhibit overall growth of seedlings. Age and competition stress were also found to influence drought response. In a study conducted by 
Martínez-Vilalta et al. (2012), Scots pine (Pinus sylvestris) was found to be more susceptible to drought-induced decline or mortality when trees were older or were growing in dense stands. The same occurrence has been noted in other studies where larger or older trees are some of the first to be affected by drought (Allen et al., 2010; Floyd et al., 2009). Lagged response to drought has also been observed in some species, making the effects of drought more difficult to determine as mortality does not occur immediately and may take years or even decades to manifest following a water deficit (Allen et al., 2010; Bigler et al., 2007).

Insect and disease outbreaks have been observed across the US and Canada, and some more destructive outbreaks have been attributed to changes in the conditions insects experience due to warming temperatures (Allen et al., 2010; Ayers and Lombardero, 2000). Bark beetles and fungal root infections comprise some of the most impactful disturbance agents in pine forests of the US (Ayers and Lombardero, 2000; Logan et al., 2003) and gypsy moth defoliation, oak wilt, and red oak decline have impacted oak forests of the Central Hardwoods Region (Ayers and Lombardero, 2000; Dwyer et al., 2007; Voelker et al., 2008).

Increased tree mortality, combined with historic fire suppression and dry conditions can increase woody debris and fuels in many areas. This combination of factors has been projected to cause an increase in the frequency and severity of wildfires, as already being seen in the western US and Canada (Canadell and Raupach, 2008; Guyette et al., 2014). Stand-replacing wildfires can burn 
thousands of hectares of wildland, threatening not only the carbon budget, but timber products, wildlife habitats, cities, and homes (Kirilenko and Sedjo, 2007).

As climate change-induced tree mortality increases, Allen et al. (2010) suggest that the Earth's forests - sinks that hold over $80 \%$ of the global terrestrial aboveground carbon - have the potential to become a net source of atmospheric carbon. Dead and decaying trees that no longer actively store carbon as biomass may release pulses of carbon into the atmosphere as a byproduct of decomposition (Allen et al., 2010; Birdsey, 1992). Large-scale forest mortality could alter carbon budgets in surrounding areas and potentially undermine the capacity of forests to store and sequester carbon (Allen et al., 2010). Already, in parts of Canada that have seen devastating wildfires, forests have transitioned from sinks of carbon prior to 2000 to current sources of atmospheric $\mathrm{CO}_{2}$ (Canadell and Raupach, 2008).

\section{Part II: Forest Management: Addressing Traditional and Emerging Objectives}

Traditional single-objective forest management practices have largely focused on managing trees as crops to meet demands for wood products (Anning and McCarthy, 2013; Puettmann et al., 2009; Smith et al., 1997; Zeide, 2001). The practice of thinning developed as a response to long periods between harvests and subsequent wood product shortages associated with the widespread establishment of even-aged stands in the fourteenth century (Puettmann et al., 2009). Although thinning began as a mechanism for quickly fulfilling demand for wood products, through time, a better understanding of the 
concept of growing space has spurred the evolution of thinning into a practice used to sustainably enhance growth of residual trees, remove anticipated mortality, and shorten rotation times (Anning and McCarthy, 2013; Puettmann et al., 2009).

With rising concerns for protecting and maintaining forest ecosystems in the face of an uncertain future, forest management practices have begun to move away from a focus on wood production objectives and toward multiresource management, with recent interest in climate change mitigation and adaptation objectives (Behan, 1990). Thinning intensity, thinning method, and length of rotation have been found to affect the natural capacity of forests to adapt to and mitigate climate change through effects on carbon sequestration and storage (mitigation) and resistance and resilience to disturbances (adaptation) (Cain and Shelton, 2003; Canadell and Raupach, 2008; Cescatti and Piutti, 1998; D'Amato et al., 2011; Duveneck et al., 2014; Hoover and Stout, 2007; Laurent et al., 2003; Powers et al., 2010; Zeide, 2001). A better understanding of the effects of thinning and rotation length can inform specific management prescriptions designed to meet climate objectives.

\section{A. Climate Change Mitigation}

Climate change mitigation strategies are defined as actions that enable ecosystems to reduce anthropogenic influences on global climate (Millar et al., 2007). There are several ways that managers can alter thinning prescriptions to affect carbon accumulation. Thinning intensity describes the amount of material removed from the stand and consequently the amount of growing space created. 
The method of thinning determines which trees get removed and often focuses on small diameter removals (i.e., thinning from below) or removal of larger trees (i.e., crown thinning). Finally, the thinning schedule and rotation length are important for controlling the balance of carbon accumulation vs removal over the life of the stand. Each of these factors affects both carbon sequestration and storage rates at the stand and individual tree levels.

By manipulating stand density, thinning intensity has been shown to influence carbon storage and carbon sequestration rates. D'Amato et al. (2011) used five long-term thinning experiments in the Upper Great Lakes region to assess the influence of thinning intensity on the compatibility of managing for both increased carbon storage and sequestration rates. The authors found that higher density stands stored more aboveground carbon than low density stands, but thinning encouraged growth, and subsequently, increased stand-level carbon sequestration rates in periods of no treatment. Cescatti and Piutti (1998) modeled the effects of over twenty different thinning intensities and found that it was possible to increase carbon storage and sequestration rates in individual trees and entire stands through thinning, with higher density stands resulting in the greatest amount of standing biomass by 2100 .

Thinning and harvest methods, including single-tree and group selection and thinning from above and below, have been shown to influence forest climate mitigation potential. Hoover and Stout (2007) found that thinning method affected carbon sequestration rates, such that thinning from below increased stand-level carbon sequestration compared to thinning from above or selection thinning. The 
authors also found that thinning methods that favored carbon sequestration also favored carbon storage and volume production. Davis et al. (2009) compared four different fifty-year harvest histories in the Central Appalachians (no harvest, clear-cutting, single-tree selection, and diameter limit cutting) to determine the effects of management method on carbon sequestration rates and forest carbon sinks. The authors found that over 55 years of management, long-term carbon sequestration rates were not significantly impacted by management, but singletree selection cutting and diameter-limit cutting resulted in 37\% more carbon stored over 50 years compared to no management.

Rotation length has also been shown to positively influence climate mitigation potential by increasing average tree size and increasing structural complexity. D'Amato et al. (2011) found that live-tree carbon stores increased with stand age up to age 350, regardless of thinning treatment, even though sequestration rates slowed with age. Duveneck et al. (2014) concluded that extended rotations increase aboveground biomass when compared to traditional management in Northern Great Lakes forests.

\section{B. Adaptation to Climate Change}

Forest adaptability has commonly been assessed through resistance and resilience to a changing climate or disturbance events. Given future uncertainties associated with climate change, it may be increasingly important to prescribe management to increase ecosystem resistance and resilience to disturbance. Resistance strategies attempt to maintain ecosystem integrity when challenged by a disturbance, and resilience strategies allow systems to absorb some 
disturbance and reorganize while retaining essentially the same structure and function (DeRose and Long, 2015; Janowiak et al., 2014; Walker et al., 2004).

Dendrochronological methods have been developed to determine relationships between tree growth and climate conditions, providing insight into the potential resistance and/or resilience of trees to climate stress. Estes (1970) used ring-width chronologies from three central Mississippi Valley species (Quercus velutina, Q. alba, Pinus echinata) to determine species growth response to climatic influences and found that black oak generally responded more to climatic influences than to other environmental factors such as soil type or site. Similarly, Gea-Izquierdo et al. (2011) determined that Quercus ilex was sensitive to increasing temperatures and decreasing water availability caused by climate change in Spain. In a study looking at the influence of site on Norway spruce (Picea abies) growth and response to drought, Laurent et al. (2003) found that in humid stands, growth was related to lagged climate effects while in dry stands, growth was related to water availability during the early part of the growing period.

Management practices including thinning and extended rotations have been found to promote climate adaptation by allowing forests to accommodate change while continuing to provide ecosystem goods and services (Duveneck et al., 2014). Several studies have considered the use of thinning intensity, method of thinning, and rotation length to facilitate climate change adaptation by increasing growing space and structural and compositional complexity, supporting redundant functional species, favoring future climate suitable species, 
and encouraging complementarity over competitive exclusion (D'Amato et al., 2011; Duveneck et al., 2014; Janowiak et al., 2014; Millar et al., 2007; Paquette and Messier, 2011).

Thinning intensity has been shown to influence resistance and resilience to changes in water availability (drought). D'Amato et al. (2013) found that thinning intensity was positively associated with increased rate of growth recovery following drought (resilience) in young pine stands. In a study of the effects of thinning intensity on Norway spruce (Picea abies) growth and response to drought, Laurent et al. (2003) found that thinning increased individual-tree resistance to drought stresses compared to no thinning. Cescatti and Piutti (1998) used tree ring width chronologies of a 140-year-old even aged European beech (Fagus sylvatica) forest and found that competition level (low or high) had a significant effect on water sensitivity and growth, in which high competition level and temperature resulted in low individual tree growth.

Thinning method has also been shown to affect resistance and resilience to changes in climate and water availability. In a long-term thinning study in red pine (Pinus resinosa), Magruder et al. (2013) found that thinning from below resulted in an increased resilience to temperature variation, precipitation variation, and moisture index variation and led to increased tree-level productivity compared to thinning from above or no thinning. Due to stand and individual tree trade-offs associated with biomass accumulation, the authors showed that thinning from below resulted in larger residual trees with lower total biomass accumulation. 
Increasing time before final harvest through extended rotations has been shown to increase stand-level species and structural complexity. D'Amato et al. (2010) found that the use of extended rotations in red pine stands resulted in stand composition and structure that closely resembled that of old growth forests while simultaneously continuing to store carbon and produce valuable timber.

\section{Competing Objectives}

Forest management is a decision-driven process, based on landowner objectives, financial considerations, and ecological constraints. In the past, forest management practices were commonly designed to optimize individual objectives, providing the foundation for maximum sustained yield approaches to plantation management (Behan, 1990). Through time, there became increased interest in managing forests for multiple objectives, such as providing wildlife habitat while simultaneously generating timber revenue. However, Bradford and D'Amato (2011) suggest that there are often trade-offs that should be considered when managing for multiple objectives.

With increased interest in management that addresses climate change, information is needed regarding how silvicultural practices affect trade-offs among climate change objectives. For example, although mitigation potential was high, D'Amato et al. (2011) found that maintaining higher stocking and carbon storage levels in a red pine forest resulted in decreased structural and compositional complexity (i.e., increased mitigation caused decreased adaptability). Similarly, Burton et al. (2013) found that understory plant species 
diversity (adaptability) suffered when stands were managed to maximize carbon storage (mitigation).

Forest management for climate change objectives may also create tradeoffs with traditional management objectives. Long-term studies originally designed to assess the effects of management on volume yield may offer insight into trade-offs associated with managing for both volume yield and increased climate mitigation. Volume objectives typically require short-rotation management practices that promote growth of a single species to a desired size in the least amount of time (high carbon sequestration rates) (Roach and Gingrich, 1968). Conversely, climate change mitigation objectives may favor long rotations over which growing space is fully utilized with a mixture of species (high carbon storage capacity). Few studies have compared these two contrasting objectives, but managing for both may become an important consideration for the future as timber markets and climate objectives continue to evolve.

Bradford and D'Amato (2011) suggest a thorough consideration of objectives to determine thresholds for benefits and trade-offs of proposed management practices. Acknowledging the disparity between objectives (mitigation and adaptation or mitigation and volume-yield) may supply insight into the next steps in developing management practices that address multiple competing objectives as effectively as possible.

\section{Part III: Central Hardwoods of Missouri}

The Central Hardwoods Region of the United States spans over 89 million hectares from Oklahoma, east to the Appalachians, north to southern Maine, 
across the southern Great Lakes region, and encompasses the Driftless Area in southern Wisconsin (Johnson et al., 2009). Characteristic tree species of the region include black oak (Quercus velutina), white oak ( $Q$. alba), scarlet oak ( $Q$. coccinea), chestnut oak (Q. montana), post oak (Q. stellata), northern red oak ( $Q$. rubra), southern red oak ( $Q$. falcata), bur oak ( $Q$. macrocarpa), pignut hickory (Carya glabra), mockernut hickory (C. tomentosa), sugar maple (Acer saccharum), red maple (A. rubrum), black gum (Nyssa sylvatica), black cherry (Prunus serotina), and flowering dogwood (Cornus florida) (Johnson et al., 2009). Central hardwood forests are dominant on several prominent landforms in the central eastern US including the Appalachian Mountains, Allegheny Plateau, the Ohio Valley, and the Ozark Highlands (Johnson et al., 2009).

The Missouri Ozarks, located in the westernmost portion of the Central Hardwoods Region, is characterized by a deeply dissected, low structural dome. Soils are old, heavily weathered, well-drained, acidic, and rocky (Brandt et al., 2014). In some areas, rock content is as high as $35 \%$ by volume, and a variety of parent materials, including dolomite and sandstone, contribute to the heterogeneity of sites in the Ozarks (Brandt et al., 2014; Guldin, 2007). Forest types common to the Missouri Ozarks include upland oak forests, mixed oakshortleaf pine forests, and oak/gum/cypress forests (Piva, 2015).

\section{A. Upland Oak Forests}

In the Ozarks, black, white, scarlet, and northern red oaks are important species of the upland central hardwood forest type (Johnson et al., 2009; Roach and Gingrich, 1968). Upland hardwood forests are most abundant on dry 
ridgetops and backslopes, and associated species such as hickories, flowering dogwood, and shortleaf pine (Pinus echinata) are present in varying densities (Brinkman and Smith, 1968; Johnson et al., 2009). Black oak and white oak are two of the most abundant tree species in the Ozarks and are among the most desirable for timber products. In the Ozarks, these two species are often found together on better sites where shortleaf pine cannot compete. Both black and white oak are classified as intermediate in shade tolerance, but white oak is considered more tolerant of shade than black oak. Due to the species' slow growth and higher tolerance to shade, white oak can persist in the understory for up to 90 years, responds well to release, and is considered a climax species in the Ozarks (Brinkman and Smith, 1968; Rogers, 1990).

Management guides for Missouri upland oak forest types commonly recommend even-aged management methods to encourage oak regeneration and increase the quality and growth rate of remaining crop trees (Roach and Gingrich, 1968). Specifically, clear-cutting with subsequent intermediate thinnings was recommended as the optimal management regime for quickly producing merchantable timber in the Ozarks region (Roach and Gingrich, 1968). In fact, Roach and Gingrich (1968) expressly state that uneven-aged management is ineffective and undesirable in upland oak systems. Specifically, black oaks are unable to regenerate under heavy shade, and white oaks seedlings are quickly overtopped by faster growing species. Although even-aged management is effective for managing upland oak ecosystems, uneven-aged management in the Missouri Ozarks is viable. For over 60 years, Pioneer Forest, which includes > 
62,000 hectares of privately owned oak-hickory forest in the Missouri Ozarks, has been successfully managed with single-tree selection (Guldin et al., 2008; Larsen et al., 1997; Larsen et al., 1999; Loewenstein et al., 2000).

Upland oaks in the Ozarks have been documented as vulnerable to forest health concerns that include oak decline and Armillaria root rot (Bruhn et al., 2005; Kabrick et al., 2004; Sander, 1990). Oak decline was first noted in the Missouri Ozarks in the 1970s and by 1999 had become widespread throughout the Interior Highlands (Dwyer et al., 2007; Kabrick et al., 2008). Most prominent in the red oak group (up to ten-fold greater occurrence than in white oaks), the disease complex has been found to be incited by drought events and exacerbated by boring insects, Armillaria root rot, and other mortality causing agents (Kabrick et al., 2004; Kabrick, et al., 2008). Studies showed that decline occurred in physiologically mature red oaks $(>45 \mathrm{~cm})$ growing on ridgetops, back slopes, and droughty, rocky soils (Guldin et al., 2006; Kabrick et al., 2004; Kabrick et al., 2008). However, Kabrick et al. (2008) determined that red oak mortality was greater on poor sites because red oak species were more prevalent on those sites. After adjusting for initial density of red oaks, Kabrick et al. (2008) found that red oaks on poor sites were just as likely to succumb to decline as red oaks on better sites. Additionally, multiple studies determined that decline was present in red oak species across all diameter classes (Guldin et al., 2006; Heitzman et al., 2004; Kabrick et al., 2008).

Attempts to reduce the rate of red oak decline through the application of silvicultural practices have been nominally successful (Dwyer et al., 2007; Wang 
et al., 2013). Dwyer et al. (2007) applied improvement harvests in mature, previously unmanaged, upland oak stands exhibiting signs of oak decline to determine if forest management had any effect on the rate of decline. The authors found that improvement harvests did not mitigate the effects of oak decline in mature stands but also did not accelerate decline over 14 years. Wang et al. (2013) modeled the effects of three different management regimes - clearcutting, thinning, and group selection - on mitigating oak decline. The authors found that group selection and clearcutting were most effective at mitigating oak decline in the short- and mid-term, respectively, and that thinning reduced mortality and resulted in maintaining the most biomass on the site over the projected 50 years.

\section{B. Shortleaf Pine}

Of the four major southern yellow pines, shortleaf pine is the most widely distributed (Brinkman and Smith, 1968; Will et al., 2014). Its range extends across 22 states from New York, south to Florida, and west to Texas and Oklahoma (Guldin, 2007; Lawson, 1990). Shortleaf pine is the only pine native to Missouri and is found primarily in the Ozark Highlands, most often in association with upland oaks and hickories and in small pure stands initiated by fire or intense management (Brinkman and Rogers, 1967; Brinkman and Smith, 1968; Guldin, 2007). As a historically highly desired timber species, heavy harvesting practices in the early $20^{\text {th }}$ century decreased shortleaf pine's prominence in the Missouri Ozarks (Brinkman and Smith, 1968; Guldin, 2007). Today, pure stands are uncommon in the Ozarks and historical high-grading by paper and lumber 
mills led to local extirpation of the species in previously mixed oak-pine stands (Guldin, 2007).

As a highly drought- and fire-tolerant generalist, shortleaf pine can outcompete most oaks on sites with low soil moisture (Brinkman and Smith, 1968; Guldin, 2007). In the Missouri Ozarks, shortleaf pine can be found on ridgetops, upper slopes, and south and west facing slopes where moisture is limited by cherty soils and an impermeable fragipan layer (Brinkman and Rogers, 1967; Brinkman and Smith, 1968; Walker and Wiant, 1966). As site quality increases, the proportion of shortleaf pine decreases as it is outcompeted by black and northern red oaks.

Silvicultural guidelines for shortleaf pine in the Missouri Ozarks have not been updated for decades, when it was managed for timber production in nearly pure, even-aged stands (Brinkman and Smith, 1968). On sites with black oak site index of 45-55 (index age 50), shortleaf pine can be managed as pure stands. As black oak site index increases, mixtures of pine and oak are more productive, and at high black oak site indices (75+), oaks should be favored as they will outcompete shortleaf pine in height growth (Brinkman and Rogers, 1967; Brinkman and Smith, 1968). Brinkman and Rogers (1967) suggest that intermittent thinning to control density and composition will produce maximum volume and returns by increasing available growing space to residual pines and decreasing competition from oaks and other hardwoods. Commercial thinning can begin at age 20-25. Depending on the product goal, rotation ages of 70 years or less can be attained for intensively managed stands and even shorter 
rotations (40-45 years) can be reached in plantations. On better sites, rotation ages of $90+$ years may be beneficial if there is a market for large sawlog timber (Brinkman and Rogers, 1967; Brinkman and Smith, 1968).

Due to heavy harvesting of shortleaf pine in the early $20^{\text {th }}$ century and subsequent fire suppression, much of the acreage of shortleaf pine across the southern US has been lost to competition from hardwoods or replaced with faster growing loblolly pine (Pinus taeda) plantations (Guldin, 2007). In 1965, stands dominated by shortleaf pine covered 134,000 hectares in Missouri, and oak-pine stands contributed an additional 259,000 hectares (Brinkman and Smith, 1968). In 2013, FIA data reported shortleaf pine and oak-pine forest types covered a total of only 235,000 hectares in Missouri, which is a $40 \%$ reduction in area (Oswalt, 2013). As management objectives, silvicultural interests, and timber markets fluctuated through time, shortleaf pine forests were largely left unmanaged in favor of oaks in Missouri and faster growing loblolly pine in the south. More recently however, management interests involving shortleaf pine have been renewed with focus on restoration and regeneration of the species and associated forest types including shortleaf pine-bluestem woodlands, mixed oak-pine forests, and pure shortleaf pine stands (Elliott et al., 2012; Kabrick et al., 2017; Will et al., 2014).

\section{Climate Change and the Central Hardwoods Region}

Climate change has been projected to alter the ranges of most, if not all major tree species in the Central Hardwoods Region. Regardless of future emissions levels, the extent of suitable sites for black oak and shortleaf pine are 
projected to remain unchanged (black oak) or increase (shortleaf pine) in the Missouri Ozarks (Brandt et al., 2014) (Appendix: Figure A.1; A.2). Kabrick et al. (2017) found that oak-pine mixedwoods of the Ozarks are most compatible with and adaptable to future climate scenarios when $50 \%$ the stand is composed of shortleaf pine. Current interests in restoring shortleaf pine-oak forests in the Ozarks may benefit future Ozark forest adaptability.

Future species composition cannot be accurately predicted due to the uncertainty surrounding the effects climate change will have on species interactions. Specifically, it is largely unknown how southern tree species, wildlife, and insects will impact northern communities as rising temperatures and altered precipitation regimes facilitate northward migration (Brandt et al., 2014). For example, shortleaf pine is highly susceptible to mortality caused by southern pine beetle (Dendroctonus frontalis), which is uncommon in Missouri but prevalent in the southeast and may become more prominent as the climate warms and new parts of the US become hospitable to the beetle (Elliott et al., 2012). Similarly, suitable habitat for loblolly pine is projected to increase in the Ozarks. With similar habitat requirements but faster early growth than shortleaf pine, loblolly pine may be able to outcompete shortleaf pine for resources and eventually replace the Ozark native (Will et al., 2014).

\section{Part IV: Conclusion}

Due to the uncertain consequences of a changing climate and the impacts it may have on disturbance regimes, forest composition, and species ranges, the application of simple yet dynamic sustainable management practices has 
become increasingly necessary. Forest management practices may be designed to increase forest biomass and carbon accumulation (climate change mitigation) and/or promote structural and compositional complexity and climate change resistance (adaptation). Long-term studies and dendrochronological assessments are useful for assessing the long-term impacts of traditional forest management on current climate related objectives. There remains a large knowledge gap surrounding the impacts of traditional management on climate change mitigation and adaptation in the Ozark Highlands and Central Hardwoods Region. 


\section{Project Overview}

This project is based on two long-term thinning studies initiated between 1952 and 1961 by the USDA Forest Service on the Mark Twain National Forest. The two studies included the Pine Stocking Study (PSS) and the Oak Stocking Study (OSS), which were both designed to assess the effects of stand density and repeated thinning on growth and volume yield in Missouri Ozark upland forests. The two studies were maintained for $>60$ years and have contributed to multiple publications (Brinkman et al., 1965; Gingrich et al., 1965; Loewenstein, 2005; Rogers and Brinkman, 1965).

\section{Study Site}

These studies were conducted on the Sinkin Experimental Forest (SEF) in Dent County, southeastern Missouri (Figure 1.1). Located in the Current River Hills subsection of the Ozark Highlands ecological section (Nigh and Schroeder, 2002), the SEF was designated as an Experimental Forest by the USDA Forest Service in 1950 and was maintained by the USDA Forest Service Northern Research Station as part of the Mark Twain National Forest. The SEF contains acidic soils with low nutrient supply capacity, derived from highly weathered sandstone and dolomite parent materials (Adams et al., 2004). Common soil series include Clarksville very gravelly silt loam and Coulstone-Clarksville complexes, which are typical for the area (Adams et al., 2004). Topography on the Sinkin is characterized by narrow ridges with steep side slopes and elevations ranging from $335 \mathrm{~m}$ to $412 \mathrm{~m}$ above mean sea level. Average annual precipitation from 1918 to 2015 was $1100 \mathrm{~mm}$ with 60 percent falling from April to 
September. Average daily temperature ranged from $1.7^{\circ} \mathrm{C}$ from December to February to $24.2^{\circ} \mathrm{C}$ from June to August.

Oak-pine forests typical of the Ozark Highlands section dominate the SEF. Common tree species include black oak, white oak, northern red oak, pignut hickory, mockernut hickory, shortleaf pine, black walnut (Juglans nigra), black cherry, and flowering dogwood. The forests on the SEF are primarily second growth forests established following heavy harvesting in the late $19^{\text {th }}$ and early $20^{\text {th }}$ centuries (Brinkman et al., 1962; Rogers and Liming, 1951). Historically, shortleaf pine comprised about half of the basal area on the SEF but now makes up about 15 to 20 percent (Adams et al., 2004).

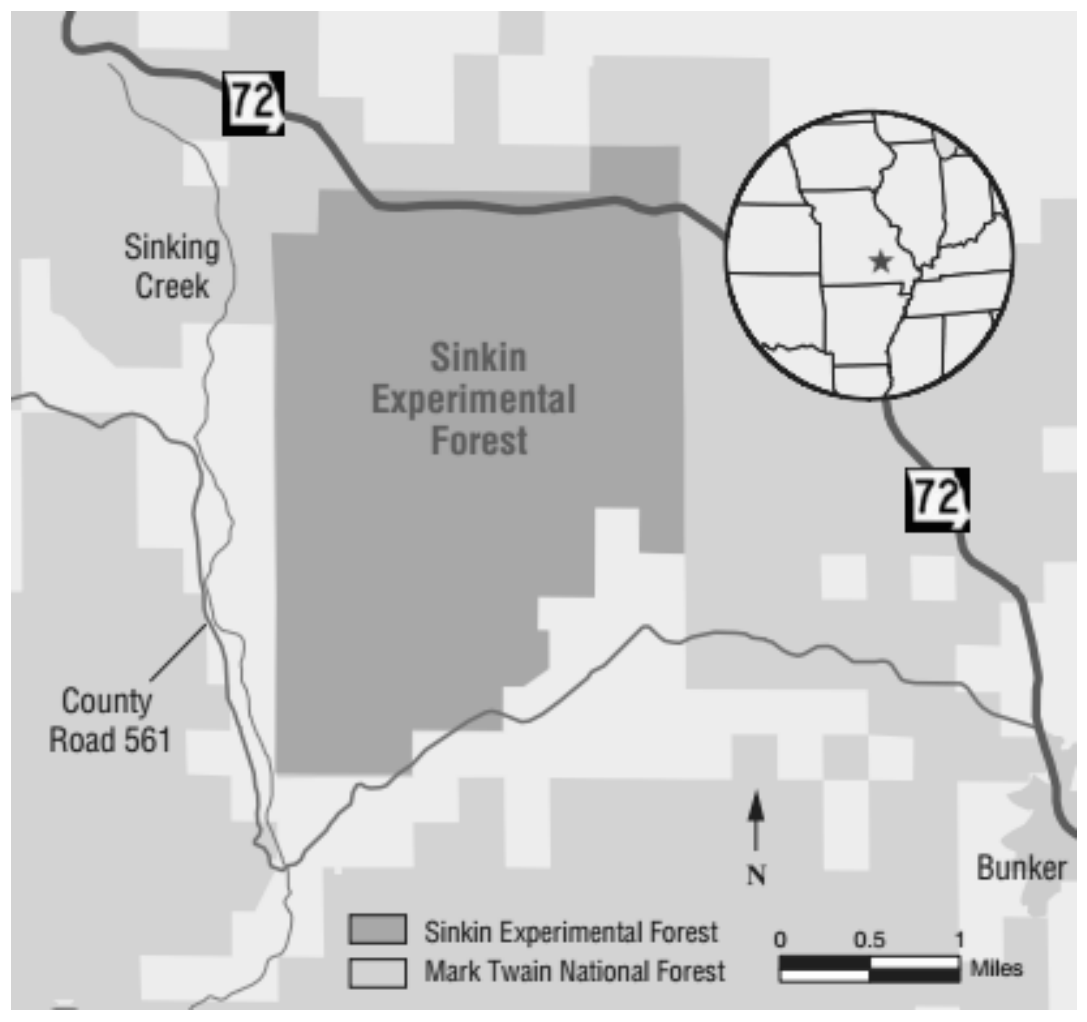

Figure 1.1. Sinkin Experimental Forest (SEF) map (Adams et al., 2004). 
Both the OSS and PSS were confined to xeric broad ridge top, shoulder, and upper backslope positions with slopes ranging from 4 to $32 \%$. A few plots in both studies contained steep drainages that channeled water during and immediately following heavy rains. Elevation within the study areas ranged from 350 to 410 meters above mean sea level. Clarksville gravelly silt loam was the dominant soil series on the ridges and upper slopes. Site index (base age 50, shortleaf pine) of 60 was measured in 1952 for the PSS, and site index (base age 50, black, scarlet, and white oaks) of 65 to 79 was measured in 1961 for the OSS (Brinkman et al., 1962; Carmean et al., 1989; McQuilkin, 1974; Nash, 1963; Seidel, 1963).

\section{Pine Stocking Study (PSS) History}

The even-aged shortleaf pine stands included in the PSS were initiated through natural seeding after an oak-pine stand was harvested from 1918-1920. In 1934, the Civilian Conservation Corps (CCC), charged with the task of locating and releasing shortleaf pine stands to encourage regeneration and growth after the species was heavily harvested in the late 1800 s and early 1900 s, cut and girdled the hardwood overstory remaining in the stands. During that time, the pines were thinned from about 2700 to 1480 trees per hectare (Brinkman et al., 1962).

In 1952, 30 fifth-hectare permanent plots were established on the SEF with the objective of determining the effects of stocking level on shortleaf pine stand development, growth, and yield. The study used a randomized complete block design that included three blocks, each with ten plots. Each plot was 
thinned to one of four levels of basal area $\left(11.5,16.1,20.7\right.$, or $\left.25.3 \mathrm{~m}^{2} / \mathrm{ha}\right)$ or maintained as an unthinned control (30 $\mathrm{m}^{2} / \mathrm{ha}$; two controls per block) (Rogers and Liming, 1951). Each block included three $16.1 \mathrm{~m}^{2} / \mathrm{ha}$ plots to test the effects of different methods of thinning on stand development and growth. In addition to selection thinning (applied to all other plots), one $16.1 \mathrm{~m}^{2} / \mathrm{ha}$ plot was thinned from below and one was thinned from above in each block. The effects of leaving hardwoods in the midstory and understory were also tested by leaving hardwoods uncut in one $16.1 \mathrm{~m}^{2} /$ ha plot and one control plot per block. Each plot was surrounded by a 9-m buffer that was treated with the plot to decrease edge effects. All plots were thinned twice in the first ten years of the study: in 1952 to establish the treatment levels and in 1960, following that year's stand inventory, to thin back to the originally assigned basal areas (Table 1.1). 
Table 1.1. Summary of 1952 Pine Stocking Study (PSS) treatments.

\begin{tabular}{|c|c|c|c|c|c|}
\hline \multicolumn{3}{|c|}{ Plot Number } & \multirow{2}{*}{$\begin{array}{c}\text { BA } \\
\left(\mathrm{m}^{2} / \mathrm{ha}\right)\end{array}$} & \multirow{2}{*}{$\begin{array}{c}\text { Hardwoods } \\
\text { Left }\end{array}$} & \multirow{2}{*}{$\begin{array}{l}\text { Thinning } \\
\text { Method }^{*}\end{array}$} \\
\hline Block 1 & Block 2 & Block 3 & & & \\
\hline 137 & 146 & 134 & 11.5 & $\mathrm{~N}$ & S \\
\hline 129 & 148 & 144 & \multirow{4}{*}{16.1} & $\mathrm{~N}$ & S \\
\hline 143 & 127 & 132 & & $\mathrm{~N}$ & B \\
\hline 147 & 126 & 138 & & $\mathrm{~N}$ & $A$ \\
\hline 130 & 125 & 150 & & Y & S \\
\hline 139 & 153 & 151 & 20.7 & $\mathrm{~N}$ & $\mathrm{~S}$ \\
\hline 142 & 131 & 133 & \multirow{2}{*}{25.3} & \multirow{2}{*}{$\mathrm{N}$} & \multirow{2}{*}{ S } \\
\hline 145 & 136 & 135 & & & \\
\hline 128 & 140 & 149 & \multirow{2}{*}{ C } & $\mathrm{N}$ & \multirow{2}{*}{--} \\
\hline 152 & 154 & 141 & & Y & \\
\hline \multicolumn{6}{|c|}{ * $S=$ Selection thinning; $A=$ thin from above; $B=$ thin from below } \\
\hline Plots used in & tal analyses & & & & \\
\hline $\begin{array}{l}\text { Plots compl } \\
\text { Plots maint }\end{array}$ & $\begin{array}{l}\text { removed fr } \\
1952-2015\end{array}$ & asdy in 19 & & & \\
\hline
\end{tabular}

In 1972, the study was altered to address new management questions regarding large pole and sawtimber production. Four $16.1 \mathrm{~m}^{2} /$ ha plots were completely harvested to determine what species would become dominant after pine removal. Those plots were subsequently dropped from the PSS study. Remaining plots were reassigned basal area densities that were either $+/-4.6$ $\mathrm{m}^{2} /$ ha of their original assignment or kept the same. Additionally, four of the six control plots were thinned from approximately $46 \mathrm{~m}^{2} /$ ha basal area to $11.5 \mathrm{~m}^{2} / \mathrm{ha}$. Following the changes made in 1972, eight plots were thinned in 1985, sixteen plots were thinned in 1995, and five plots were thinned in 2007 (Appendix: Table 
A-1). The four control plots that were thinned in 1972 were not thinned again. Hardwood ingrowth was controlled with herbicide in all but the six previously mentioned plots (three $16.1 \mathrm{~m}^{2} /$ ha and three controls) in 1952, 1955, 1959, 1963, and 1972.

\section{Oak Stocking Study (OSS) History}

The even-aged oak-hickory stands included in the Oak Stocking Study (OSS) were initiated through advanced regeneration and stump sprouts following a clearcut harvest in 1920 (Seidel, 1963). Prior to study initiation, the oak stands were fully stocked with characteristic Ozark species including, in order of abundance, black oak, white oak, scarlet oak, post oak, northern red oak, and hickories. Average basal area before treatment was $22.0 \mathrm{~m}^{2} / \mathrm{ha}$, with an average of 1900 trees per hectare and an arithmetic mean diameter of $12.2 \mathrm{~cm}$.

The OSS, established in 1961, utilized the framework of a work plan published and implemented in 1959 by the USDA Forest Service North Central Experiment Station in Berea, KY (Dale and Sander, 1959). This work plan described the experimental design, with the following stated objectives: to determine the effect of various levels of stand density on (1) total wood production per acre, (2) growth rates of residual trees and stands, (3) quality of trees, and (4) range of basal areas where total production is essentially the same (Brinkman, 1961).

The OSS consisted of 36 permanent plots within even-aged, upland oakhickory stands across the USFS Salem Ranger District and included plots on the 
SEF, the Mark Twain National Forest, and Deer Run State Park (Current River Conservation Area). The study included two initial age classes (20 and 40 years), three broad site index groups $(65,75$, and 85 at midpoints), and four basal area density treatments $\left(6.9,11.5,16.1,20.7 \mathrm{~m}^{2} / \mathrm{ha}\right)$ (Seidel, 1963). Twenty of the plots in the 40-year age group were located on the SEF (Table 1.2).

Similar to the PSS, plot design for the OSS consisted of fifth-hectare square or rectangular plots with a 9-m surrounding buffer. The study was thinned in 1961 and 1974 using 'free thinnings', with the goal of maintaining evenly spaced crop trees. The 1961 thinning established the assigned plot densities, with leave trees chosen based on their crop tree potential. Species chosen as leave trees were favored in the following order: black oak, northern red oak, white oak, scarlet oak, and post oak. Herbicide were applied to cut stumps to control hardwoods following thinning in 1962 and 1974. Between thinnings, foliage sprays were applied in 1963, 1965, and 1975 (Progress Report, 1976). 
Table 1.2. Summary of 1961 Oak

Stocking Study (OSS) treatments

\begin{tabular}{|c|c|c|c|c|}
\hline \multicolumn{3}{|c|}{ Plot } & \multirow[t]{2}{*}{$\mathrm{N}$} & $\begin{array}{c}\text { Trt BA } \\
\left(\mathrm{m}^{2} / \mathrm{ha}\right)\end{array}$ \\
\hline 671 & 677 & 683 & & \\
\hline 685 & $\begin{array}{c}686^{*} \\
689\end{array}$ & 688 & 7 & 6.9 \\
\hline $\begin{array}{l}672^{\star} \\
682^{*}\end{array}$ & $\begin{array}{l}673 \\
684\end{array}$ & $\begin{array}{l}674 \\
687\end{array}$ & 6 & 11.5 \\
\hline $\begin{array}{l}670 \\
680\end{array}$ & $\begin{array}{c}676 \\
681^{*}\end{array}$ & 678 & 5 & 16.1 \\
\hline 679 & 675 & & 2 & 20.7 \\
\hline \multicolumn{5}{|c|}{ *Understory control applied } \\
\hline \multicolumn{5}{|c|}{ Plots completely removed from study } \\
\hline $\begin{array}{l}\text { Plots ma } \\
\text { analysis }\end{array}$ & intained 1 & 40 & & \\
\hline
\end{tabular}

In the Berea Work Plan, Dale and Sander (1959) stated that "because stand growth slows as it ages, maintaining the same basal area the entire time is a waste of potential and by continuously increasing the density of subsequent thinnings, leaves more older trees to continue to yield optimal growth rates". The thinning process, as written in the Berea Work Plan and the Oak Stocking Study Plan, would result in the gradual increase in basal area of the plots. However, during the time of the Oak Stocking Study establishment, Samuel Gingrich had been developing tree-area relationship equations for central hardwood oakhickory stands, resulting in an improved measure of stand occupancy known as stocking. Gingrich, who was involved in the both PSS and OSS, suggested in a personal memo that all future thinnings following establishment be made using 
stocking percent because "a constant percent results in an increase in basal area with increasing stand age" (Gingrich, 1961).

In consequence, the second thinning of the OSS in 1974 applied Gingrich's percent stocking method (Progress Report, 1976; Gingrich, 1967). Also in 1974 , all plots that were originally thinned to $20.7 \mathrm{~m}^{2} /$ ha were deemed 'check' plots with the intention of being excluded from future thinnings. However, after the 1974 cut, for undocumented reasons, no further thinnings were applied to any of the remaining plots. Since 1974, many of the plots were abandoned, with only 16 of the original 36 plots retained through 2015 , all of which were located on the SEF.

\section{Disturbance}

A number of disturbances influenced the development of the PSS and OSS over the 65-year span of the studies, including multiple ice storms and tornados, lightning strikes, droughts, and the 2009 derecho, which caused mortality across both studies. Red oak decline was first noted in the Ozarks in the 1970s (Dwyer et. al, 2007) and may be the cause of some mortality in the OSS. A concentrated outbreak of Fomes annosus root rot in the PSS forced the harvest of a single plot in the 1970 s to prevent spread to other plots. Fire was not present in the study area after 1933. In 2015, trees still present in both studies were approximately 95 years old. 


\section{CHAPTER II}

\section{CARBON DYNAMICS OF TWO LONG-TERM THINNING STUDIES IN THE MISSOURI OZARKS}

\section{Introduction}

Forest management has evolved through time to meet the changing objectives and demands of society. Traditional objectives focusing on timber production have broadened to address emerging interests such as wildlife habitat management, water quality, and more recently, carbon dynamics and climate change mitigation. Thinning has been used to achieve traditional and emerging objectives alike, and in the face of a changing climate, has been considered as an important tool for maintaining healthy, productive forests. Using retrospective studies, determining how forests respond to thinning and traditional management in the context of climate change is important for developing simple, effective management techniques that foster climate change mitigation.

Thinning has been shown to have variable effects on forest carbon dynamics. Aboveground carbon storage is often greatest in unthinned stands; however, thinning promotes increased stand- and tree- level carbon sequestration rates between stand entries. These results have been observed in multiple ecosystems including western Douglas-fir stands, the Upper Great Lakes, the Appalachian Mountains, and the Northeast (Anning and McCarthy, 2013; Burton et al., 2013; D'Amato et al. 2011; Davis et al., 2009; Harmon and Marks, 2002; Schaedel et al., 2017). Compared to heavily thinned stands (low 
density) or stands clearcut and regenerated, lightly thinned stands (high density) or stands left uncut have been shown to store more carbon over $50+$ years (D’Amato et al., 2011; Harmon et al., 2009). However, thinning may increase gross stand-level carbon storage potential if the material removed from the stand continues to store carbon as building materials or other durable products (Fahey et al., 2010). The use of thinning was found to increase short-term sequestration rates and stimulate stand-level carbon sequestration in the central Appalachians and Upper Great Lakes regions (D'Amato et al., 2011; Davis et al., 2009), suggesting that repeated thinning could increase total carbon production over the entire rotation.

The aboveground portion of stored carbon is the most dynamic carbon pool in a forest and can be influenced not only by management but through disturbance-induced changes in stand structure and composition (Fahey et al., 2010). Forests are natural carbon sinks, storing and sequestering atmospheric carbon as biomass in wood, soil, vegetation, and debris. However, the ability of a forest to remain a net sink of carbon can be compromised by natural disturbances and forest management. Natural disturbances such as drought, wildfire, and insect and disease outbreaks have been projected to increase in frequency, severity, and extent with climate change and are expected to cause mortality in managed and unmanaged stands alike (Kabrick et al., 2004). While the loss of a single tree may not significantly affect the total carbon stored in a stand, a strong storm or disease outbreak could cause significant mortality resulting in a forest becoming a net source of carbon (Allen et al., 2010; Canadell 
and Raupach, 2008). Similarly, forest management has the potential to transform carbon sinks into net sources of carbon if removals are heavy enough and materials removed are not stored as long-lived wood products (Fahey et al., 2010). Determining the stand density or range of densities that will effectively increase growing space for residual trees, minimize carbon loss from mortality, and maintain forest status as a net carbon sink are important considerations surrounding climate change management.

As managing forest carbon becomes more prevalent, land managers will need to consider compatibility of silvicultural practices with traditional objectives such as volume growth and yield (Bradford and D'Amato, 2011). Traditional approaches to maximizing volume yield typically include short rotations of single species to promote quick growth to a desired size (Brinkman and Rogers, 1967), which may correspond to high carbon sequestration rates over short time periods. Conversely, climate mitigation objectives focusing on long-term carbon storage may require long rotations over which growing space is fully utilized with a mixture of species (Canadell and Raupach, 2008; Millar et al., 2007; Puettmann et al., 2009). Research comparing these contrasting objectives is scarce but managing for both may become an important consideration as timber markets and climate-related objectives continue to evolve.

In the Missouri Ozarks, projected climate scenarios suggest that shortleaf pine, black oak, and white oak will remain prominent in the region into the future. These forest types possess characteristics that make them desirable for managing for climate mitigation including drought and fire tolerance and wide 
habitat suitability (Brandt et al., 2014; Kabrick et al., 2017). This study uses longterm thinning studies established by the USDA Forest Service to quantify carbon dynamics of upland oak and shortleaf pine stands in the Missouri Ozarks. Results from these long-term studies will become invaluable for informing future Ozark management techniques.

\section{Objectives}

Considering the implications of future climate change and increased global atmospheric $\mathrm{CO}_{2}$ levels, I studied the effects of repeated thinning in two longterm (>50 year) density management studies in the Missouri Ozarks on: (1) individual tree- and stand-level carbon storage and sequestration patterns through time; (2) sink/source dynamics associated with thinning through the duration of the studies; (3) mortality and species composition changes in managed upland oak forests; and (4) trade-offs associated with managing for both volume and carbon storage in shortleaf pine stands. 


\section{Methods}

\section{Site}

The Pine Stocking Study (PSS) and Oak Stocking Study (OSS) were located at the Sinkin Experimental Forest (SEF), within the Current River Hills subsection of the Ozark Highlands. Topography on the SEF is characterized by ridges and steep slopes with well-drained, acidic soils and a low nutrient supply capacity. As a result, the sites favored shortleaf pine and Central Hardwoods species including black oak, white oak, northern red oak, and hickories. The second growth forests included in both studies were established following harvesting in the early 1900s (Rogers and Liming, 1951; Brinkman et al., 1962). For more information on the SEF and site characteristics refer to Chapter 1: Project Overview.

\section{Experimental Design}

In 1952, 30 fifth-hectare permanent plots were established in the evenaged shortleaf pine stands on the SEF. Using a randomized complete block design, each plot was thinned to one of four levels of basal area $(11.5,16.1$, 20.7 , or $\left.25.3 \mathrm{~m}^{2} / \mathrm{ha}\right)$ or maintained as an unthinned control $\left(30 \mathrm{~m}^{2} / \mathrm{ha}\right)$ (Rogers and Liming, 1951). All plots were thinned twice in the first ten years of the study: in 1952 to establish the treatment levels and in 1960, following that year's stand inventory, to thin back to the originally assigned basal areas. In 1972, plots were reassigned basal area densities based on new objectives. Following the changes made in 1972, eight plots were thinned in 1985, sixteen plots were thinned in 1995, and five plots were thinned in 2007 (Appendix: Table A-1). 
The OSS consisted of 20 permanent plots in even-aged upland oak stands on the SEF. Similar to the PSS, plot design for the OSS consisted of fifthhectare square or rectangular plots with a 9-m surrounding buffer that were thinned to one of four basal areas, $6.9,11.5,16.1$, or $20.7 \mathrm{~m}^{2} / \mathrm{ha}$. Thinning took place in the OSS in 1961 and 1974. The 1961 thinning established assigned plot densities. As per the updated plan, the 1974 thin used percent stocking as a guide for thinning, and all plots originally assigned to $20.7 \mathrm{~m}^{2} /$ ha were deemed control plots and were not thinned again. No further management took place in the OSS after 1974. Detailed descriptions of the original experimental designs, study history, and modifications for both the PSS and OSS can be found in Chapter 1: Project Overview.

Due to study changes made in 1972, only 26 PSS plots were available for sampling in 2015 . Of the 20 original OSS plots located on the SEF, 18 were believed to be usable at the start of the 2015 data collection period. However, it was discovered that all overstory trees in one plot had been killed, either by windthrow caused by the 2009 derecho or other unknown causes, and the plot was subsequently removed from the study. A second plot was deemed unusable due to unclear plot boundaries and low number of surviving overstory trees ( $\mathrm{n}=$ 4), leaving 16 OSS plots to be sampled.

\section{Data Collection}

All trees that were $\geq 1.5 \mathrm{~cm}$ diameter at breast height $(\mathrm{DBH})$ and located inside PSS and OSS plots at study initiation were tagged with numbered aluminum tags. Only shortleaf pines were tagged in the PSS. Inventories of the 
tagged trees of the PSS were completed every two years from 1952 to 1960. Following 1960, inventories were spaced to approximately five year intervals and were made in 1965, 1971, 1976, 1980, 1985, 1990, 1995, 2000, 2007, and 2015 (Appendix: Table A-1). Inventories of tagged trees in the OSS were made approximately every five years: 1961, 1967, 1971, 1974, 1976, 1981, 1986, 1991, 1996, 2001, 2009, and 2015. Plot inventories preceded a thin (if one occurred) in the same year, and no ingrowth was tagged or measured in either study prior to 2015 .

During the 2015 inventory, heights all live trees were measured in 15 randomly chosen PSS plots, with 3 plots from each of the five original 1952 treatments. Heights were measured using multiple methods based on availability including a Suunto clinometer, Haglof Vertex IV Hypsometer, and a TruPulse $360^{\circ} \mathrm{B}$ laser rangefinder. Heights were not collected in the OSS.

In 2015, ingrowth was inventoried in all plots. All untagged trees $\geq 10.0 \mathrm{~cm}$ DBH within all plots were identified by genus and species, measured for $\mathrm{DBH}$, and tagged with numbered aluminum tags, beginning with tag number 7002 (PSS) and 9467 (OSS). 7002 was chosen to maintain continuity with the PSS as the last living tree tagged in the study was 7001.9467 was chosen for the OSS as it was the next number available after tagging all ingrowth in the PSS.

\section{Pine Stocking Study}

Due to the changes made in the PSS in 1972 (see Chapter 1: Project Overview), three broad treatment groups were created based on long-term 
density trends to determine the effects of maintaining stands at relatively low, medium, or high densities over 55 years. These treatments, summarized in Table 2.1, include a 'Low' density, a 'Mid' density, and a 'High' density treatment. One of the remaining two control plots began to decline in the late 1970s and was rendered unusable following the 2009 derecho. Thus, only one control plot was available for use as a visual comparison.

Table 2.1. Summary of PSS treatment groups. Basal area and \% stocking averaged across entire study period (19522007)

\begin{tabular}{|c|c|c|c|c|c|}
\hline Treatment & $\mathbf{N}$ & TPH & $\begin{array}{l}\text { QMD } \\
\text { (cm) }\end{array}$ & $\begin{array}{c}\text { BA } \\
\left(\mathrm{m}^{2} / \mathrm{ha}\right) \\
\end{array}$ & $\begin{array}{c}\% \\
\text { Stocking } \\
\end{array}$ \\
\hline Low & 2 & & & \multirow{3}{*}{17.2} & \multirow{3}{*}{46.4} \\
\hline 1952 & & 498.9 & 19.4 & & \\
\hline 2007 & & 140.8 & 42.9 & & \\
\hline Mid & 4 & & & \multirow{3}{*}{20.4} & \multirow{3}{*}{55.0} \\
\hline 1952 & & 550.8 & 19.7 & & \\
\hline 2007 & & 150.7 & 42.0 & & \\
\hline High & 4 & & & \multirow{3}{*}{25.9} & \multirow{3}{*}{71.8} \\
\hline 1952 & & 841.0 & 19.2 & & \\
\hline 2007 & & 201.3 & 39.4 & & \\
\hline Control & 1 & & & \multirow{3}{*}{40.4} & \multirow{3}{*}{119.3} \\
\hline 1952 & & 1422.7 & 17.9 & & \\
\hline 2007 & & 637.3 & 27.9 & & \\
\hline
\end{tabular}


Oak Stocking Study

Of the available 16 oak plots, 10 were chosen to be used in all analyses based on long-term basal area and stocking levels. The 1961 basal area density assignments determined the three treatment groups: $6.9,11.5$, and $16.1 \mathrm{~m}^{2} / \mathrm{ha}$ (Table 2.2). One plot, which was cut to $20.7 \mathrm{~m}^{2} / \mathrm{ha}$ in 1961 and was never cut again, was available for use as a visual comparison control.

Table 2.2. Summary of OSS treatment groups. Basal area and \% stocking averaged across entire study period (19612001)

\begin{tabular}{cccccc}
\hline Treatment & $\mathbf{N}$ & TPH & $\begin{array}{c}\text { QMD } \\
(\mathbf{c m})\end{array}$ & $\begin{array}{c}\text { BA } \\
\left(\mathbf{m}^{\mathbf{2}} / \mathbf{h a}\right)\end{array}$ & $\begin{array}{c}\% \\
\text { Stocking }\end{array}$ \\
\hline $\mathbf{6 . 9}$ & 3 & & & & \\
1961 & & 166.3 & 23.4 & 13.2 & 47.0 \\
2001 & & 136.7 & 42.4 & & \\
$\mathbf{1 1 . 5}$ & 4 & & & & \\
1961 & & 335.9 & 21.0 & 18.6 & 69.3 \\
2001 & & 250.7 & 35.8 & & \\
$\mathbf{1 6 . 1}$ & 3 & & & & \\
1961 & & 464.4 & 21.1 & 22.8 & 86.3 \\
2001 & & 307.9 & 34.1 & & \\
Control & 1 & & & & \\
1961 & & 731.1 & 18.9 & 26.1 & 104.1 \\
2001 & & 469.3 & 28.4 & & \\
\hline
\end{tabular}




\section{Data Analysis}

Repeated Measures Analysis of Variance (ANOVA)

Due to treatment and design differences between the PSS and OSS, the two studies were analyzed separately but with the same analytical approach. For each study, data were summarized by plot and year, expanded to a per hectare basis, and averaged by treatment group. Descriptive stand statistics included trees per hectare $(T P H)$, quadratic mean diameter (QMD; $\mathrm{cm})$, basal area (BA $\mathrm{m}^{2} / \mathrm{ha}$ ), and percent stocking. For the OSS, percent stocking was calculated using the minimum tree area relationship equation from Gingrich (1967). For the PSS, percent stocking was calculated using a minimum tree area equation developed specifically for shortleaf pine in Missouri from Rogers (1982) (Table 2.3).

Table 2.3. Percent stocking equations developed for shortleaf pine*

\begin{tabular}{l}
\hline $\begin{array}{c}\text { Maximum tree area }(\mathbf{B} \\
\text { line stocking) }\end{array}$ \\
$\begin{array}{l}\text { Minimum tree area }(\mathbf{A} \\
\text { line stocking) }\end{array}$ \\
$\begin{array}{l}{ }^{*} \text { From Rogers (1982) } \\
{ }^{* *} \text { Percent stocking developed for data in imperial units only } \\
{ }^{* *} \mathrm{n}=\text { trees per plot }\end{array}$
\end{tabular}


Total aboveground biomass ( $\mathrm{Mg} / \mathrm{ha})$ was determined using speciesspecific allometric equations based on individual-tree diameter (Chojnacky et al. 2013) and was then converted to aboveground carbon ( $\mathrm{Mg} / \mathrm{ha}$ ) by multiplying biomass by 0.5 , assuming that carbon accounts for $50 \%$ of a tree's dry weight (D'Amato et al., 2011; Jenkins et al., 2003). Individual-tree aboveground carbon (Mg/ha/tree) was calculated by dividing total aboveground carbon by TPH for each inventory year. Stand-level carbon sequestration rates (Mg/ha/year) were calculated by finding the periodic annual increment (PAI) of carbon for trees that survived from one measurement year to the next for each of the measurement periods in both studies ( $n=10$, PSS; $n=8$, OSS). PAI was calculated by determining the change in stand-level carbon storage in surviving trees in each measurement period and dividing that amount of carbon by the number of years in the measurement period. Individual-tree carbon sequestration rates (Mg/ha/tree/year) were found by dividing carbon sequestration rate by $\mathrm{TPH}$.

Trees removed from the OSS during the 1974 thin were documented, allowing mortality in terms of carbon loss $(\mathrm{Mg} / \mathrm{ha})$ to be accurately quantified for the OSS. Carbon loss from 1967 through 2015 was determined by species group (white oak group, red oak group, and 'other' species group).

Overstory species percentages in the OSS, based on number of trees in 1961 were compared to overstory percentages present in 2001 and 2015.

All above variables were analyzed using repeated measures Analysis of Variance (ANOVA) with the SAS statistical software package (version 9.4, SAS Institute, Inc, Cary, NC, USA) to determine the effects of treatment ( $n=3$, PSS; 
$n=3$, OSS $)$ and time ( $n=12, P S S ; n=10$, OSS) on stand and individual-tree level response variables. The MIXED procedure was used for all data that met the assumptions of normality and equal variance or could be transformed to meet assumptions. In some cases, the data were better suited to a gamma or lognormal distribution. In those cases, the GLMMIX procedure was used to analyze the non-normal variables (Table $2.4 ; 2.5$ ). Unless otherwise stated, all analyses included sampling periods up to 2001 (OSS) or 2007 (PSS) due to the 2009 derecho wind storm that drastically altered the densities of a number of plots in 2009 and 2015. Due to the high number of familywise comparisons associated with both studies, results of all pairwise tests were adjusted for error inflation using Tukey's Honest Significance Difference (HSD) adjustment. Statistical difference was determined if $p<0.05$.

Table 2.4. PSS variables, transformations, distributions, and analysis summary

\begin{tabular}{|c|c|c|c|}
\hline \multirow[b]{2}{*}{$\underline{\text { Variable }}$} & \multicolumn{3}{|c|}{ Pine Stocking Study } \\
\hline & Distribution & Analysis & Transformation \\
\hline \multicolumn{4}{|l|}{ Stand Level } \\
\hline Basal Area & Normal & RM ANOVA & $\log$ \\
\hline Trees per Hectare & Normal & RM ANOVA & $\log$ \\
\hline QMD & Normal & RM ANOVA & $\log$ \\
\hline Percent Stocking & Normal & RM ANOVA & $\log$ \\
\hline Aboveground Carbon & Normal & RM ANOVA & $\log$ \\
\hline C Sequestration & Normal & RM ANOVA & -- \\
\hline Total Gross Carbon & Normal & $\begin{array}{c}\text { One Way } \\
\text { ANOVA }\end{array}$ & -- \\
\hline Study Gross Carbon & Normal & $\begin{array}{c}\text { One Way } \\
\text { ANOVA }\end{array}$ & -- \\
\hline Merchantable Volume & Normal & $\begin{array}{l}\text { One Way } \\
\text { ANOVA }\end{array}$ & -- \\
\hline \multicolumn{4}{|l|}{ Individual-Tree } \\
\hline Average Aboveground C & Gamma & GLM & -- \\
\hline Average C Sequestration & Normal & RM ANOVA & $\log$ \\
\hline
\end{tabular}


Table 2.5. OSS variables, transformations, distributions, and analysis summary

\begin{tabular}{|c|c|c|c|}
\hline \multirow[b]{2}{*}{ Variable } & \multicolumn{3}{|c|}{ Oak Stocking Study } \\
\hline & Distribution & Analysis & Transformation \\
\hline \multicolumn{4}{|l|}{ Stand Level } \\
\hline Basal Area & Normal & RM ANOVA & square root \\
\hline Trees per Hectare & Normal & RM ANOVA & -- \\
\hline QMD & Gamma & GLM & -- \\
\hline Percent Stocking & Normal & RM ANOVA & -- \\
\hline Aboveground Carbon & Gamma & GLM & -- \\
\hline C Sequestration & Normal & RM ANOVA & -- \\
\hline Study Gross Carbon & Normal & $\begin{array}{c}\text { One Way } \\
\text { ANOVA }\end{array}$ & -- \\
\hline Mortality & Normal & RM ANOVA & \\
\hline Species Composition & Normal & Paired T & -- \\
\hline \multicolumn{4}{|l|}{ Individual-Tree } \\
\hline Average Aboveground C & Gamma & GLM & -- \\
\hline Average C Sequestration & Lognormal & GLM & -- \\
\hline
\end{tabular}

\section{One-Way ANOVA}

To calculate merchantable volume $\left(\mathrm{m}^{3} / \mathrm{ha}\right)$ in the PSS and avoid confounding effects of the 2009 derecho, merchantable heights in 2007 were estimated based on the height data collected in 2015. Brinkman (1968) suggests that after age 60 , shortleaf pine puts on about 0.152 meters of height growth per year. Using this assumption, individual total tree heights for 2007 were estimated by subtracting 1.22 meters ( 0.152 meters * 8 years) from their 2015 height. Taper equations developed for shortleaf pine based on diameter, total height, and live crown ratio (LCR) (assuming live crown ratio in 2015 equaled LCR in 2007) were used to determine the height to a diameter inside bark (dib) of $20.8 \mathrm{~cm}$ (Farrar and Murphy, 1987). International $1 / 4$, a common volume calculator used in the Missouri Ozarks and an equation developed by Grosenbaugh (1952), were used 
to calculate standing volume in cubic meters of the PSS in 2007 , with the assumption that all trees measured for height were free of defect and all material up to $20.8 \mathrm{~cm}$ dib was merchantable (Husch et al., 2003; USFS, 2011). Volumes for trees that died, were removed, or were otherwise not measured for height in 2015 were estimated by determining the average number of logs in trees of the same stand density and diameter in 2007. Cubic meter volumes were then estimated by applying the average number of logs and the $2007 \mathrm{DBH}$ to a form class 82 International 1/4 volume table. Per hectare volume was averaged by treatment density to determine treatment effect on merchantable volume in 2007.

Total gross carbon (TGC) in the PSS was calculated as the total overstory aboveground carbon in tagged overstory trees that lived, died, or were removed from the stands until 2015 and included material that was removed in the establishment thin in 1952. Study gross carbon (SGC) for the PSS and OSS was determined by the total overstory aboveground carbon that lived, died, or was removed after the establishment thin. TGC and SGC in 2015 were averaged by treatment density to determine treatment effect on gross carbon production.

To evaluate carbon sink/source dynamics in the PSS through the duration of the study period, periodic growth following each thinning was compared to the amount of material removed. In addition, carbon lost to mortality or removed over the entire study period (1952-2007) and during each treatment period was compared to the amount of carbon stored in those same periods. To determine net change in aboveground carbon (net carbon storage) as an indicator of sink vs 
source dynamics, total carbon loss from 1952-2007 was subtracted from total carbon gain.

One-way ANOVA was used to determine the effect of treatment density on standing merchantable volume, TGC, SGC, and net carbon storage. A one-way ANOVA was also used to compare the effect of year on net carbon stored within each treatment density.

\section{Paired t-tests}

To further explore the sink/source relationship in the PSS, net change in each treatment period within each separate treatment density (Low, Mid, High) was tested if significantly different from zero using paired t-tests. Zero net change suggests that the stand recovered what was lost in a thin/mortality event prior to the next thinning. A negative net change suggests that the thinning/mortality event was a net source of carbon. A positive net change showed that the stand recovered more carbon than was removed (sink) in that period.

To determine if species composition in the OSS had changed over 55 years, a paired t-test was used to compare composition in 1961 to 2015. Three broad species groups were assessed including a 'red oak' group (Quercus. velutina, $Q$. rubra, $Q$. coccinea), a 'white oak' group (Q. alba, $Q$. stellata), and an 'other species' group (Carya spp., Pinus echinata, Juglans nigra, Nyssa sylvatica, Ulmus spp., Acer rubrum, Sassafrass albidum, Prunus serotina, Cornus spp., Acer saccharum, Diospyros virginiana, and Morus spp.). 
Separately, ingrowth was included in total species composition in 2015 and compared to total composition in 1961 with a paired t-test. 


\section{Results}

Stand Description - PSS

There was an interaction between treatment density and year for TPH, QMD, basal area, and percent stocking (Table 2.6; Figure 2.1; 2.2).

All years that the stands were thinned (Appendix: Table A-1) showed a significant reduction in TPH for all treatments (Figure 2.1A). The High treatment had significantly more TPH than the Low treatment from 1965-1995 and significantly more TPH than the Mid treatment from 1965-1985. Tukey's pairwise comparisons showed that TPH was not significantly different among the three treatment densities from 1952-1960 and 2000-2007. Because ingrowth was not included in the inventories, the expected 'stair step' progression of overstory tree loss from thinning events is evident with very little non-harvest mortality affecting TPH in the PSS.

Although there was a significant treatment effect on QMD in 1971 and 1985, Tukey's HSD adjustment resulted in no pairwise differences among treatments in any year (Figure 2.1B). The QMD in each year was significantly greater than the previous year in all treatment densities, regardless of the occurrence of a thinning. 
Table 2.6. Repeated measures ANOVA results stand structure variables for PSS and OSS. $P$ values represent significant effect at 0.05 level.

\begin{tabular}{|c|c|c|c|c|c|c|}
\hline \multirow[b]{2}{*}{ Variable } & \multicolumn{6}{|c|}{ Pine Stocking Study } \\
\hline & $\begin{array}{c}F \\
\text { value }\end{array}$ & Trt & $\begin{array}{c}F \\
\text { value }\end{array}$ & Year & $\begin{array}{c}\mathrm{F} \\
\text { value }\end{array}$ & $\mathrm{Trt}^{*}$ year \\
\hline Trees per Hectare & 19.06 & 0.0005 & 102.72 & $<0.0001$ & 2.91 & 0.0003 \\
\hline QMD & 3.03 & 0.1100 & 411.98 & $<0.0001$ & 2.68 & 0.0008 \\
\hline Basal Area & 22.74 & 0.0003 & 49.35 & $<0.0001$ & 3.11 & 0.0002 \\
\hline \multirow[t]{3}{*}{ Percent Stocking } & 24.29 & 0.0002 & 49.18 & $<0.0001$ & 3.08 & 0.0002 \\
\hline & \multicolumn{6}{|c|}{ Oak Stocking Study } \\
\hline & $\begin{array}{c}F \\
\text { value }\end{array}$ & Trt & $\begin{array}{c}F \\
\text { value }\end{array}$ & Year & $\begin{array}{c}\mathrm{F} \\
\text { value }\end{array}$ & $\mathrm{Trt}^{*}$ year \\
\hline Trees per Hectare & 38.20 & 0.0001 & 32.89 & $<0.0001$ & 3.59 & $<0.0001$ \\
\hline QMD & 121.91 & $<0.0001$ & 106.05 & $<0.0001$ & 0.46 & 0.9669 \\
\hline Basal Area & 44.96 & $<0.0001$ & 100.01 & $<0.0001$ & 1.63 & 0.0807 \\
\hline Percent Stocking & 40.58 & 0.0002 & 80.03 & $<0.0001$ & 2.21 & 0.0112 \\
\hline
\end{tabular}

Thinning significantly reduced basal area and stocking percent in all treatment densities and all thinning years except in the High treatment in 1985 and 1995 (Figure 2.2A; 2.2B). Basal area in the High treatment was significantly greater than the Low treatment in 1952-56 and 1965-95 and was significantly greater than the Mid treatment in 1952 and 1965-71. The Low treatment had significantly less basal area than the Mid treatment in 1956 and 1976-95. Low and Mid treatment stocking was never significantly different but both treatments had significantly lower stocking than the High treatment from 1952-95 (Low), and 1952-56 and 1965-71 (Mid). 
Stand Description - OSS

In the OSS, there was significant interaction between treatment density and year for TPH and percent stocking. Both treatment and year effects were significant for QMD and basal area (Table 2.6; Figure 2.1; 2.2; 2.3).

The 1974 thin significantly reduced TPH in both the 11.5 and $16.1 \mathrm{~m}^{2} / \mathrm{ha}$ treatments while $\mathrm{TPH}$ in the $6.9 \mathrm{~m}^{2} /$ ha treatment did not significantly change with time (Figure 2.1C). There was also a second reduction in only the $16.1 \mathrm{~m}^{2} / \mathrm{ha}$ treatment in 1991, which was not related to a thinning event. All treatments were significantly different from each other from 1967-76, and 1981-2001. The 6.9 $\mathrm{m}^{2} /$ ha treatment was significantly lower than the 11.5 and $16.1 \mathrm{~m}^{2} /$ ha in those years.

QMD showed significant treatment and year effects. Year effects showed a significant increase in tree size through time (Figure 2.3A). Treatment effects showed the $6.9 \mathrm{~m}^{2} /$ ha treatment having the greatest average QMD and the 16.1 $\mathrm{m}^{2} /$ ha having the lowest average QMD (Figure 2.3B). Although statistically there was no interaction between treatment density and year, QMD in the $6.9 \mathrm{~m}^{2} / \mathrm{ha}$ treatment appears to be increasing at a different rate from the two more dense treatments (Figure 2.1D).

Both year and treatment significantly affected stand basal area. Year effects showed that average basal area increased through time except for 1976, which was not significantly different from 1971 (Figure 2.3C). Basal areas were significantly different among the three densities (Figure 2.3D). 
The three treatment densities were significantly different in percent stocking in 1961 (Figure 2.2D). The second thinning in 1974 only significantly reduced percent stocking in the $11.5 \mathrm{~m}^{2} /$ ha treatment but maintained significant differences between all three treatment densities. By 1981, the 11.5 and 16.1 $\mathrm{m}^{2} /$ ha treatments were no longer significantly different and remained that way until 1991.
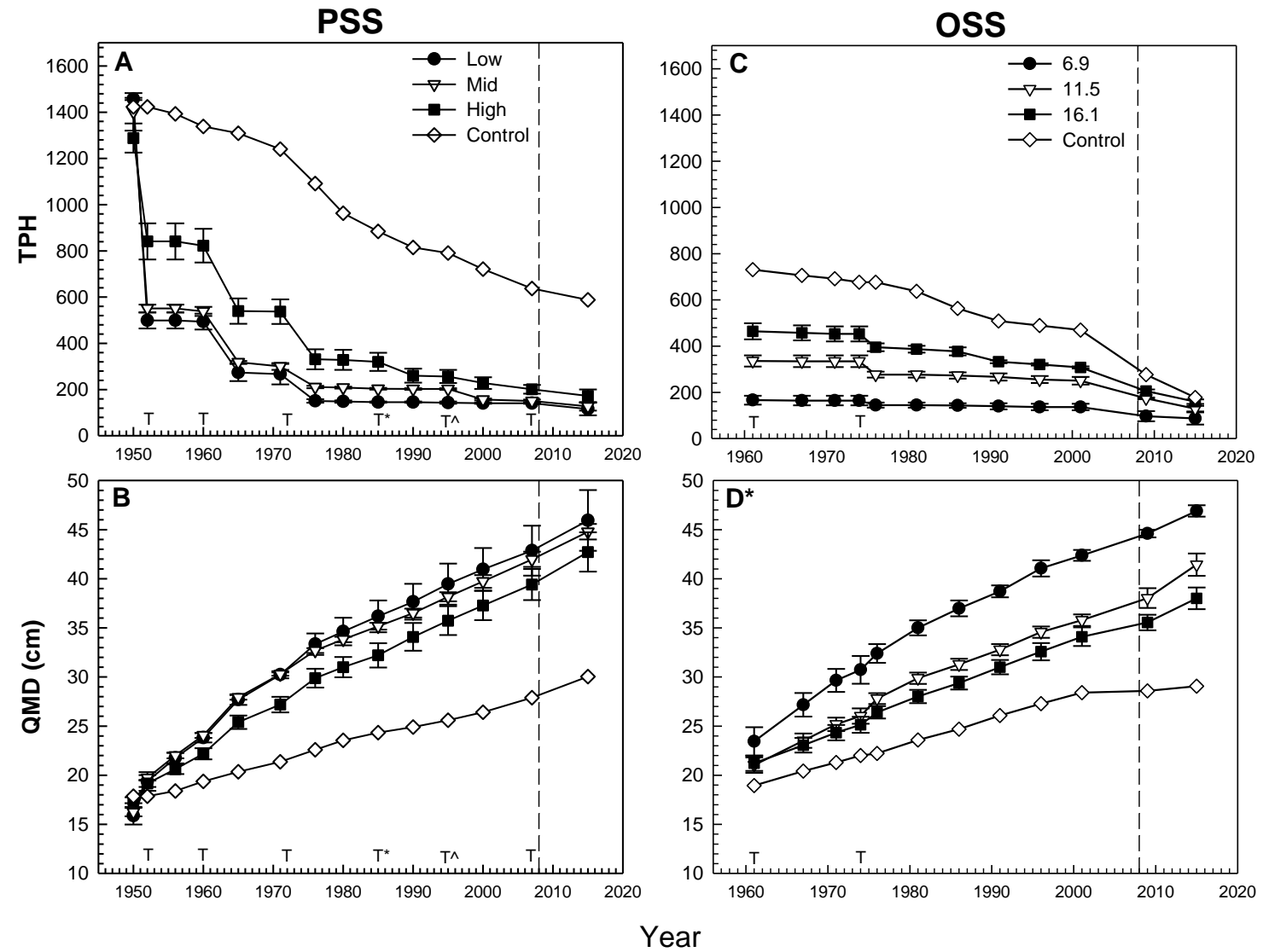

Figure 2.1. Descriptive stand metrics - Trees per hectare (TPH) and quadratic mean diameter (QMD) for PSS (A-B) and OSS (C-D). Dashed line represents end of analysis period due to the 2009 derecho. TS represent thinning years. *OSS QMD did not have a significant interation-panel is to show pattern of development. 

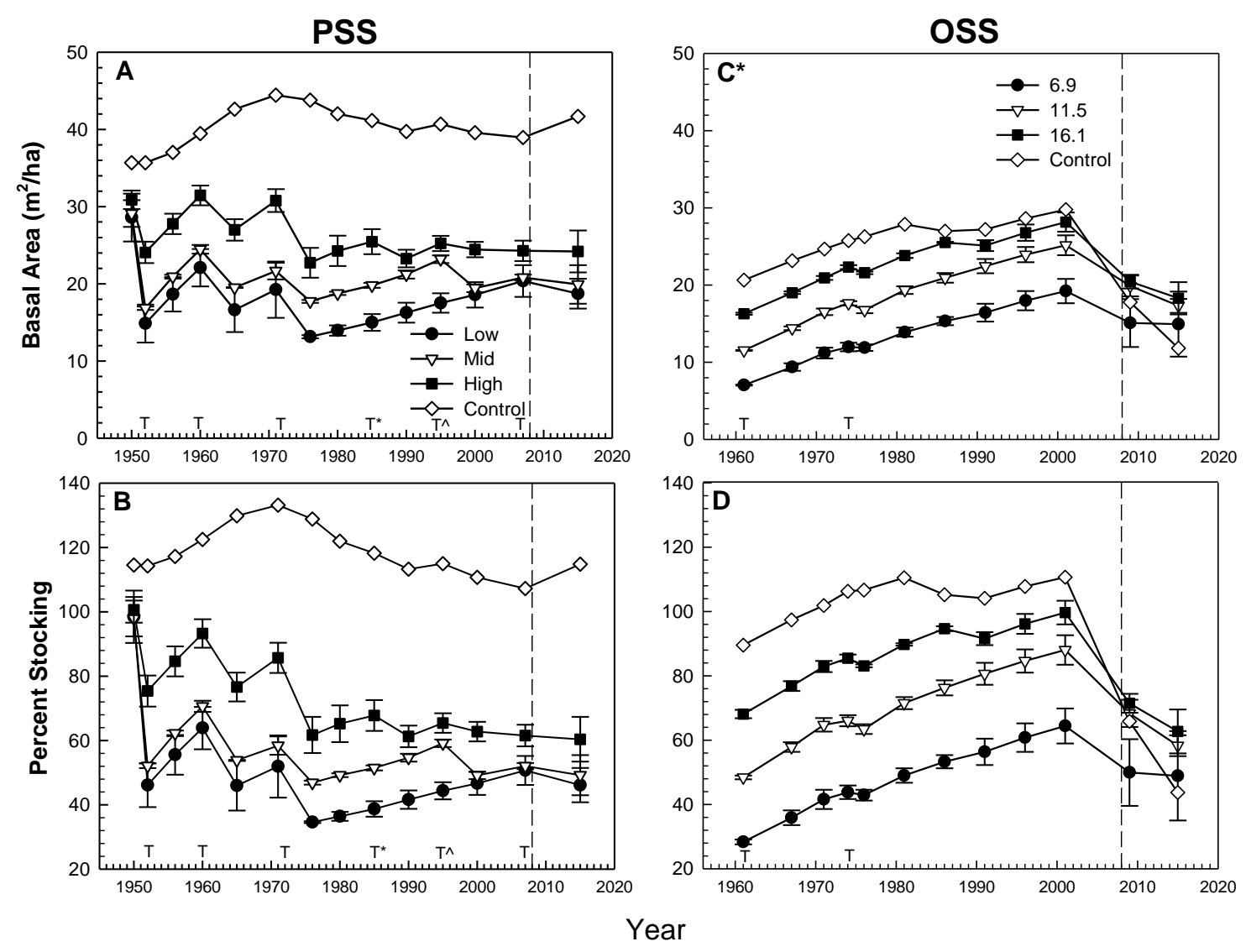

Figure 2.2. Descriptive stand metrics - Basal area and percent stocking for PSS (A-B) and OSS (C-D) Dashed line represents end of analysis period due to the 2009 derecho. Ts represent thin years. ${ }^{*}$ OSS basal area did not have a significant interation-panel shows pattern of development. 

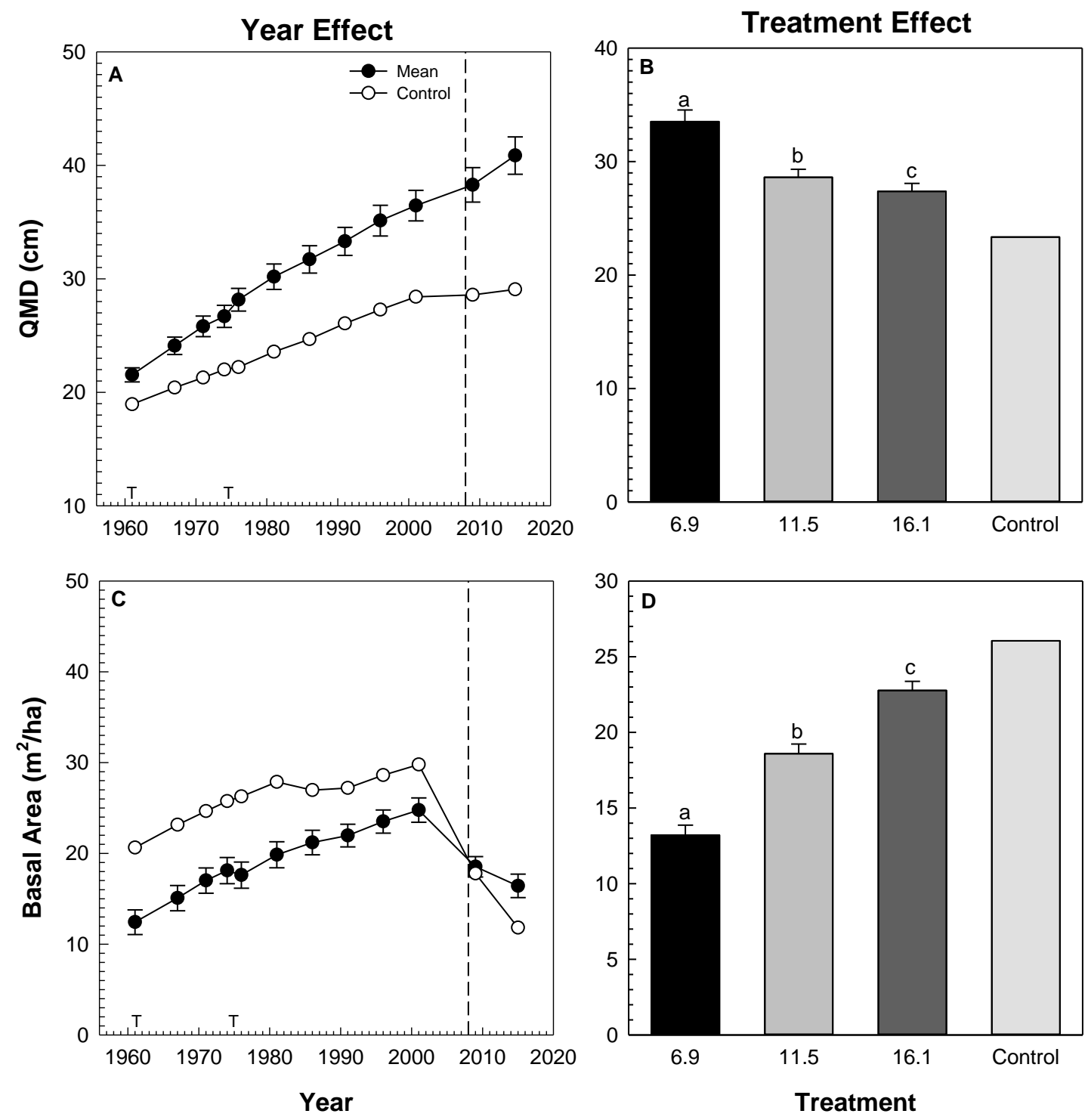

Figure 2.3: $Q M D(A$ and $B)$ and basal area $(C$ and $D)$ year and treatment effects in the OSS. Letters of significance represent treatment differences. Thinning application years are indicated by ' $T$ '.

\section{Carbon Dynamics - PSS}

In the PSS, there was an interaction between treatment density and year for stand-level aboveground carbon storage and individual-tree carbon storage (Table 2.7; Figure 2.4). Treatment and year effects were both significant for stand- and individual tree-level carbon sequestration rates (Figure 2.6; 2.7; 2.8). 
Similar to percent stocking, stand-level carbon storage in the PSS showed significant reductions following thinning in the Low and Mid treatment densities (Figure 2.4A). However, in the High treatment, only the 1972 thin significantly reduced total aboveground carbon. The High treatment was significantly greater than the Low treatment in 1952 and 1965-1985 but was only significantly greater than the Mid treatment in 1952. Slice effects showed that there were significant differences among treatments for all years except 2007, however, after Tukey's HSD adjustment, no treatments were significantly different from 1956-60 and 1990-2007.

Although there was a significant treatment effect for individual-tree carbon storage from 1960-85, Tukey's HSD adjustment resulted in no significant pairwise differences among treatments (Figure 2.4B). Like QMD, each measurement year resulted in significantly greater individual-tree carbon storage than the prior year.

Both treatment and year effects were significant for stand-level carbon sequestration rates. Treatment effects showed the Low and Mid treatments were not significantly different from each other, but each had significantly less carbon sequestration than the High treatment (Figure 2.7B). Year effects showed high levels of carbon sequestration early in the study (Figure 2.7A). After 1960, sequestration rates showed a decline until 1976, when rates remained steady until 2007. The only exception was 1995 , which showed an increase in sequestration rates that did not persist in 2000 . 
Individual-tree carbon sequestration rates in the PSS were influenced by both treatment and year. Year effect showed a slight increase in individual-tree carbon sequestration rates through time (Figure 2.8A). Treatment effects showed that the Low treatment had the highest individual-tree carbon sequestration rates, and the High treatment had the lowest rates (Figure 2.8B). The Mid treatment was not significantly different from either the Low or High treatment.

Table 2.7. Carbon dynamics repeated measures ANOVA results at stand and individual tree level for PSS and OSS. P values represent significant effect at 0.05 level.

\begin{tabular}{|c|c|c|c|c|c|c|}
\hline \multirow[b]{2}{*}{ Variable } & \multicolumn{6}{|c|}{ Pine Stocking Study } \\
\hline & $\begin{array}{c}F \\
\text { value }\end{array}$ & Trt & $\begin{array}{c}\mathrm{F} \\
\text { value }\end{array}$ & Year & $\begin{array}{c}F \\
\text { value }\end{array}$ & $\mathrm{Trt}^{\star}$ year \\
\hline \multicolumn{7}{|l|}{ Stand-Level } \\
\hline C Storage & 14.92 & 0.0019 & 64.64 & $<0.0001$ & 3.14 & 0.0002 \\
\hline C Sequestration & 11.65 & 0.0007 & 58.28 & $<0.0001$ & 1.55 & 0.1093 \\
\hline \multicolumn{7}{|c|}{ Individual Tree-Level } \\
\hline C Storage & 2.61 & 0.1423 & 420.05 & $<0.0001$ & 2.50 & 0.0017 \\
\hline \multirow[t]{3}{*}{ C Sequestration } & 5.38 & 0.0234 & 7.30 & $<0.0001$ & 1.29 & 0.2266 \\
\hline & \multicolumn{6}{|c|}{ Oak Stocking Study } \\
\hline & $\begin{array}{c}F \\
\text { value }\end{array}$ & Trt & $\begin{array}{c}\mathrm{F} \\
\text { value }\end{array}$ & Year & $\begin{array}{c}F \\
\text { value }\end{array}$ & $\mathrm{Trt}^{\star}$ year \\
\hline \multicolumn{7}{|l|}{ Stand-Level } \\
\hline C Storage & 55.81 & $<0.0001$ & 159.29 & $<0.0001$ & 3.59 & $<0.0001$ \\
\hline C Sequestration & 6.24 & 0.0118 & 9.23 & $<0.0001$ & 0.75 & 0.7286 \\
\hline \multicolumn{7}{|c|}{ Individual Tree-Level } \\
\hline C Storage & 11.32 & 0.0064 & 129.20 & $<0.0001$ & 1.29 & 0.2259 \\
\hline C Sequestration & 189.81 & $<0.0001$ & 8.60 & $<0.0001$ & 1.59 & 0.1008 \\
\hline
\end{tabular}




\section{Carbon Dynamics - OSS}

In the OSS, there was a significant interaction between treatment density and year for stand-level aboveground carbon storage (Table 2.7; Figure 2.4; 2.6). Both treatment and year effects were significant for individual-tree carbon storage, stand-level carbon sequestration rate, and individual-tree carbon sequestration rate (Figures $2.5 ; 2.7 ; 2.8$ ).

Stand-level carbon storage showed similar patterns to basal area and percent stocking (Figure 2.4C). The 1961 establishment thin created three significantly different amounts of stored carbon which remained significantly different until 1976 . From 1961 to 1996 the $6.9 \mathrm{~m}^{2} /$ ha treatment remained significantly lower than both the 11.5 and the $16.1 \mathrm{~m}^{2} / \mathrm{ha}$ treatments and in 2001 was significantly lower than the $16.1 \mathrm{~m}^{2} /$ ha treatment. The 1974 thin did not cause a significant reduction in stand-level carbon storage in any of the treatment densities.

Individual-tree carbon storage was influenced by both treatment and year. Year effect showed that individual-tree carbon storage significantly increased through time with each measurement year being significantly greater than the last (Figure 2.5A). Treatment effects showed that an average tree in the 6.9 $\mathrm{m}^{2} /$ ha treatment held significantly more carbon than both the Mid and High treatments (Figure 2.5B).

Stand-level carbon sequestration rates were influenced by both treatment and year. Year effect showed fluctuations through time that were not necessarily 
related to thinning events but resulted in slightly decreased levels of stand-level carbon sequestration by 2001 compared to 1961 (Figure 2.7C). Treatment effects showed that the 11.5 and $16.1 \mathrm{~m}^{2} /$ ha density stands sequestered more carbon per year than the $6.9 \mathrm{~m}^{2} /$ ha treatment (Figure 2.7D).

Individual-tree carbon sequestration rates were influenced by both treatment density and year. Year effect showed a slight increase in sequestration rates through time (Figure 2.8C). Treatment effects showed all three densities had significantly different levels of individual-tree carbon sequestration rates with $6.9 \mathrm{~m}^{2} /$ ha being the greatest and $16.1 \mathrm{~m}^{2} /$ ha the lowest (Figure $2.8 \mathrm{D}$ ). 
PSS

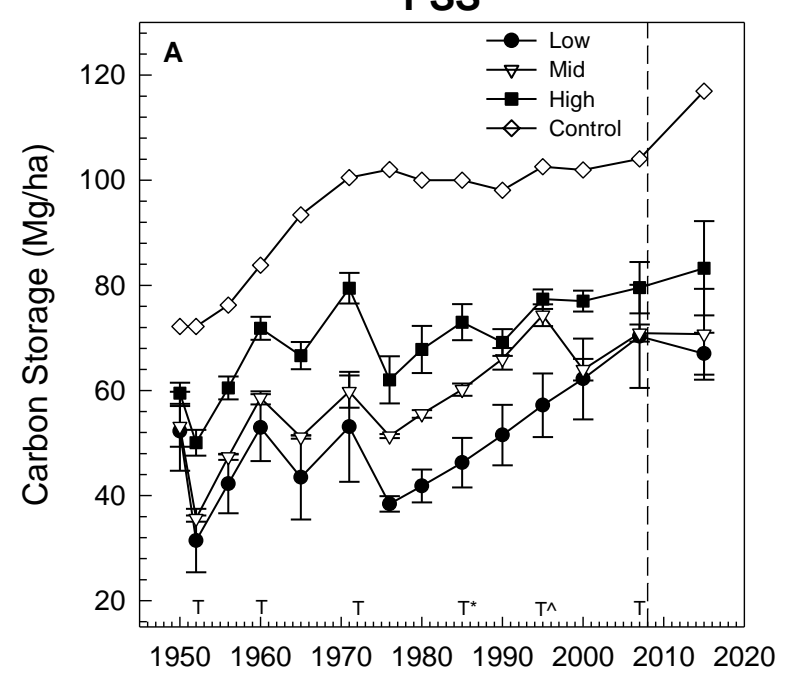

oss

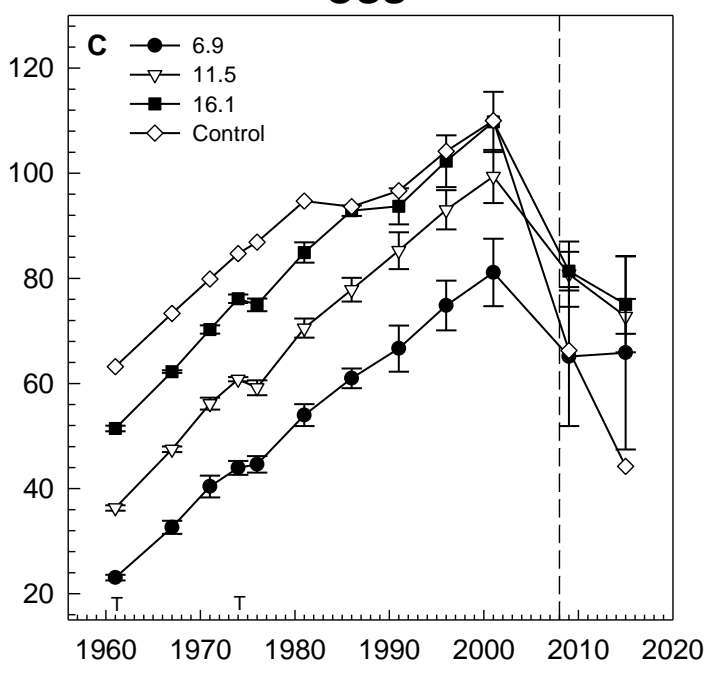

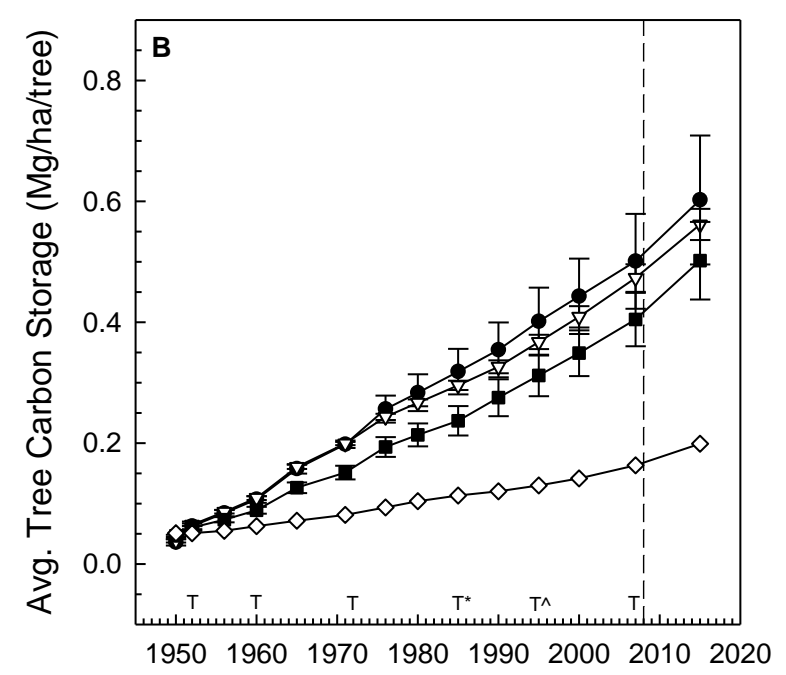

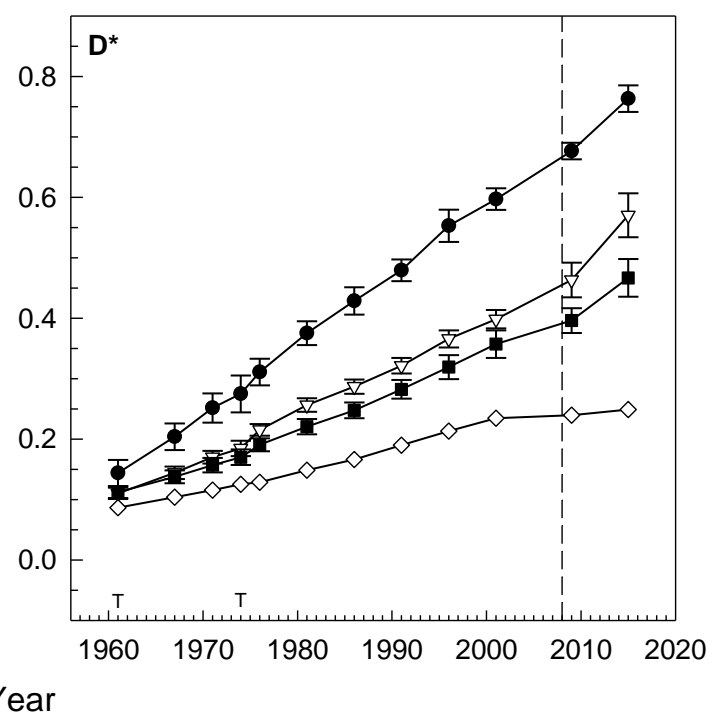

Figure 2.4. Total aboveground carbon storage and average tree aboveground carbon storage for the PSS (A $\& B)$ and OSS $(C \& D)$. T's represent thinning years. $T^{*}$ - only the High treatment was thinned. $T^{\wedge}$ - only High and Mid treatments thinned. Vertical line represents the final year included in the analysis period due to the 2009 derecho. *OSS Individual-tree carbon storage did not have an interaction - panel to show pattern. 

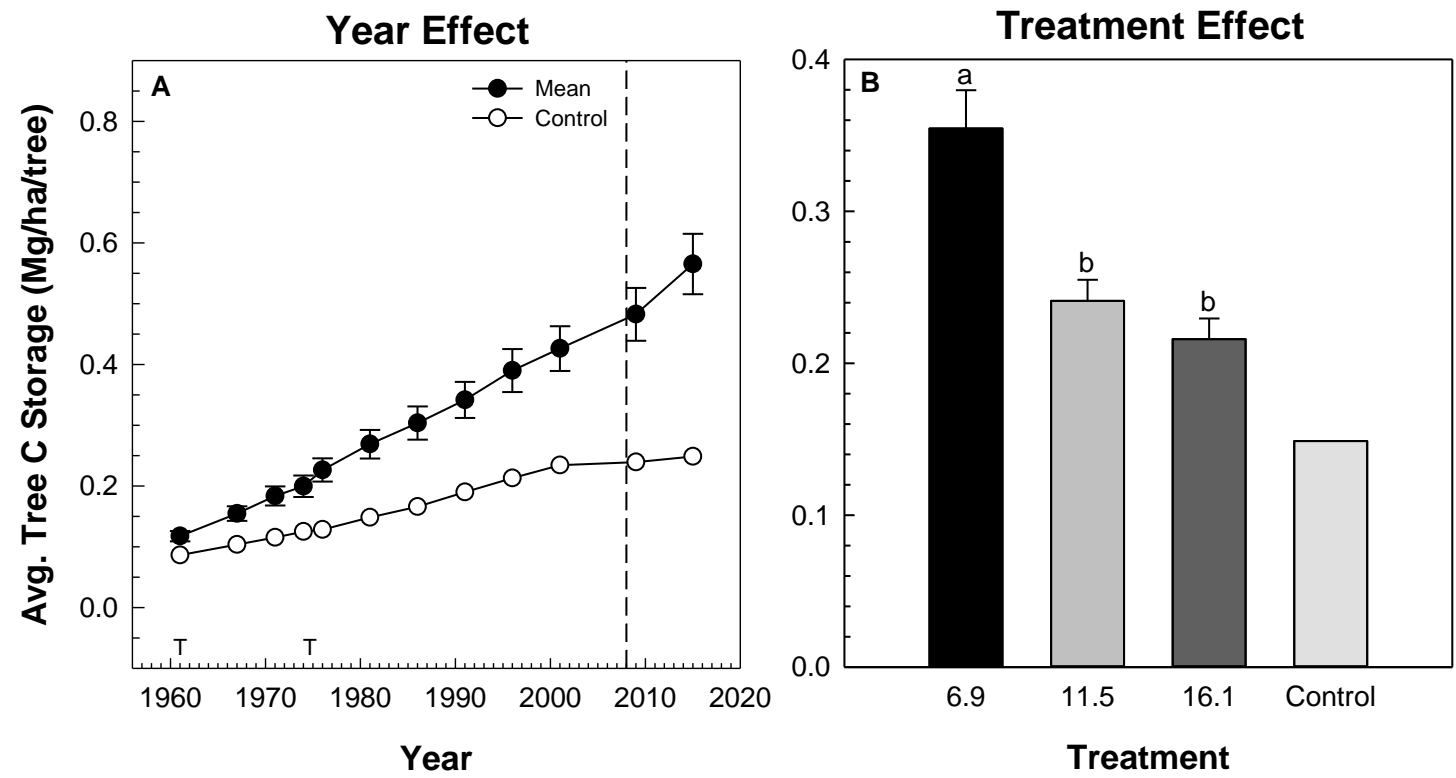

Figure 2.5: Individual tree carbon storage for the OSS including year and treatment effects. Letters of significance represent differences in treatment densities. Years of thinning application are indicated by ' $T$ '. Vertical line represents the final year included in the analysis period due to the 2009 derecho. 

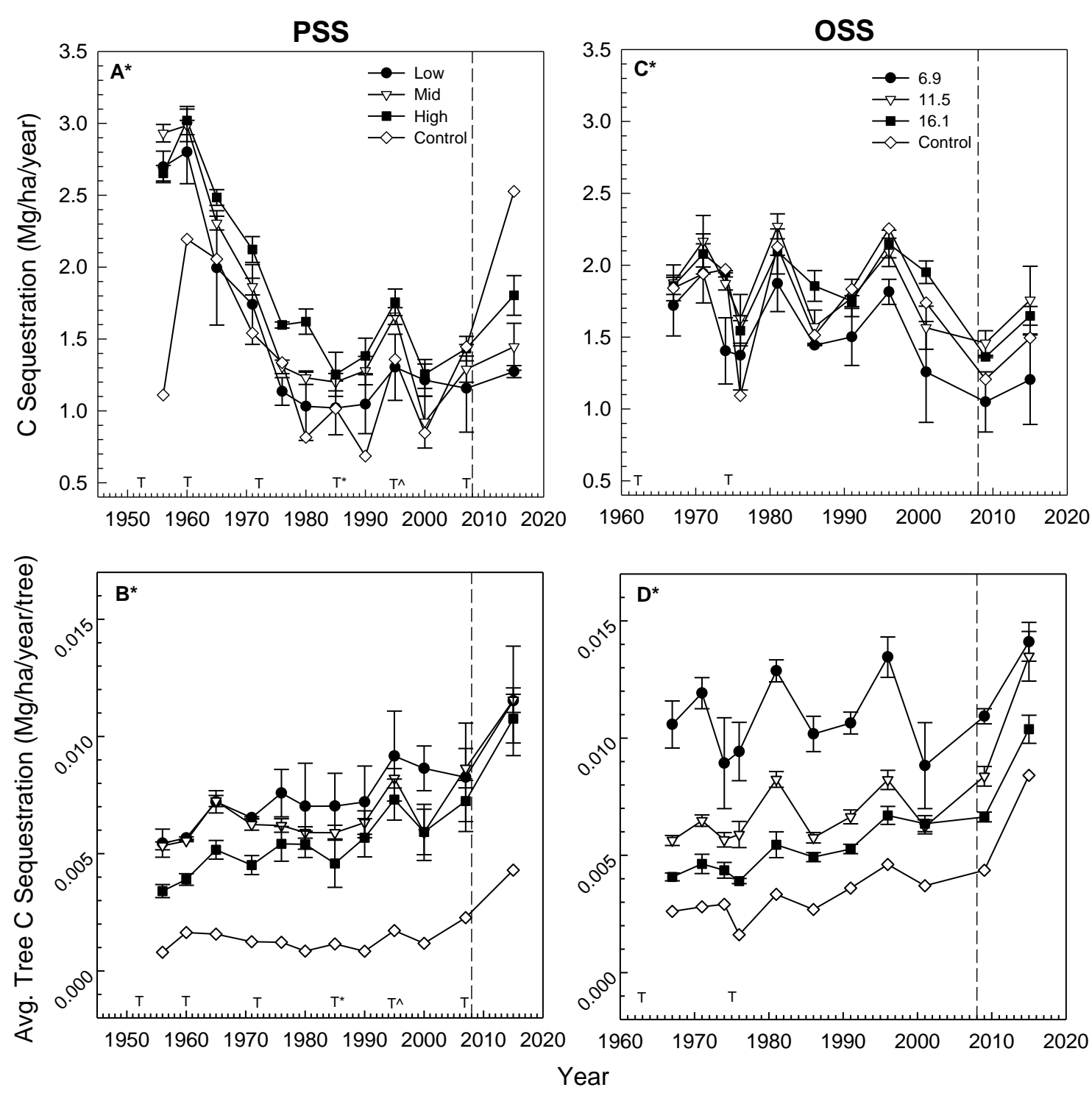

Figure 2.6. Stand and individual tree level carbon sequestration for the PSS (A\&B) and OSS (C \&D). T'S represent thinning years. $T^{*}$ - only the High treatment was thinned. $T^{\wedge}$ - only High and Mid treatments thinned. Vertical line represents the final year included in the analysis period due to the 2009 derecho. *PSS and OSS carbon sequestration (stand and individual) did not show interaction - panels to show patterns in development. 


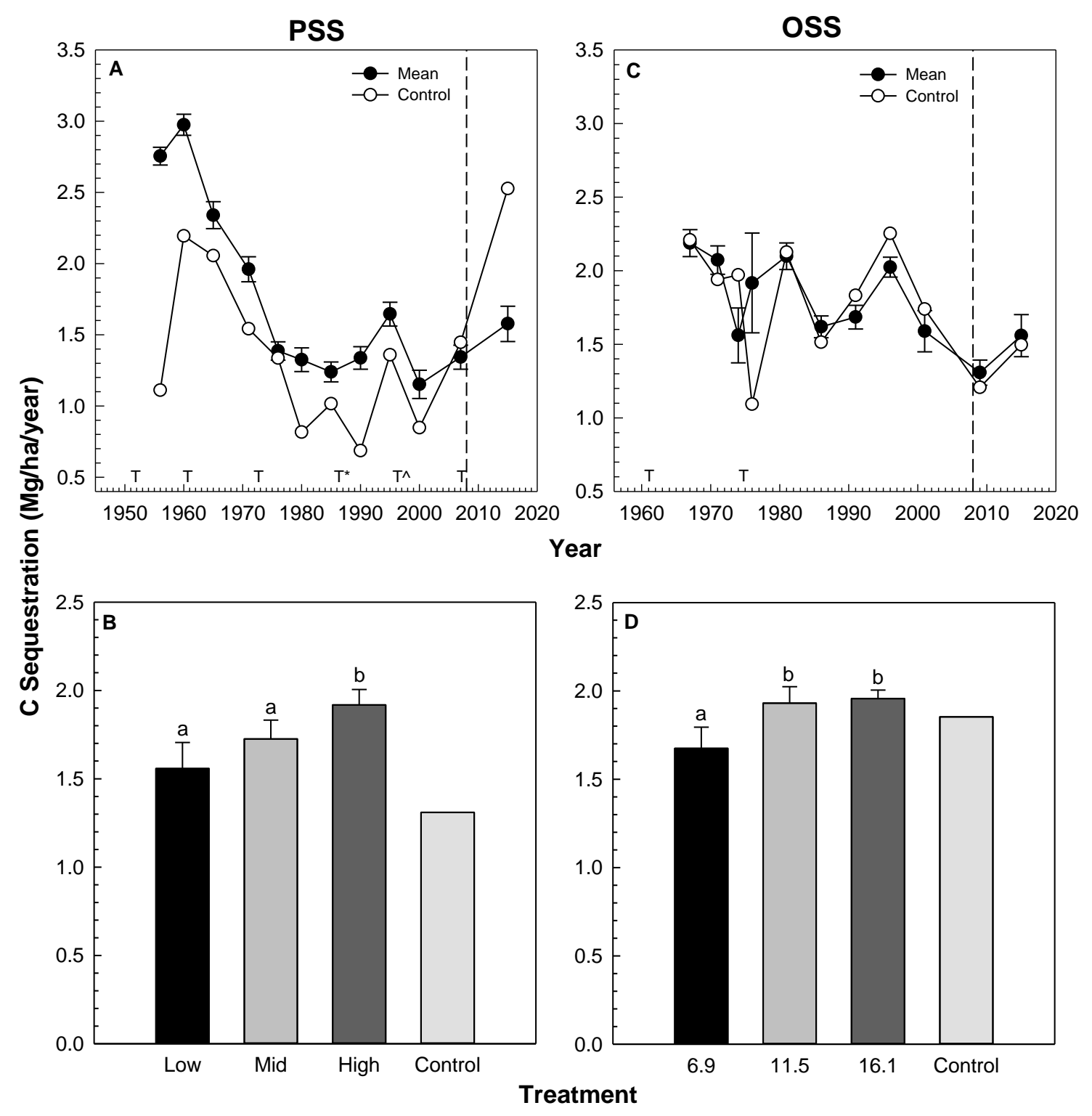

Figure 2.7: Stand-level carbon sequestration rate year and treatment effects for PSS (A and B) and OSS (C and $D$ ). Letters of significance indicate differences among treatment densities. Years of thinning application indicated with ' $T$ '. $T^{*}$ - only the High treatment was thinned. $T^{\wedge}$ - only High and Mid treatments thinned. Vertical line represents the final year included in the analysis period due to the 2009 derecho. 
PSS

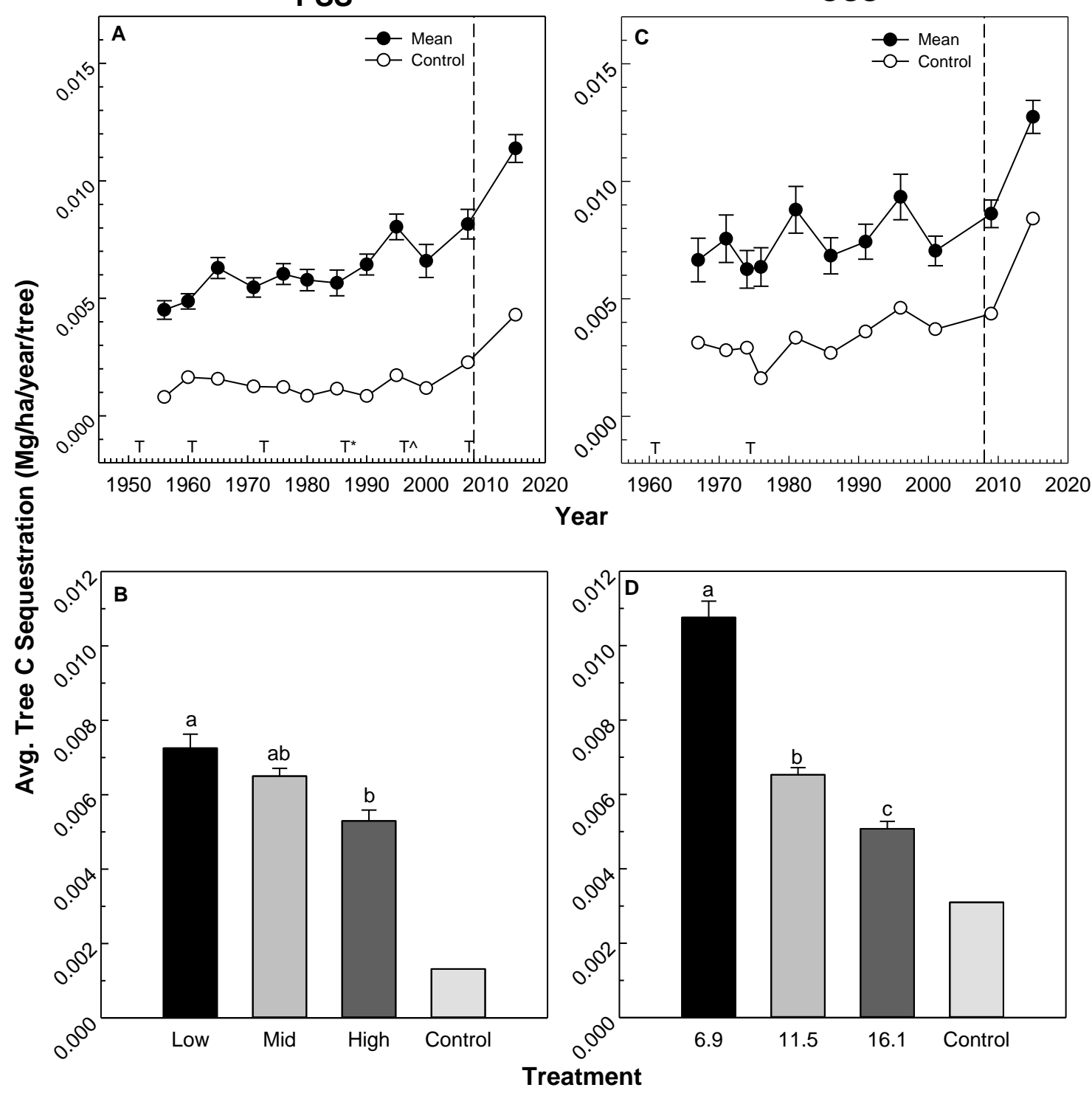

Figure 2.8: Individual-tree carbon sequestration rate year and treatment effects for PSS (A and B) and OSS $(C$ and $D)$. Letters of significance indicate differences among treatment densities. Years of thinning application indicated with ' $T$ '. $T^{*}$ - only the High treatment was thinned. $T^{\wedge}$ - only High and Mid treatments thinned. Vertical line represents the final year included in the analysis period due to the 2009 derecho.

\section{Gross Carbon}

In the PSS, TGC was not significantly different among treatment densities in 2015 (Table 2.8, Figure 2.9). However, treatment density did have a significant effect on SGC. Since the first thinning in the study, the High treatment produced 
and stored a significantly greater amount of carbon than both the Mid and Low density treatments. The Mid and Low density treatments were not significantly different from each other. In the OSS, treatment density also had a significant effect on SGC. The $6.9 \mathrm{~m}^{2} /$ ha treatment held significantly less total carbon than the 11.5 and $16.1 \mathrm{~m}^{2} /$ ha treatments. The 11.5 and $16.1 \mathrm{~m}^{2} /$ ha treatments were not significantly different from each other.

Table 2.8. Gross carbon results of one-way ANOVA. Total gross carbon (TGC) for the PSS and study gross carbon (SGC) in overstory trees in the PSS and OSS. P values represent a significant treatment effect at 0.05 level

\begin{tabular}{ccc|ccc}
\hline Variable & $\begin{array}{c}F \\
\text { value }\end{array}$ & Trt & Variable & $\begin{array}{c}F \\
\text { value }\end{array}$ & Trt \\
\hline PSS & & & OSS & & \\
SGC & 10.2 & 0.0049 & SGC & 16.06 & 0.0024 \\
TGC & 3.69 & 0.0630 & & &
\end{tabular}


Study Gross Carbon 2015
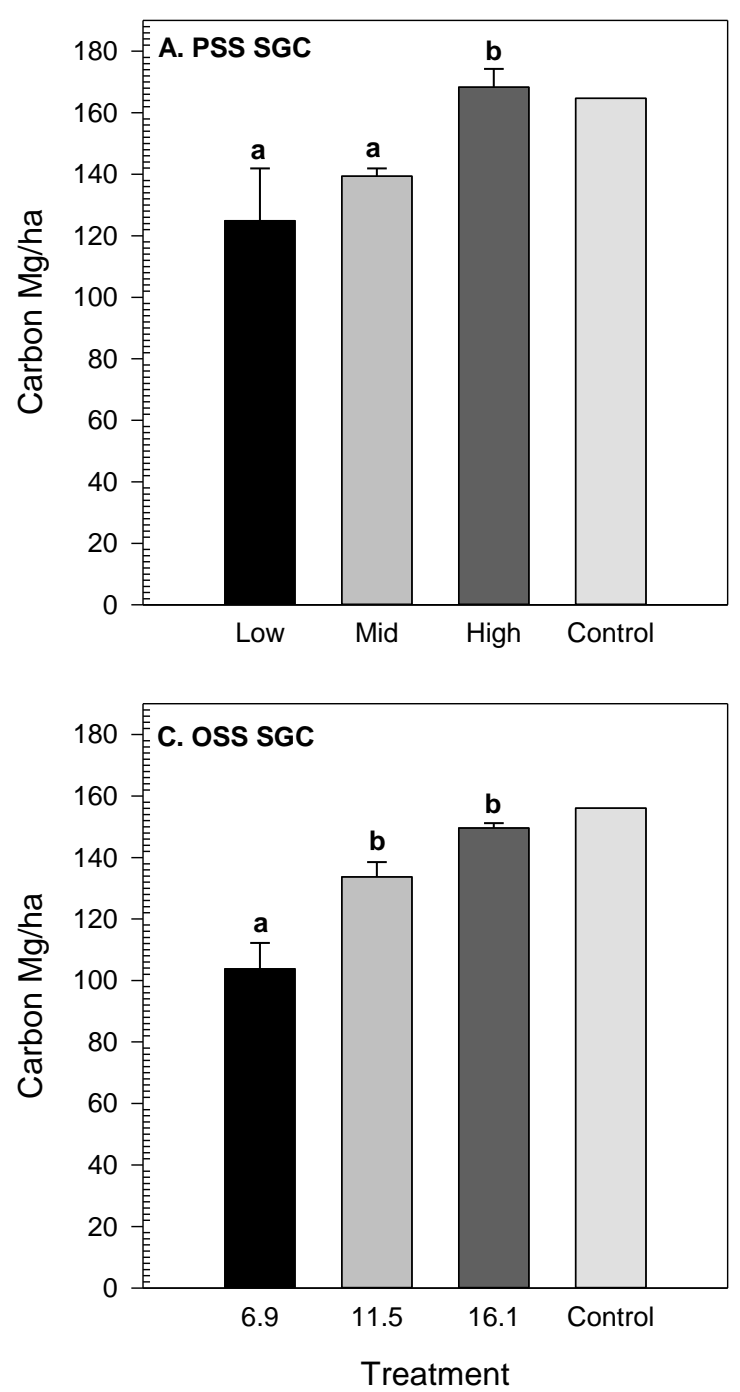

Total Gross Carbon 2015

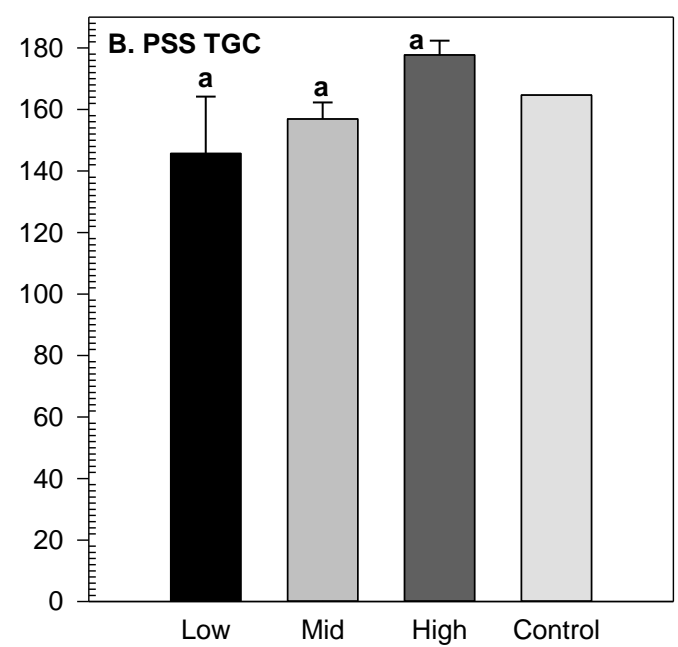

Figure 2.9. Study gross carbon (SGC) for the PSS and OSS and total gross carbon (TGC) for the PSS. Letters represent significant differences among treatment densities with a visual comparison control plot. Pre-treatment data was unavailable to calculate TGC for the OSS. 


\section{Sink/Source}

The sink/source analysis showed a significant net gain in aboveground carbon from 1952-2007 ( $p<0.0001)$ and no significant differences in net carbon among treatment densities (Figure 2.10). There was also no significant net loss of carbon in any treatment period in any of the treatment densities (Figure 2.11). In each treatment density, at least one thinning period showed a significant net gain of carbon. In the Low treatment, the period from 1971 to 2007 showed a net gain (Figure 2.12A). In the Mid treatment, the period from 1971 to 1995 showed a net gain, and in the High treatment, two periods, 1952-1960 and 1960-1971 showed net gains in carbon (Figures 2.12B, 2.12C).

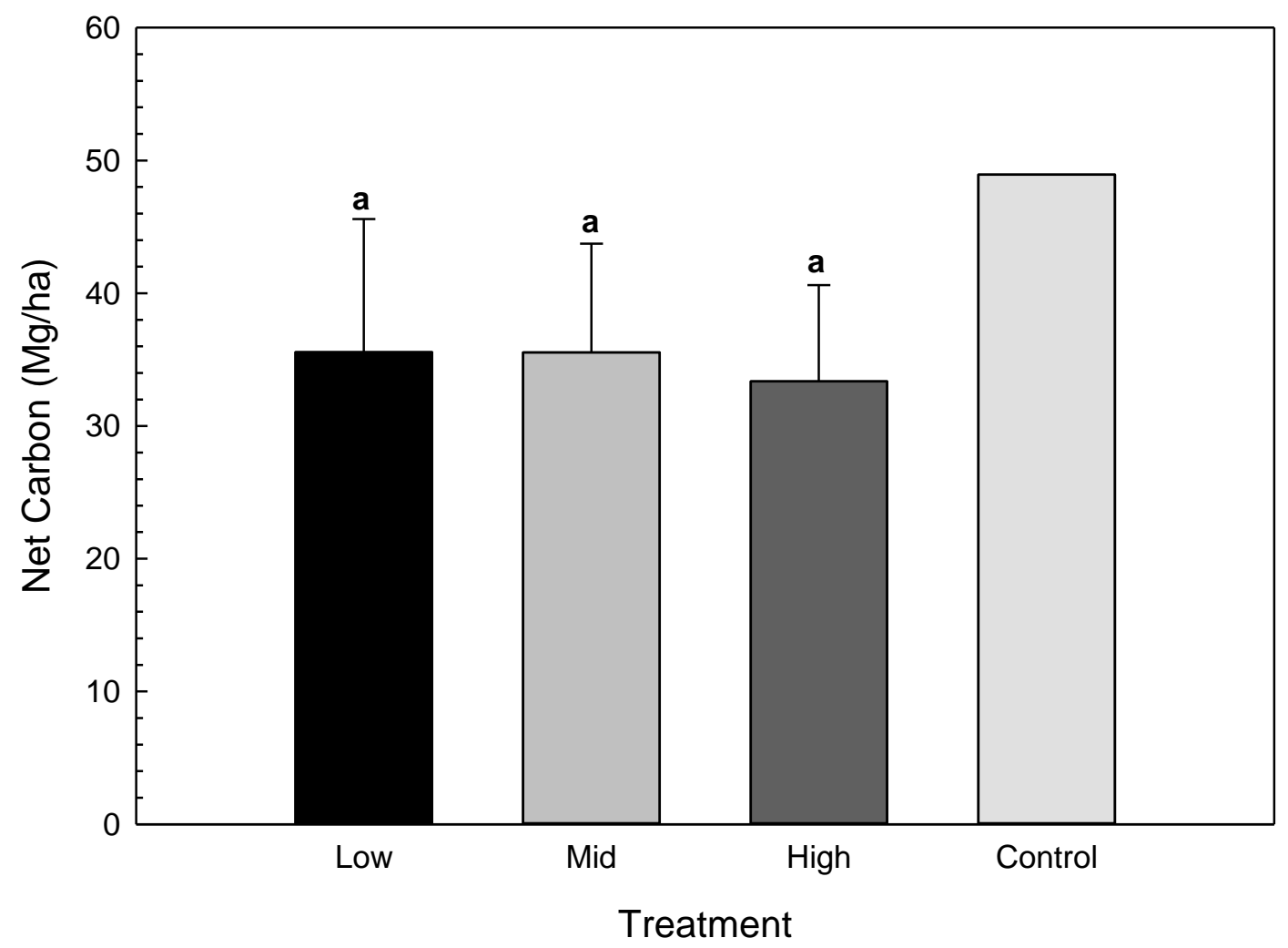

Figure 2.10: Net change in aboveground carbon storage 1952-2007. Letters of significance indicate significant differences among treatment densities. 


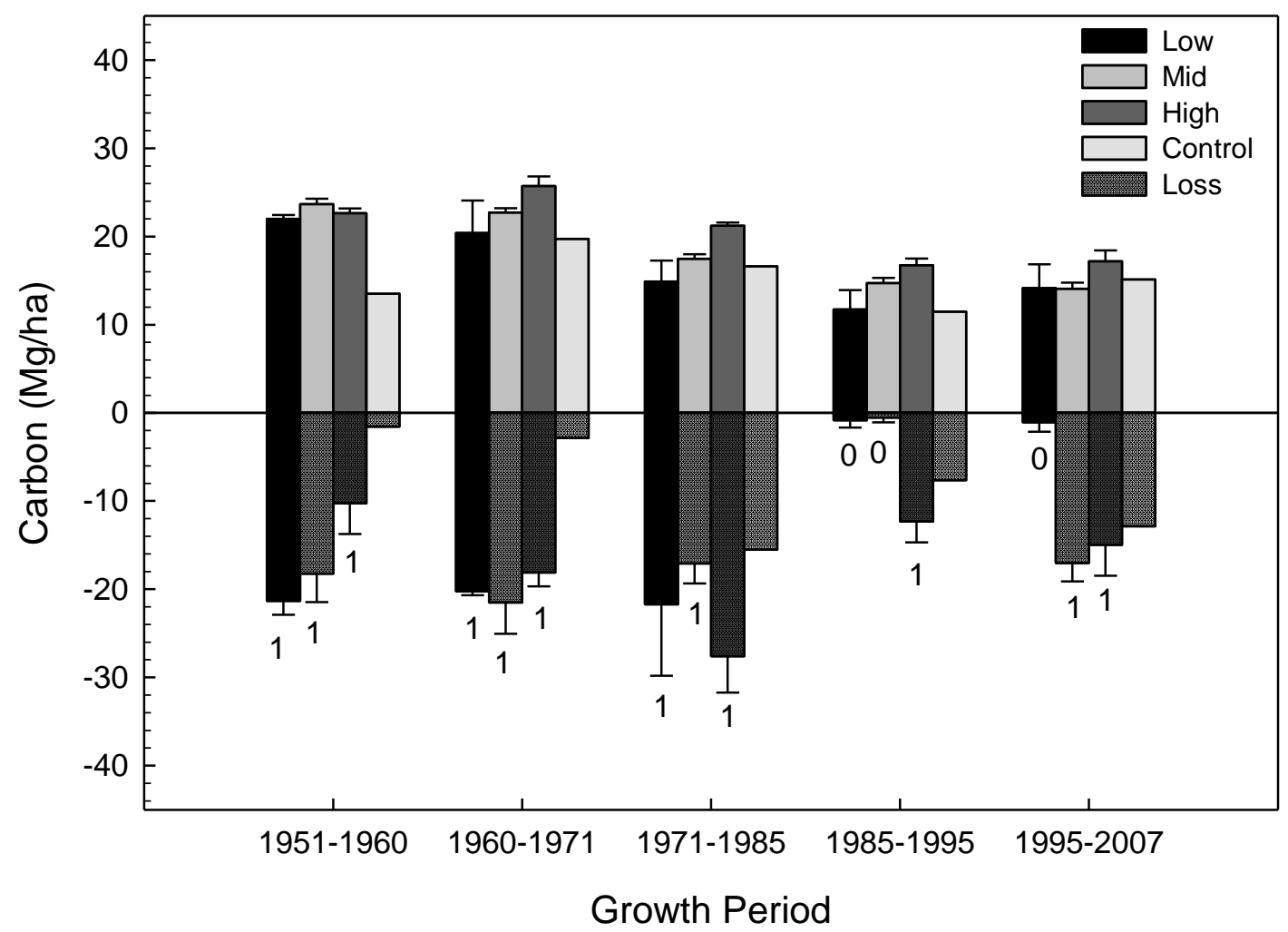

Figure 2.11: Sink v. Source. Comparison of growth and removal/mortality by treatment and growth period. Numbers below bars represent number of thins that occurred in that treatment density in that period. 

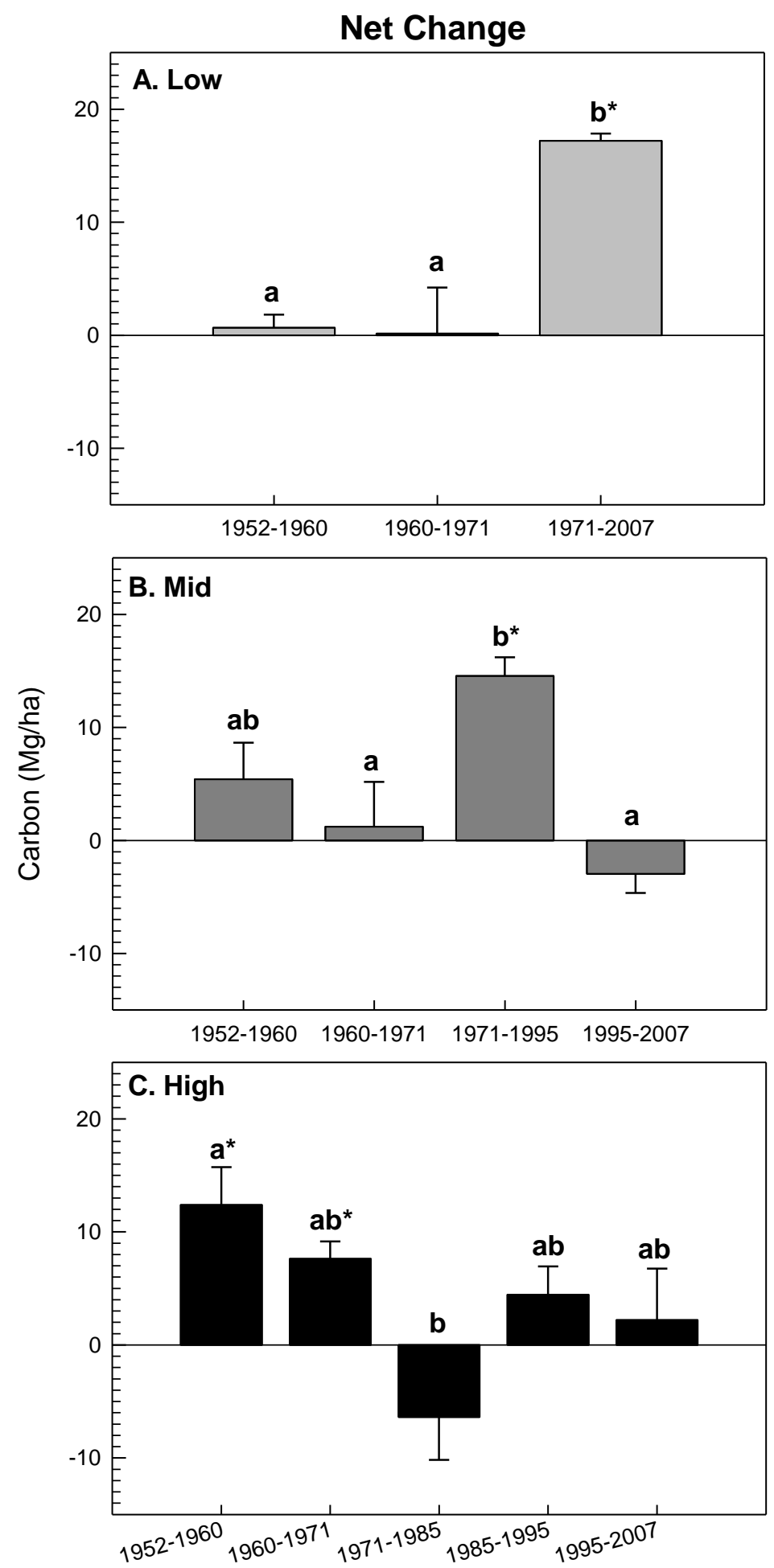

Growth Period

Figure 2.12. Sink v Source. Separated by treatment due to differences in thinning schedules. Letters of significance represent within treatment differences among treatment periods. ${ }^{*}$ represents net change in carbon significantly different from 0 net change. 


\section{Merchantable Volume}

In the PSS, treatment density did not have a significant effect on standlevel cubic meter volume in $2007(p=0.0966)$ (Figure 2.13). Considering time to reach merchantable sawlog size, defined here as $25.4 \mathrm{~cm}$ QMD, an average tree in the High treatment reached sawolg size by 1965 (stand age 45), only 3 years later than the Low and Mid treatments (Figure 2.1B). In contrast, the uncut control stand did not reach a QMD of $25.4 \mathrm{~cm}$ until 1995 (stand age 75), which is 30 years after the High treatment.

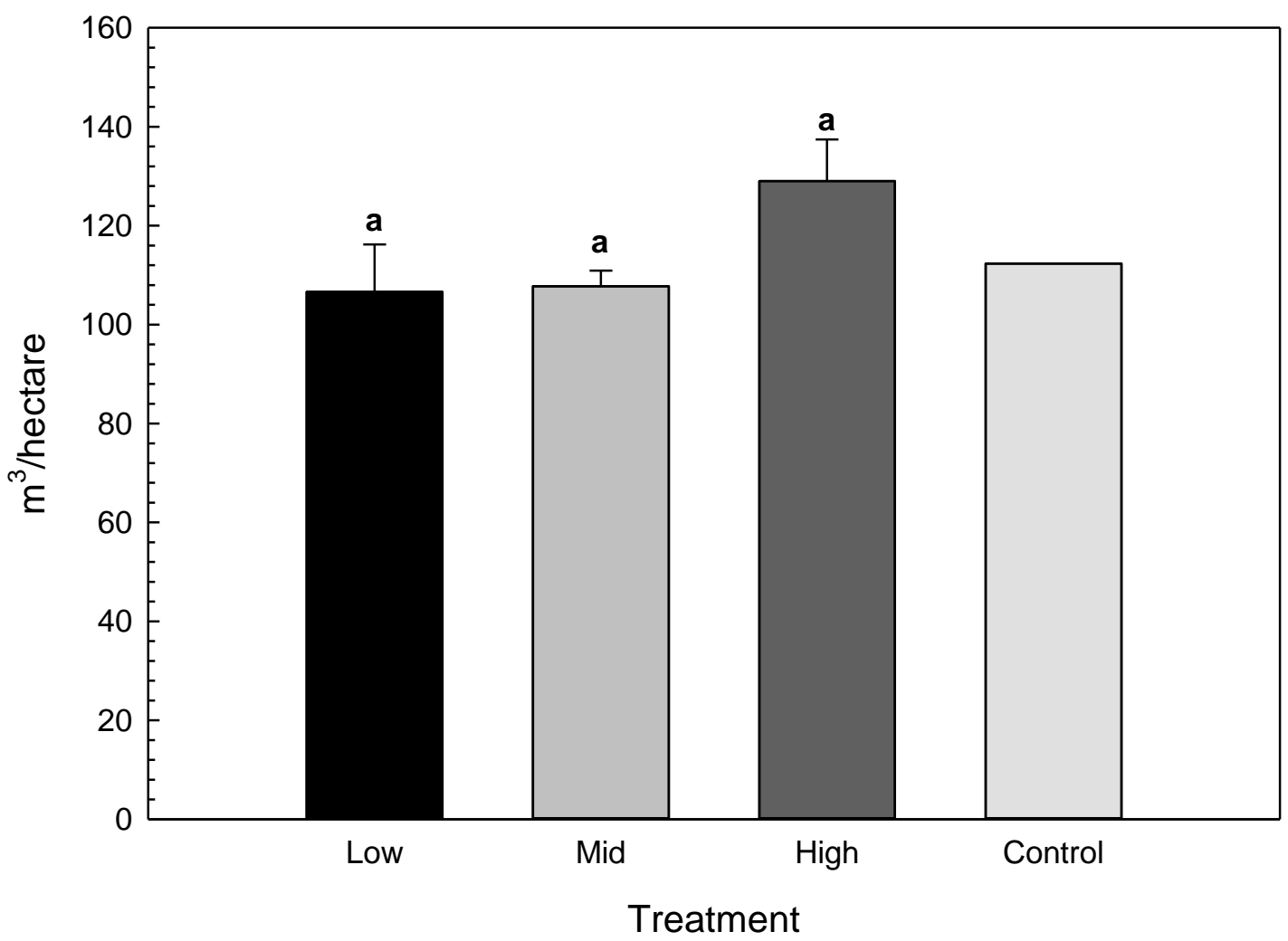

Figure 2.13. Merchantable volume $\left(\mathrm{m}^{3} / \mathrm{ha}\right)$ by treatment density of the PSS in 2007. 


\section{Mortality}

Carbon loss due to mortality within species groups in the OSS was influenced only by year for the red oak group and the white oak group (Table 2.9). Carbon loss from 1961 through 2001 for all species groups was not significantly different. In the red oak group, carbon loss from 2001-2009 was significantly greater than any other period, and loss from 2009-2015 was significantly greater than all periods other than 2001-2009 (Figure 2.14). Carbon loss in the white oak group from 2001 to 2009 was greater than all other periods. The 'other species' group, which included hickories, shortleaf pine, and black walnut, showed no significant carbon loss due to mortality in any year. Treatment effect on carbon loss in the red oak group was marginal in significance and is shown in Figure 2.15.

Table 2.9. OSS mortality repeated measures ANOVA results based on carbon loss (Mg/ha). P values represent effect at the 0.05 level.

\begin{tabular}{ccccccc}
\hline Variable & $\begin{array}{c}F \\
\text { value }\end{array}$ & Trt & F value & Year & $\begin{array}{c}F \\
\text { value }\end{array}$ & Trt $^{*}$ year \\
\hline Red Oak Group & 2.89 & 0.0722 & 31.78 & $<0.0001$ & 0.90 & 0.5874 \\
White Oak Group & 0.25 & 0.7790 & 3.77 & 0.0008 & 0.14 & 1.0000 \\
Other Species Group & 0.39 & 0.6837 & 0.78 & 0.6450 & 0.75 & 0.7577 \\
\hline
\end{tabular}




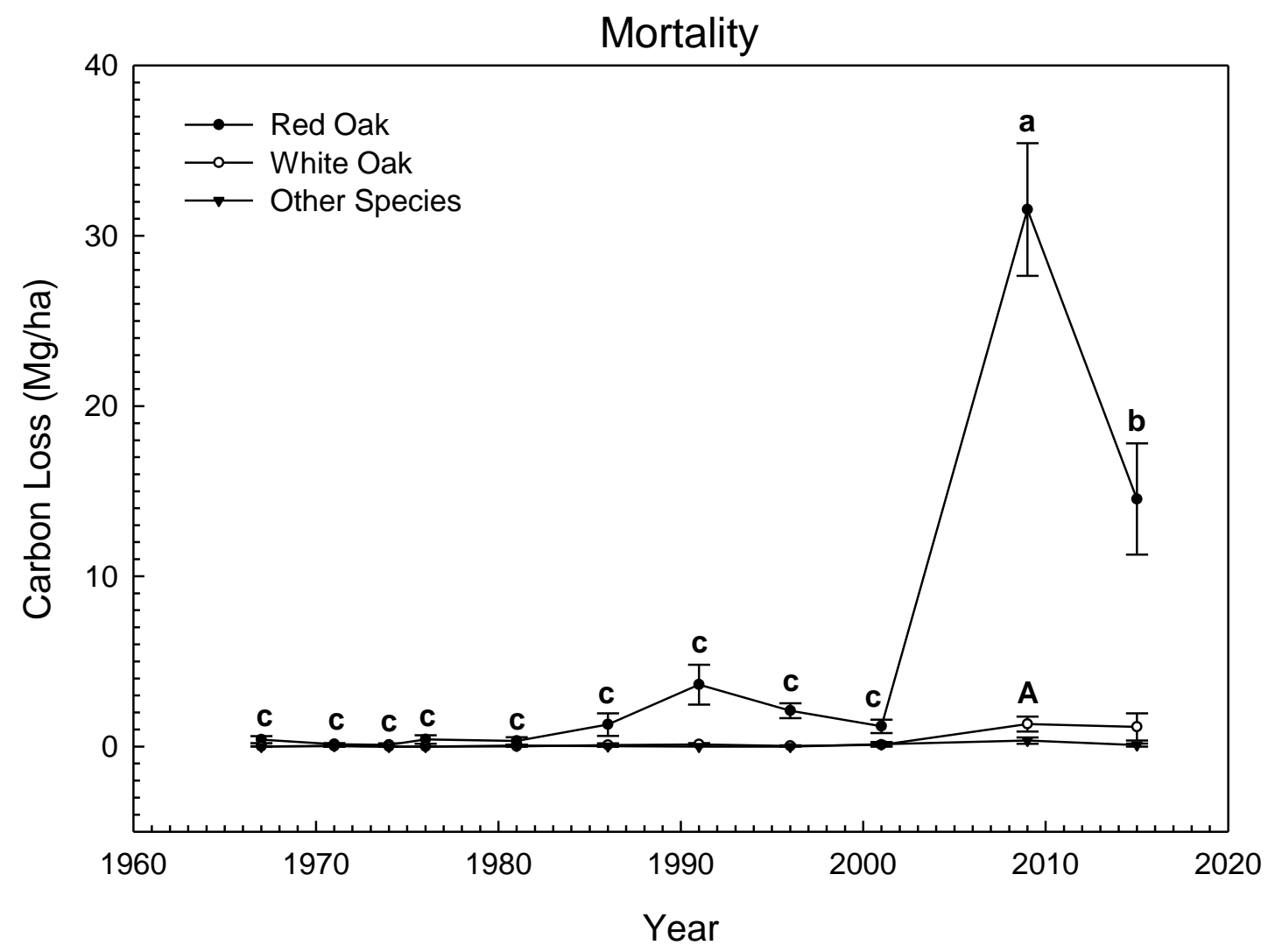

Figure 2.14. Carbon loss to mortality in OSS. Lowercase letters represent significantly different carbon loss in that year due to mortality in the red oak group at 0.05 level. Uppercase letter represents significantly different carbon loss due to mortality compared to all other years in the white oak group at 0.05 level. 


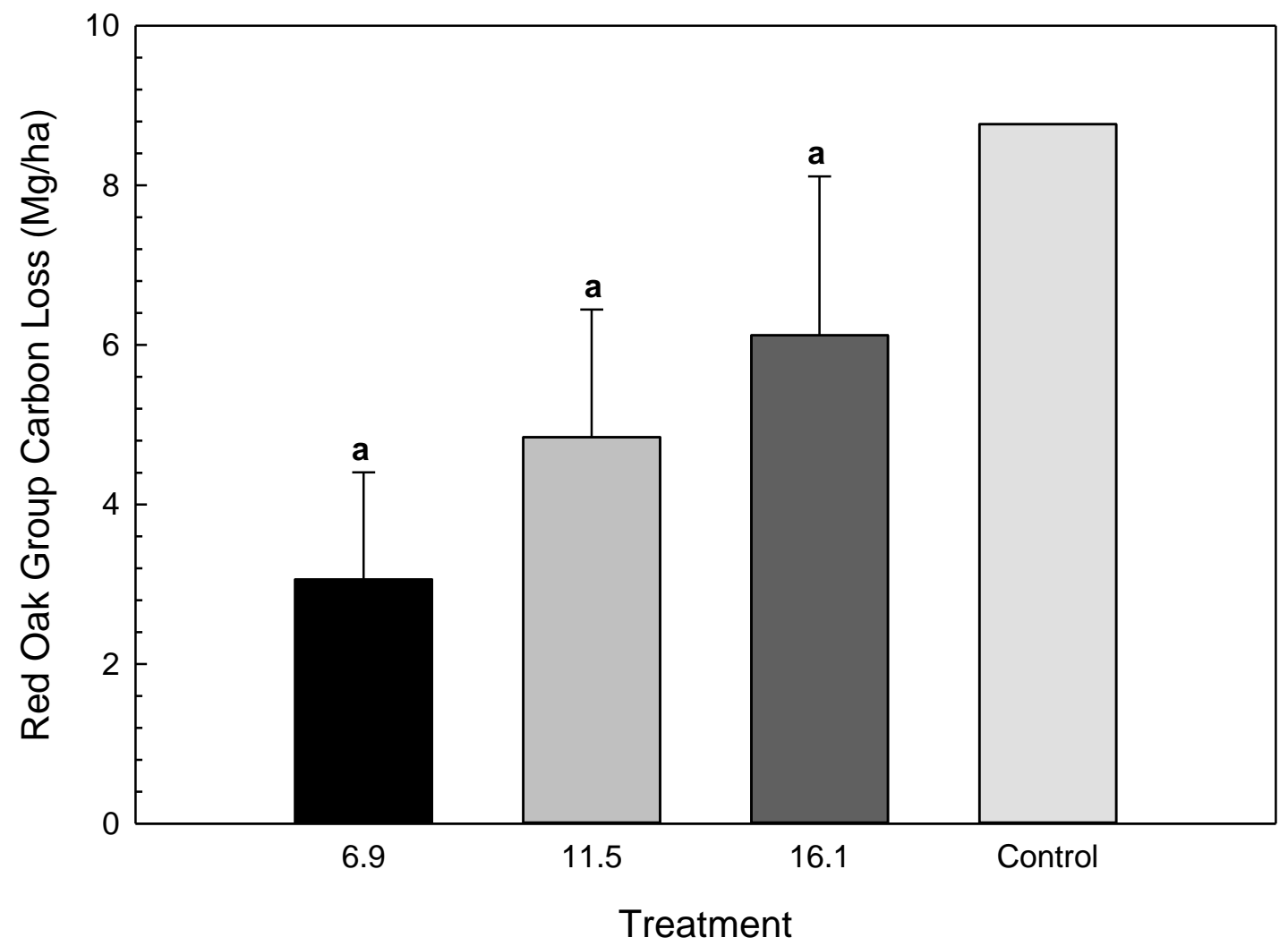

Figure 2.25. Red oak group carbon loss (Mg/ha). The effect of treatment on carbon loss was marginally significant between the 6.9 and $16.1 \mathrm{~m}^{2} /$ ha density treatments $(p=0.0596)$ in the red oak group.

\section{Species Composition}

Year significantly affected overstory composition for the red oak and white oak species groups, and there was no significant treatment effect (Figure 2.16). In 2015, the relative compositions for the red and white oak groups were significantly different from that in both 1961 and 2001. Specifically, percent of overstory based on TPH in the red oak group decreased from 2001 to 2015, and percent of overstory in the white oak group increased from 2001 to 2015 (Table 2.10). When ingrowth ( $\geq 10 \mathrm{~cm} \mathrm{dbh}$ ) was included in the 2015 species composition totals, there was a significant difference between 1961 and 2015 for 
all species groups (red oaks, white oaks, and other species) (Table 2.11).

Specifically, there was a significant loss of red oak group species, most

significantly in $Q$. velutina, and a significant gain of white oak group and 'other'

group species, specifically, Q. alba, Carya spp., and 'other' species percentages

increased (Table 2.11).

Table 2.10. Overstory species composition change 1961 to 2015

based on TPH. P values represent significant change in overstory species or group percentage at 0.05 level. * represents a significant loss in the species or group.

\begin{tabular}{cccccc}
\hline Species & \multicolumn{5}{c}{ \% of Total } \\
& 1961 & 2001 & 2015 & $\begin{array}{c}\text { Change } \\
\text { '61-'15 }\end{array}$ & P value \\
\hline Red Oak Group & 81.05 & 81.50 & 71.77 & -9.27 & $0.0214^{*}$ \\
Q. velutina & 75.08 & 74.72 & 68.21 & -6.87 & 0.1947 \\
Q. rubra & 4.28 & 5.10 & 1.74 & -2.55 & 0.0862 \\
Q. coccinea & 1.68 & 1.68 & 1.83 & 0.15 & 0.9488 \\
White Oak Group & 15.86 & 16.06 & 25.36 & 9.50 & 0.0148 \\
Q. alba & 15.64 & 15.86 & 25.36 & 9.73 & 0.0112 \\
Q. stellata & 0.36 & 1.97 & 0.00 & -0.36 & 0.2347 \\
Other Species & 1.29 & 2.25 & 2.74 & 1.44 & 0.5602 \\
Group & 1.77 & 1.49 & 1.87 & 0.10 & 0.84 \\
Carya spp. & 0.36 & 0.00 & 0.00 & -0.36 & --- \\
Pinus echinata & 1.20 & 1.20 & 1.36 & 0.16 & 0.2856 \\
Juglans nigra & & & & & \\
\hline
\end{tabular}


Table 2.11. Total species composition change 1961 to 2015 based on TPH. 2015 includes ingrowth $\geq 10 \mathrm{~cm} \mathrm{DBH}$. P values represent a significant change in total species composition at the 0.05 level. * represents a significant negative change in species or group composition. ^Species in 'Other' category include (in order of abundance) Nyssa sylvatica, Ulmus spp., Acer rubrum, Sassafrass albidum, Prunus serotina, Cornus spp., Acer saccharum, Diospyros virginiana, and Morus spp.

\begin{tabular}{ccccc}
\hline \multirow{2}{*}{ Species } & \multicolumn{2}{c}{$\%$ of Total } & & \\
& 1961 & $2015^{\wedge}$ & Change & P value \\
\hline Red Oak Group & 75.60 & 36.40 & -39.20 & $<0.0001^{*}$ \\
Q. velutina & 68.90 & 34.20 & -34.70 & $0.0002^{*}$ \\
Q. rubra & 1.90 & 1.00 & -0.90 & 0.0556 \\
Q. coccinea & 4.80 & 1.20 & -3.60 & 0.2581 \\
White Oak Group & 20.00 & 41.40 & 21.40 & 0.0124 \\
Q. Alba & 19.80 & 41.10 & 21.30 & 0.0137 \\
Q. stellata & 0.20 & 0.30 & 0.10 & 0.5827 \\
Other Species & 4.00 & 21.80 & 17.80 & 0.0004 \\
Group & & & & \\
Carya spp. & 2.60 & 4.80 & 2.20 & 0.0401 \\
Pinus echinata & 0.60 & 3.40 & 2.80 & 0.2405 \\
Juglans nigra & 0.80 & 1.30 & 0.50 & 0.3303 \\
Other spp^ & 0.00 & 12.30 & 12.30 & 0.0005 \\
& & & & \\
\hline
\end{tabular}




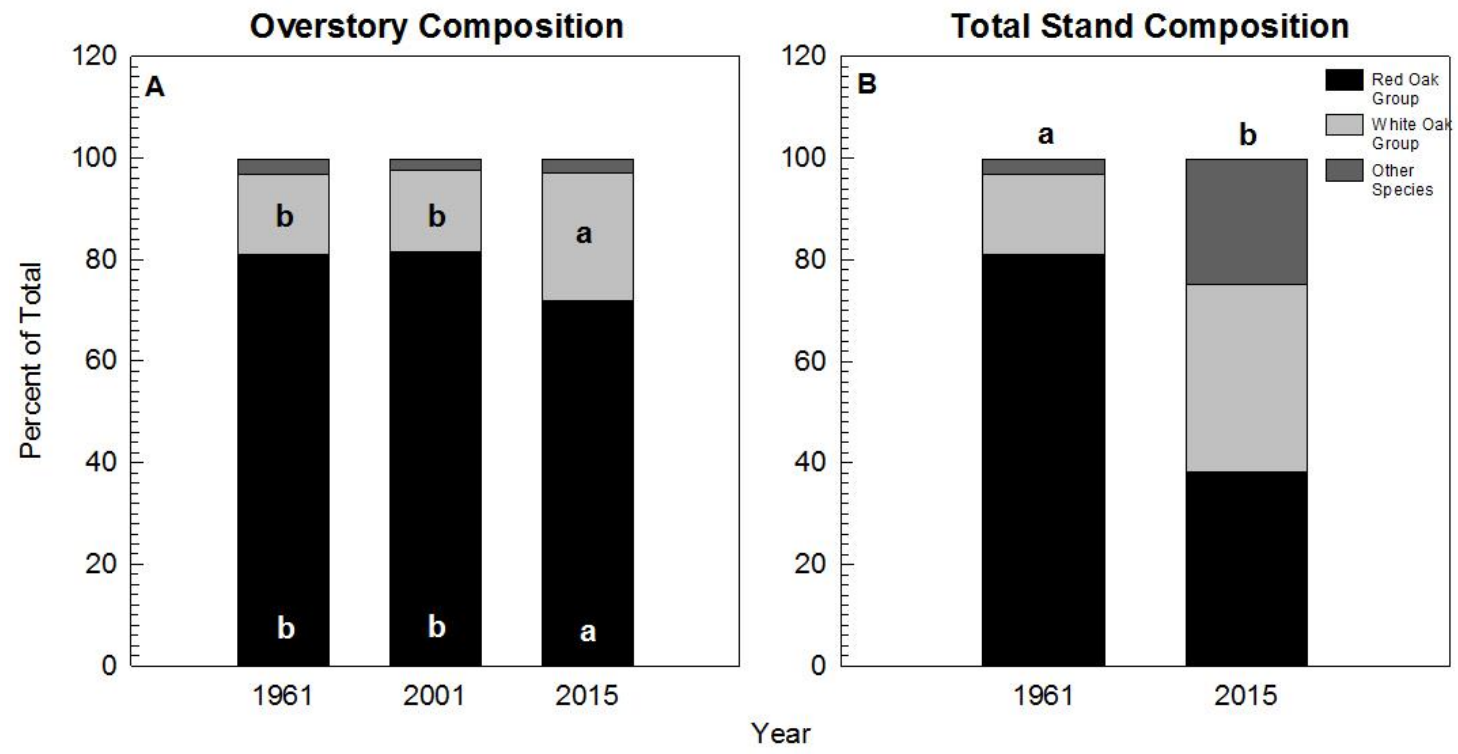

Figure 2.16. Species composition of the OSS- 1961, 2001, 2015 based on TPH. Graph A shows overstory composition only. Graph B shows overstory composition in 1961 and overstory plus ingrowth $\geq 10 \mathrm{~cm} \mathrm{DBH}$ in 2015. Letters show significant differences between years at 0.05 level of significance. 


\section{Discussion}

Aboveground Carbon Storage

Previous studies have shown stands with higher basal area store more aboveground standing carbon than stands thinned to maintain low basal area (D'Amato et al., 2011; Davis et al., 2009; Harmon and Marks, 2002; Harmon et al., 2009; Hoover and Stout, 2007; Schaedel et al., 2017). Stand-level carbon storage results from this study are consistent with findings from previous studies. Although statistical comparisons were not possible, the unthinned control stands used for reference in this study stored the most aboveground carbon. However, the control stands were also overstocked and resulted in increased mortality, lower growth rates, and smaller trees compared to thinned stands. Among the thinned treatments in both studies, the highest density treatment (High and 16.1 $\mathrm{m}^{2} /$ ha treatments) stored the most carbon over the course of the studies and had little mortality aside from removals during thinning. The SGC (study gross carbon) analysis, which showed higher density stands storing more total carbon than lower density stands over $55+$ years also supports this claim. Although TGC (total gross carbon) was not statistically influenced by thinning density over 55+ years, the pattern across treatments is similar to SGC, suggesting that there may be some significant ecological effect of thinning density on gross carbon production. The High treatment shows greater TGC than the control stand, which may suggest that, while not necessarily storing a significantly greater amount of carbon, thinning may be able to increase the total amount of carbon produced over the life of a stand. 
D'Amato et al. (2011) found that rapid increases in carbon stores occurred between thinnings in red pine forests of the Great Lakes Region, which suggests increased rates of stand- and tree-level carbon sequestration during that time. Sink/source results from the PSS support these findings and show that in all treatment densities, carbon removed during a thinning or lost to mortality was recovered before the next thinning occurred but at different rates based on stand density. For example, in the period from 1952 to 1960 , the High treatment returned to zero net carbon loss 2.1 times faster than the Low treatment (3.6 compared to 7.7 years of growth).

The rate of stand-level carbon accumulation between thinning entries may be influenced by both residual stand density and amount of material removed. The High treatment was at a stand density that fully utilized available growing space, whereas the Low and Mid treatments were thinned so heavily they were understocked (Appendix: Figure A-3). As a result, both the Low and Mid treatments were likely not sequestering carbon to the full potential of the stand. However, it is also important to note that less carbon was removed from the High treatment than the Low and Mid treatments at establishment, requiring less carbon accumulation to reach net zero carbon growth. In fact, approximately the same amount of carbon was stored in each of the three density treatments during the first 8 years following the establishment thin, suggesting that a wide range of stocking $(45 \%-75 \%)$ will result in the same total growth response and may suggest that stocking density is less relevant in younger shortleaf pine stands. This also supports our results that show lower individual tree carbon 
sequestration rates in the High treatment compared to the Low and Mid treatments, as more trees in the High treatment produced the same amount of carbon as fewer trees in the Low and Mid treatments. Interestingly, the relationship between stand density and amount of material removed from the stand reversed over time where more trees were removed from the High treatment later in the study (1972 and 1985 thins) to maintain assigned basal areas.

Yuhua and Williams (2013) suggest that "C stocks increase with basal area as long as there is a corresponding increase in average tree size". In the OSS, observed increases in both basal area and stand-level carbon storage confirm this statement. The results from the PSS may go one step further and suggest that as long as tree size continues to increase, stand-level carbon storage will increase even though basal area does not change significantly over 55 years (as per the objectives of the study). Similar outcomes in the PSS and OSS, achieved via diverging management applications (repeated thinnings vs. early thinning and treatment cessation), suggest that the relationship between basal area and stand-level aboveground carbon storage is not linear and cannot be safely assumed or estimated based on basal area alone.

Extended rotations have been proposed as an effective management technique for mitigating climate change (D'Amato et al., 2010; D'Amato et al., 2011; Harmon and Marks, 2002; Millar et al., 2007; Paquette and Messier, 2011), and findings from this study support those claims. In both the PSS and OSS, stand-level aboveground carbon storage and individual-tree size continued to 
increase through stand age 95, regardless of treatment density. Few studies provide information on shortleaf pine response to thinning beyond age 40 , and our results indicate that maintaining shortleaf pine basal area through age 95 gradually increases overstory carbon storage. Similarly, in upland oaks, early thinning followed by treatment cessation resulted in constant and significant increases in stand-level aboveground carbon through time. Both management approaches (maintaining basal area through time and early thinnings followed by treatment cessation) may be relevant for combining extended rotations, increased carbon storage, and sustainable timber production.

Few studies have analyzed trade-offs associated with managing for both carbon storage and merchantable volume production. Bragg (2013) found that loblolly pine thinned repeatedly for $>40$ years produced the greatest amount of cut merchantable volume in the lowest density stands $\left(<22 \mathrm{~m}^{2} / \mathrm{ha}\right)$. However, higher yields resulted in low density stands having less standing merchantable volume remaining by stand age 65 . While our study was unable to determine the amount of merchantable volume produced in the PSS over the life of the study, trees in the High treatment reached merchantable sawlog size (based on QMD of $25.4 \mathrm{~cm}$ ) only three years later than Low and Mid stands (age 45), whereas in the control stand, sawlog size was not reached until 30 years after the High density stand reached merchantable size (age 75).

At the stand level, aboveground carbon storage and standing merchantable volume of the PSS were not significantly different among treatment densities in 2007. These results may suggest that the range of densities studied 
were not wide enough to see diverging impacts of thinning. It may also suggest that growing space on the sites was not fully utilized by the pines. B-level (full) stocking for shortleaf pine in the Ozarks is $60 \%$ and in 2007, the High treatment was only $61 \%$ stocked with both the Low and Mid treatments well below B-level stocking at $50 \%$ and $52 \%$, respectively. Considering the low stocking in all treatment densities, it may be possible that the full potential of the site was not being utilized and at higher densities, above B-level stocking, thinning may cause significant differentiation in volume production and carbon storage. Considering volume and climate mitigation objectives, based on the densities analyzed, delaying thinning in shortleaf pine by three to four years to reach individual merchantable size may be viable if that action also supports increased standlevel carbon storage.

Alternatively, our findings may support Langsaeter's Hypothesis, which states "the total production of cubic volume by a stand of given age and composition on a given site is, for all practical purposes, constant and optimum for a wide range of density of stocking" (Gilmore et al., 2005). This hypothesis suggests that even though stocking in the PSS covered a wide range, (Appendix: Figures A-3) merchantable volume production was constant over the range of densities analyzed. However, Langsaeter's hypothesis only applies to densities within the range of full stocking, and two of the three treatment densities were understocked in 2007. Data from this study alone may not be sufficient to support or refute Langsaeter's hypothesis. 
Another possible reason why there were no differences among treatment densities could be due to less intense thinnings later in the study - causing 2007 High and Low treatments to only have a $4 \mathrm{~m}^{2} /$ ha difference in basal area - which suggests that thinning densities maintained earlier in the study may not influence volume at rotation age if those densities are not maintained until rotation. Further study into the relationship between volume and carbon storage is necessary to determine how the two objectives interact through time.

\section{Carbon Sequestration}

Previous studies have generally shown stand-level carbon sequestration rates to decline with increasing stand age (D'Amato et al., 2011; Foster et al., 2014; Stephenson et al., 2014; Yuhua and Williams, 2013). These studies have cited physiological limitations to tree growth as cause for declining productivity and carbon sequestration as stands age (D'Amato et al., 2011; Foster et al., 2014). This study however, does not definitively support or reject previous findings due to opposing results in the PSS and OSS. In the OSS, there was no significant change in stand-level carbon sequestration rates between 1961 and 2001. The majority of overstory trees in the OSS in 2001 were black oaks (67\%), which have an average lifespan of approximately 100 years. In 2001, the oaks were relatively advanced in their lifespans, at about 80 years old. However, even at age 80 , stand-level carbon sequestration rates in the OSS were not significantly different from 1961 rates when the stands were 40 years old. Results from the OSS suggest that age-related decline in productivity is not occurring. In the PSS, stand-level sequestration rates were very high for the first ten years of 
the study but rapidly declined until 1976, after which they remained relatively constant. However, this is most likely a function of average individual-tree carbon sequestration rates multiplied by a high number of trees per hectare early in the study.

Stephenson et al. (2014) found that individual trees continue to sequester increased amounts of carbon as they age without showing signs of physiological decline. In both the OSS and PSS, individual-tree carbon sequestration rates either remained the same or increased over 40 and 55 years of measurements, respectively. The disparity between perceived declining stand-level rates of carbon sequestration when individual-tree carbon sequestration rates increase through time may be partially explained by differences in study design compared with previous studies (D'Amato et al., 2011; Foster et al., 2014; Stephenson et al., 2014). Most notably, our study only follows a single population of codominant and dominant overstory trees through time without the addition of ingrowth at each inventory. Including intermediate and suppressed trees in the measurements may alter the dynamics of stand-level carbon sequestration rates to more closely reflect previous studies that suggest increased stand age results in decreased productivity.

Although we were unable to statistically compare the controls to the treated stands, some interesting patterns emerge in the development of the control stands through time in both the PSS and OSS. At the stand level, the control stands expressed similar carbon sequestration rates to the treated stands. This may suggest that (1) harvests do not have significant influence on 
stand-level carbon sequestration rates, (2) increased mortality in the overstocked controls resulted in carbon sequestration rates similar to thinned stands, (3) the relatively low individual-tree carbon sequestration rates multiplied by the high number of trees in the control stand resulted in equal stand-level carbon sequestration rates to that of the thinned stands, or (4) results support Langsaeter's hypothesis that production is constant over a wide range of stocking. Davis et al. (2009) found that harvests do not significantly impact average annual stand-level carbon sequestration over the long term (55+ years). Interestingly, fluctuations in control stand-level carbon sequestration through time reflect those in treated stands, suggesting that abiotic factors have important influence on stand-level carbon sequestration rates. Conversely, individual-tree carbon sequestration rates in the controls are much lower than the treated stands, suggesting that management does impact tree-level sequestration rates. Unfortunately, these observations cannot be substantiated based on a single control stand in each study.

\section{Mortality}

Occurrence of non-harvest mortality in long-term studies is expected, and in the OSS, the red oak group had the highest levels of mortality, especially in the latter part of the study from 1990-2015. By 1999, oak decline had become widespread throughout the Interior Highlands of Missouri, Arkansas, and Oklahoma (Dwyer et al., 2007). Drought, cited as the most common oak decline inciting factor, causes physiological stress in mature upland red oaks making trees more susceptible to insect or disease damage (Dwyer et al., 2007; Shifley 
et al., 2006). Muzika and Guyette (2004) reported unprecedented outbreaks of red oak borer (Enaphalodes rufulus) in the Ozark Highlands starting in the late 1970s. Stress induced by droughts in the 1980 s and the early 2000 s combined with a larger-than-average red oak borer population may have been sufficient to incite oak decline in the mature oaks of the OSS in the 1990s and 2000s.

Conversely, based on the abundance of red oaks in the study, if mortality were to randomly occur in the stands, be it from ice, wind, or lightning, it would most likely affect a red oak. Red oaks are also shorter lived than white oaks (Shifley et al., 2006), and in 2015 were reaching the end of their lifespan of approximately 100 years. It is possible that mortality in the OSS is due to a combination of the above factors: oak decline, red oaks being the most abundant species group in the study, age, and random disturbance events, including the 2009 derecho.

\section{Species Composition}

Succession from red to white oak dominated stands is evident when total species composition (overstory and ingrowth) in 1961 was compared to 2015. White oaks and 'other' species had significantly increased in abundance over 55 years of the study, while red oaks significantly declined in abundance. This suggests that the form of management applied in these stands does not alter natural succession of upland oak communities. Given time, declining red oaks in the OSS will most likely be replaced by white oaks, which has been considered a climax species in the Missouri Ozarks and made up a majority of the mid and 
understory in 2015. Continued monitoring of this study and other Ozark upland long-term monitoring studies may confirm these predictions. 


\section{Conclusion}

The effects of long-term density management on forest carbon dynamics and related metrics were tested in natural shortleaf pine and oak-hickory stands in the Missouri Ozarks. This study confirmed previous findings that suggest higher density, fully stocked stands store more aboveground carbon through time than lower density stands. Results from control stands may suggest that no thinning would maximize stored carbon on a site but at the cost of individual tree size and increased mortality rates. Extended rotation management combined with maintaining basal area density in shortleaf pine may be a feasible practice for increasing carbon storage and merchantable timber volume. Similarly, upland oak stands thinned early followed by treatment cessation (25+ years) encourages a constant and significant increase in carbon storage through time. However, mortality caused by red oak decline should be monitored as stands age and become more heavily stocked following treatment cessation.

Shortleaf pine managed over 55 years resulted in all treatments reaching merchantable sawlog size by age 47 , and no statistical differences in total aboveground carbon storage or merchantable volume among treatments by the end of the study. These results may suggest three contrasting mechanisms (1) basal area densities were not different enough among treatments to express diverging results, (2) by 2015, stands were barely fully stocked or understocked suggesting that the stands are not at their full potential for carbon storage or volume production, or (3) basal area densities were different but merchantable volume and aboveground carbon storage remained constant over the wide range 
of stocking, supporting Langsaeter's Hypothesis. Further study into the relationship between volume and carbon storage is necessary to determine how the two objectives interact.

There were few clear patterns in stand- and individual-tree carbon sequestration rates. In upland oak stands, stand-level carbon sequestration rates did not significantly decline with stand age, and shortleaf pine stands showed declines in carbon sequestration relating to heavy tree removal early in the study. In individual trees, carbon sequestration rates increased with age in both upland oaks and shortleaf pine. The disparity between our findings and previous studies suggest more thorough research is required to appropriately assess the complexities of carbon sequestration. 


\section{CHAPTER III}

\section{SHORTLEAF PINE RESPONSE TO THINNING AT THE ONSET OF A SEVERE DROUGHT}

\section{Introduction}

Over the last century, atmospheric $\mathrm{CO}_{2}$ concentrations have continued to increase, leading to concerns over the impacts of global climate change on ecosystems (IPCC, 2014). Forests are one of the largest sinks of $\mathrm{CO}_{2}$ on Earth, but increased frequency and severity of disturbances such as drought may reduce the ability of forests to sequester carbon. Stress from drought and other disturbances, manifested through decreased tree-level productivity and vigor, increased mortality rates, and shifts in stand-level species composition (Allen et al., 2010; Bigler et al., 2007; D’Amato et al., 2013) may be alleviated through forest management practices that remove competition and increase available resources to residual trees. Given recent impacts of drought on forest ecosystems throughout the United States, understanding the effects of forest management on drought impacts has become important for making future management decisions regarding climate change.

Adaptability is defined as the ability of an ecosystem to successfully respond to climate variability by accommodating changes made to the system (IPCC, 2007; Millar et al., 2007). Two characteristics of forests, resistance and resilience, are commonly used to describe or quantify the adaptability of forests to disturbances caused by climate change. Resistance describes the ability of an 
ecosystem to remain unchanged following a disturbance. Resilience allows an ecosystem to respond to a disturbance by rearranging and retaining essentially the same structure, function, and feedbacks (DeRose and Long, 2015; Janowiak et al., 2014; Walker et al., 2004). Using forest management to increase resistance and resilience may be a strategy for preparing forest stands for future conditions.

Dendrochronology, at its most basic level, is the study of assigning specific dates to tree rings. The principles of dendrochronology can be applied to ecology, geology, and climate studies, and have been used to reconstruct stand composition and management histories and explore tree response to climate influences (Bigler et al., 2007; D’Amato et al., 2013; Estes, 1970; Fritts, 1976; Laurent et al., 2003; Speer, 1971; Stambaugh and Guyette, 2004). Tree ring width is influenced by both abiotic and biotic factors. Site characteristics (slope, aspect, soil characteristics, and elevation), climate variables (temperature and precipitation), and biological relationships with the surrounding ecosystem (competition for resources from other trees, insect defoliation during growing season) all have the potential to interact with and influence not only the current year's growth of a tree but following year's growth as well (Fritts, 1976). During a drought, resources required by trees to add diameter growth are limited, resulting in smaller growth rings. Dendrochronological methods rely on known patterns in ring widths to infer stand history and can be used to assess growth response to climate fluctuations and increased frequency, severity, and extent of droughts. To determine how severe droughts impact tree growth, Palmer Drought Severity 
Index (PDSI), which estimates relative dryness as a standardized index (-10 to 10) based on regional temperature and precipitation (Dai, 2016) can be correlated with ring-width measurements (basal area increment (BAI)).

Few studies have used dendrochronology to assess the fine-scale impacts of silvicultural practices on tree growth and climate response. Studies that have combined dendrochronological methods with determining adaptability in managed forests have found that thinning generally enhances adaptability to climate change (Cescatti and Putti, 1998; D'Amato et al., 2013; Kohler et al., 2010; Laurent et al., 2003). D’Amato et al. (2013) found that thinning altered growth response to drought in young red pine stands where lower density stands were more resistant and resilient to drought. Laurent et al. (2003) found that thinning increased individual-tree resistance to drought stresses in Norway spruce compared to no thinning. Although the impacts of density management and drought response have been studied in many ecosystems, thinning impacts have not been thoroughly assessed in terms of adaptability to drought events in the Missouri Ozarks.

Shortleaf pine is the only pine native to Missouri and is commonly found on ridgetops, upper slopes, and south- and west-facing slopes of the Ozark Highlands, where moisture is limited by cherty soils and an impermeable fragipan layer (Brinkman and Rogers, 1967; Brinkman and Smith, 1968; Walker and Wiant, 1966). Because shortleaf pine is found most often on drought-prone sites, growth data collected in the form of tree ring widths can be informative and useful 
for reconstructing regional climate history (Estes, 1970; Fritts, 1976; Stambaugh and Guyette, 2004).

A number of severe drought events have impacted southern Missouri over the last century, occurring on an approximately 20 year cycle (Stambaugh and Guyette, 2004; Stambaugh et al., 2011) including droughts in the 1930s, early 1950s, 1980s, and early 2000s (Nace and Pluhowski, 1965; Stambaugh and Guyette, 2004). From 1952 to 1956, southeastern Missouri experienced one of the most severe droughts since the 1930s Dust Bowl era. The 1950s drought resulted in record breaking years for both driest year (1953, average total precipitation for year $=64.4 \mathrm{~cm})$ and hottest temperature $\left(1954,47.7^{\circ} \mathrm{C}\right)$ recorded in Missouri for the $20^{\text {th }}$ century (Missouri Climate Center, 2017; Nace and Pluhowski, 1965). In the period from 1895 to 2015 , four of the five years from the 1950s drought were among the top 10 lowest PDSI years for the region with the top 3 lowest all from the 1950s drought. Specifically, 1954 had the lowest PDSI value at $-6.19,1953$ second lowest at -4.17 , and 1955 third lowest at -3.08 (NCDC, 2016). Average PDSI from 1952-1956 was -3.53. For comparison, the average PDSI from 1895-2015 was 0.203.

Long-term studies may offer interesting insight into the response of managed stands to unique drought events. Traditionally, periodic inventories have provided sufficient growth information to inform decisions regarding management. Dendrochronological methods are rarely used to assess fine-scale response to management in stands, but considering climate change management objectives, it may become beneficial to understand how managed 
stands and individual trees grown in a range of densities respond through time to drought, thinning, and a combination thereof.

\section{Objectives}

Using a shortleaf pine chronology developed from the Pine Stocking Study on the Sinkin Experimental Forest, I determined: (1) the extent to which thinning influences the effect of previous years' growth and PDSI on growth response, (2) the influence of the 1950s drought on growth of uncut stands, and (3) the influence of thinning on growth response during the 1950s drought. 


\section{Methods}

\section{Study Site}

This study was conducted on the Sinkin Experimental Forest (SEF) located in Dent County, southeastern Missouri. As part of the Mark Twain National Forest, the SEF is characterized by narrow ridges and steep slopes with well-drained acidic soils with low nutrient supply capacity. Central Hardwoods species including black oak, white oak, northern red oak, hickories, dogwood, and maples are dominant on the SEF. The SEF also includes pure and mixed stands of shortleaf pine and oak-pine forests.

The climate of southeastern Missouri where the SEF is located is classified as humid-continental and humid-subtropical (Stambaugh and Guyette, 2004). Average monthly precipitation from $1920-2015$ was about $9.12 \mathrm{~cm}$. Average daily temperature ranged from $1.7^{\circ} \mathrm{C}$ from December to February to $24.2^{\circ} \mathrm{C}$ from June to August. For more information on the SEF and site characteristics refer to Chapter 1: Project Overview.

\section{Experimental Design}

This study was based on a subset of plots established in the Pine Stocking Study (PSS), described in detail in Chapter 1: Project Overview. The PSS used a randomized complete block design, with 30 fifth-hectare plots (3 blocks of 10 plots) established in even-aged shortleaf pine stands on the SEF. In 1952, each plot was assigned one of five treatments that thinned the plots to different residual basal areas: 11.5, 16.1, 20.7, $25.3 \mathrm{~m}^{2} / \mathrm{ha}$, and an unthinned 
control (30 $\mathrm{m}^{2} /$ ha). A second thinning occurred in 1960 to maintain assigned treatment densities. For this study, three plots from each of the five treatment groups were randomly chosen for sampling in 2016 ( $n=15$ plots).

\section{Data Collection}

The collection of tree cores took place between August 2015 and June 2016. In 2016, twenty live trees from each plot were randomly selected to be cored. The sample population was selected using a random number generator applied to the 2015 inventory data. In 10 plots, 2 trees per plot were cored in a pilot dataset in 2015 and were included in addition to the twenty cores per plot in 2016. For each sampled tree, a single core was taken at breast height on the south side of the tree, directly below the numbered tag. If the sample tree was leaning or the south side was facing down a steep slope, cores were taken from

a side perpendicular to the lean or slope to avoid compression wood. Each core was stored in a plastic straw and labeled with plot, tree number, and date of collection. Although the approximate age of the stand was already known, every effort was made to reach the pith during core collection.

\section{Data Preparation}

All cores were dried, glued to grooved wood mounts, and sanded with increasingly fine (up to 1200) grit sandpaper. Sanded cores were crossdated using the outermost ring date and known patterns in latewood growth, as suggested by Estes (1970), who found that shortleaf pine could be as easily dated by latewood width as total ring width. Late and earlywood ring widths were 
measured using a Velmex Measurement System to a $0.01 \mathrm{~mm}$ precision. To ensure proper crossdating, width measurements were entered into COFECHA and grouped by plot (Holmes, 1983). All samples showing low correlation with the rest of the samples from the same plot were re-dated, re-measured, and run through COFECHA again. After all samples were corrected, the final $\mathrm{N}$ ranged from 20 to 28 samples per plot.

Following ring width measurements, pith estimations using the concentric circles method (CCM) (Speer, 1971) were made for all samples that did not reach the pith. This method uses the curvature of the innermost rings to determine the distance to the pith, assuming tree growth was unsuppressed during early development. This information was used to calculate basal area increment $\left(\mathrm{BAI}-\mathrm{mm}^{2}\right)$ for each sample.

Local climate data from three weather stations located in southeastern Missouri (Salem, Berryman, Rolla) supplied monthly temperature and precipitation information from 1920 to 2015 (Figure 3.1). Monthly Palmer Drought Severity Index (PDSI) data from 1895 to 2015 for Missouri Division 5 (East Ozarks) were supplied by the NOAA National Climate Data Center (NCDC, 2016). 


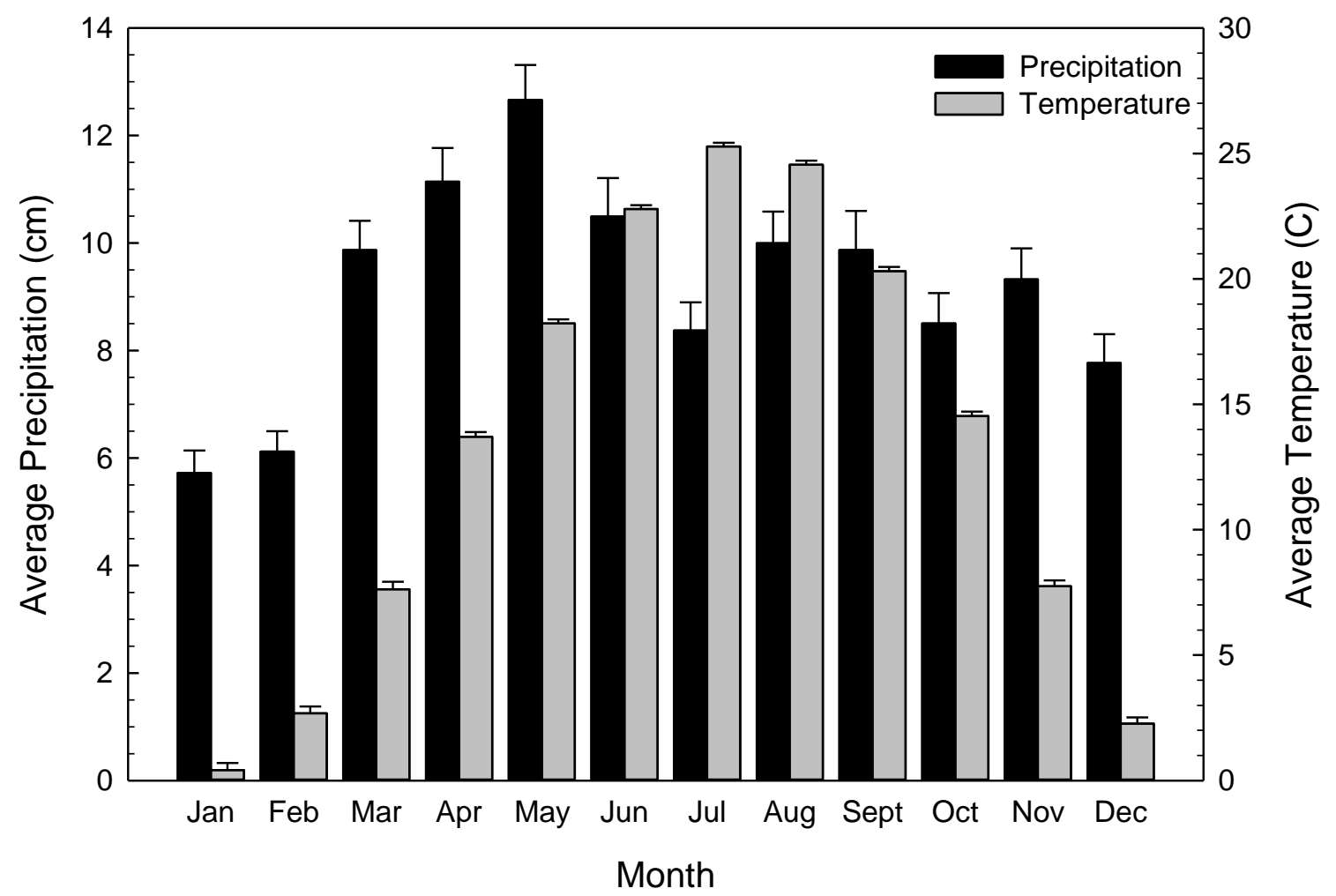

Figure 3.1: Average precipitation and temperature from 1920 - 2015 for the Missouri Ozark Region. Data supplied by the Salem weather station with gaps filled by Rolla and Berryman weather stations.

\section{Data Analysis}

BAI mean and variance were calculated for each plot and summarized by treatment and year in SAS statistical software package (version 9.4, SAS Institute, Inc, Cary, NC, USA). To avoid confounding impacts of high growth rates during stand initiation and changes to stand density treatments in 1972, all analyses were truncated to include only growth from years 1931 through 1971 . Significance was determined at the 0.05 level. 


\section{Pearson's Correlation Coefficient}

First- through fifth- order autocorrelation using Pearson's correlation coefficient were used to determine the influence of previous years' tree growth on the following year. Correlations were analyzed by treatment density both pre(1931-1951) and post-treatment (1952-1971).

To determine the Palmer Drought Severity Index (PDSI) months from 1931-1971 having a significant influence on tree growth, PDSI was summarized by month and correlated with BAI of the control treatment using Pearson's correlation coefficient. Months determined to have a significant influence on growth were averaged by year and correlated with BAI of each treatment density for the periods of 1931-1951 (pre-treatment) and 1951-1971 (post-treatment). PDSI was also lagged (-1 year lag through -4 year lag) for pre- and posttreatment periods to determine if treatment density influenced timing of climate response in shortleaf pine.

Pearson's correlations were used to determine associations among each density treatment pair, based on each year's BAI averaged across all plots within each treatment. Correlations were performed separately pre-treatment and posttreatment to determine treatment effects on BAI.

\section{Paired t-tests}

To determine the influence of the 1952-1956 drought on growth, average BAl five years prior to the beginning of the drought (1947-1951) was compared to 
average BAl during the drought (1952-1956) for the unthinned control treatment. A paired t-test was used to determine if growth during the drought was equal to growth prior to the drought. The effect of stand density created by the 1952 thinning treatment on growth response during the drought was determined by comparing pre-drought average BAI (1947-1951) and during-drought average BAI (1952-1956) with paired t-tests for each thin treatment.

\section{One-tailed t-test}

Net BAI was calculated as the change in BAI of the thinned stands minus control stand growth, essentially removing the influence of climate on growth to better understand the influence of thinning. One-tailed t-tests were used to determine if net BAI pre- and post-treatment was significantly greater than zero for any treatment density.

\section{One-Way ANOVA}

A one-way ANOVA and Tukey's HSD pairwise comparisons were used to determine if growth response following the 1952 establishment thin (during the drought) were different among the five treatment densities. To determine differences in net BAI response among treatment densities, both pre- and posttreatment net BAI was compared using a one-way ANOVA and Tukey's HSD pairwise comparisons. 


\section{Results}

Of the final 325 cores used in the chronology, 57 were measured to the pith (17.5\%). All fifteen plots had at least one sample that reached the pith. The earliest pith year at breast height was dated to 1918, with an average pith year across all plots of 1920. Although measurements after 1971 were not used for

analysis, micro rings were common in control plots from year 1980 until the early 2000s. Four cores collected from control plot 141 were unusable from 1980 to 2015 due to heavy suppression, which caused an abundance of micro and missing rings. False rings were present in all samples from all treatment densities.

\section{Basal Area Increment and Variance}

Prior to the 1952 establishment thin, BAl averaged from 1931-1951 was not significantly different among treatment densities $(p=0.2874)$. Following the establishment thin (1952-1971), BAI differed among treatments, with the 11.5 $\mathrm{m}^{2} /$ ha treatment having the greatest $\mathrm{BAI}$, the control treatment having the lowest $\mathrm{BAI}$, and the $\mathrm{BAI}$ among the other treatments inversely ranked by residual basal area (Figure 3.2). Variance among years within treatments showed a similar pattern, in which variance prior to the thin was not significantly different among treatment densities $(p=0.3944)$, and following thinning, variance differentiated in the same fashion as BAI. Pearson's correlations showed that all five treatment densities showed significant positive BAI correlation with all other treatment densities both pre-and post- treatment $(p=0.0001)$. 


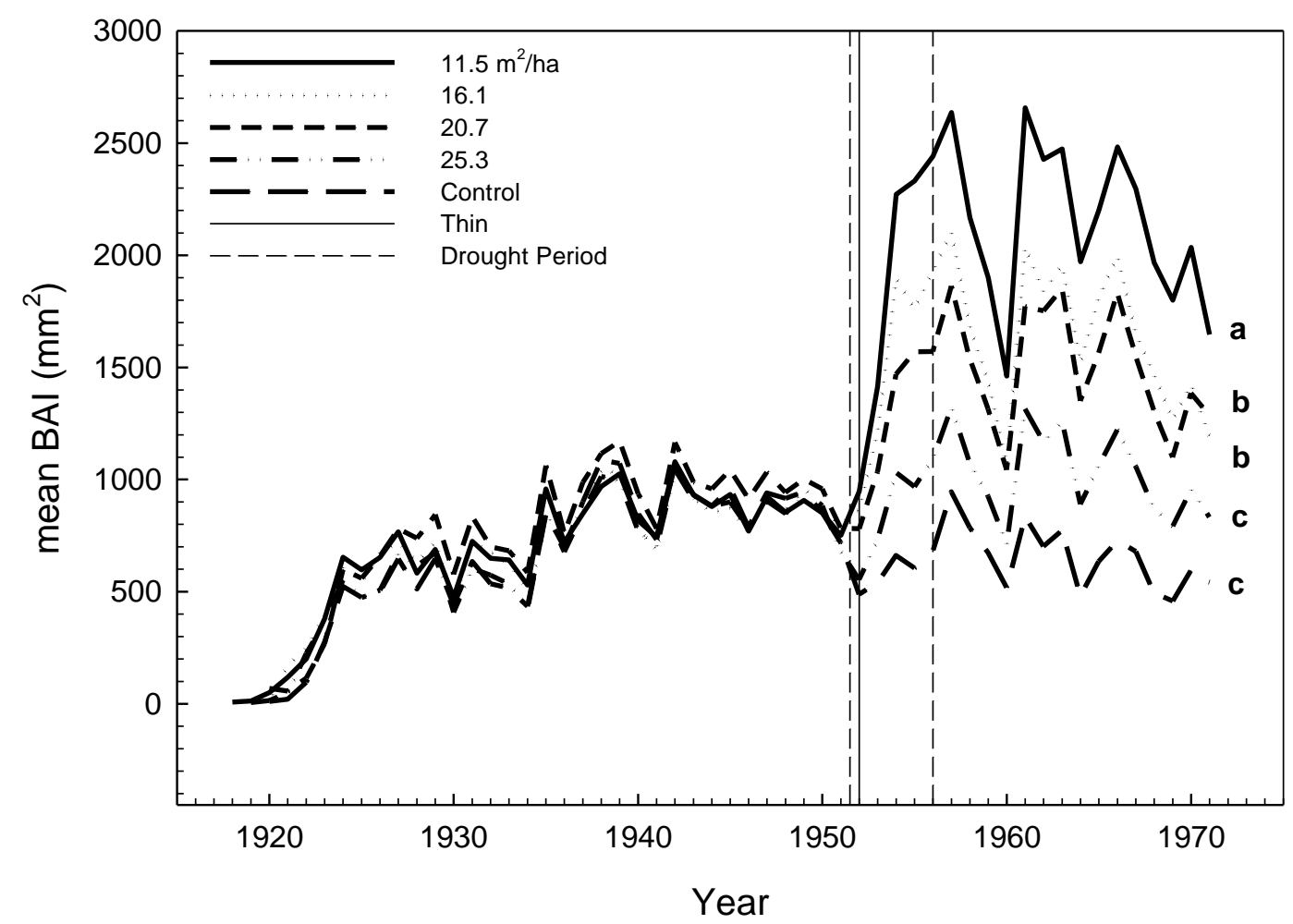

Figure 3.2. BAl from 1918 through 1971. Vertical dashed lines represent drought period; solid vertical line represents 1952 establishment thin. The CCC release is also visible as a small increase in BAI in 1934.

\section{Influence of Climate on Growth Response}

Stands showed no significant differences in BAI prior to 1952, so pretreatment BAI was averaged across all treatment densities. Pearson's correlations showed no previous growth years having a significant correlation or influence on the current year's growth prior to 1952 (Table 3.1). Post-treatment correlations with growth, split by treatment density, show a positive first-order autocorrelation (-1 year lagged) in the $11.5,16.1$, and $20.7 \mathrm{~m}^{2} /$ ha treatments. 
Table 3.1. Treatment density growth response Pearson correlations with lagged treatment growth response. Bold $r$ values represent significant correlations at 0.05 significance level.

\begin{tabular}{|c|c|c|c|c|c|}
\hline \multirow{2}{*}{$\begin{array}{c}\text { Treatment } \\
\text { Density } \\
\left(\mathrm{m}^{2} / \mathrm{ha}\right)\end{array}$} & \multicolumn{5}{|c|}{ Lagged Pre-Thin } \\
\hline & Year - 1 & Year - 2 & Year - 3 & Year - 4 & Year - 5 \\
\hline Stand & 0.41433 & 0.37778 & 0.40645 & 0.41208 & 0.19001 \\
\hline \multirow{2}{*}{$\begin{array}{c}\text { Treatment } \\
\text { Density } \\
\left(\mathrm{m}^{2} / \mathrm{ha}\right)\end{array}$} & \multicolumn{5}{|c|}{ Lagged Post-Thin } \\
\hline & Year - 1 & Year - 2 & Year - 3 & Year - 4 & Year - 5 \\
\hline 11.5 & 0.60079 & 0.37519 & 0.15604 & 0.18341 & 0.11819 \\
\hline 16.1 & 0.50643 & 0.26433 & 0.00037 & 0.03984 & -0.054 \\
\hline 20.7 & 0.54899 & 0.22108 & 0.01492 & 0.18277 & 0.09166 \\
\hline 25.3 & 0.40529 & 0.08138 & -0.1585 & 0.13353 & 0.02184 \\
\hline Control & 0.21373 & -0.1359 & -0.3213 & 0.01972 & -0.1748 \\
\hline
\end{tabular}

Palmer Drought Severity Index was significantly correlated with BAI in control stands for the months of February through August. Using those months for the PDSI average (Figure 3.3), pre-treatment Pearson correlations showed significant positive PDSI correlation with BAI of all treatment densities. However, post-treatment, same-year correlations resulted in no significant PDSI correlation with BAI in any treatment density (Table 3.2).

When PDSI was lagged to -4 years, pre-treatment PDSI correlations showed no significant correlation with growth in any treatment density. Posttreatment correlations between BAI and PDSI resulted in significant negative correlations with PDSI lagged $-1,-2$, and -3 years in the 11.5 and $16.1 \mathrm{~m}^{2} / \mathrm{ha}$ treatments, and -2 and -3 years lagged for the $20.7,25.3 \mathrm{~m}^{2} / \mathrm{ha}$, and control treatments (Appendix: Figure A-5). 
Table 3.2. Treatment density growth Pearson correlations with Palmer Drought Severity Index (PDSI) and lagged PDSI. Bold $r$ values represent significant correlations at 0.05 significance level.

\begin{tabular}{|c|c|c|c|c|c|}
\hline \multirow{3}{*}{$\begin{array}{c}\text { Treatment } \\
\text { Density } \\
\left(\mathrm{m}^{2} / \mathrm{ha}\right)\end{array}$} & \multicolumn{5}{|c|}{ Pre-Thin PDSI Correlation } \\
\hline & \multirow{2}{*}{$\begin{array}{l}\text { PDSI } \\
\text { of } \\
\text { same } \\
\text { year }\end{array}$} & \multicolumn{4}{|c|}{ Lagged PDSI } \\
\hline & & Year - 1 & $\begin{array}{c}\text { Year - } \\
2\end{array}$ & $\begin{array}{c}\text { Year - } \\
3\end{array}$ & Year - 4 \\
\hline 11.5 & 0.4935 & 0.0118 & 0.1653 & -0.0731 & -0.2522 \\
\hline 16.1 & 0.5449 & 0.0955 & 0.1920 & -0.0530 & -0.2312 \\
\hline 20.7 & 0.5098 & 0.0332 & 0.2110 & -0.0690 & -0.2475 \\
\hline 25.3 & 0.5439 & 0.1137 & 0.1472 & -0.0451 & -0.2355 \\
\hline \multirow[t]{2}{*}{ Control } & 0.4917 & 0.1501 & 0.1999 & -0.0269 & -0.3099 \\
\hline & \multicolumn{5}{|c|}{ Post-Thin PDSI Correlation } \\
\hline \multirow{2}{*}{$\begin{array}{l}\text { Treatment } \\
\text { Density } \\
\text { (m²/ha) }\end{array}$} & PDSI & \multicolumn{4}{|c|}{ Lagged PDSI } \\
\hline & $\begin{array}{c}\text { of } \\
\text { same } \\
\text { year }\end{array}$ & Year - 1 & $\begin{array}{c}\text { Year - } \\
2 \\
\end{array}$ & $\begin{array}{c}\text { Year - } \\
3 \\
\end{array}$ & Year - 4 \\
\hline 11.5 & 0.0676 & -0.4490 & -0.7385 & -0.5140 & 0.1042 \\
\hline 16.1 & -0.0250 & -0.4836 & -0.7234 & -0.4656 & 0.1757 \\
\hline 20.7 & 0.1338 & -0.3798 & -0.6595 & -0.5290 & 0.0822 \\
\hline 25.3 & 0.1801 & -0.2898 & -0.6305 & -0.5089 & 0.0515 \\
\hline Control & 0.2902 & -0.1119 & -0.4926 & -0.5519 & -0.1108 \\
\hline
\end{tabular}




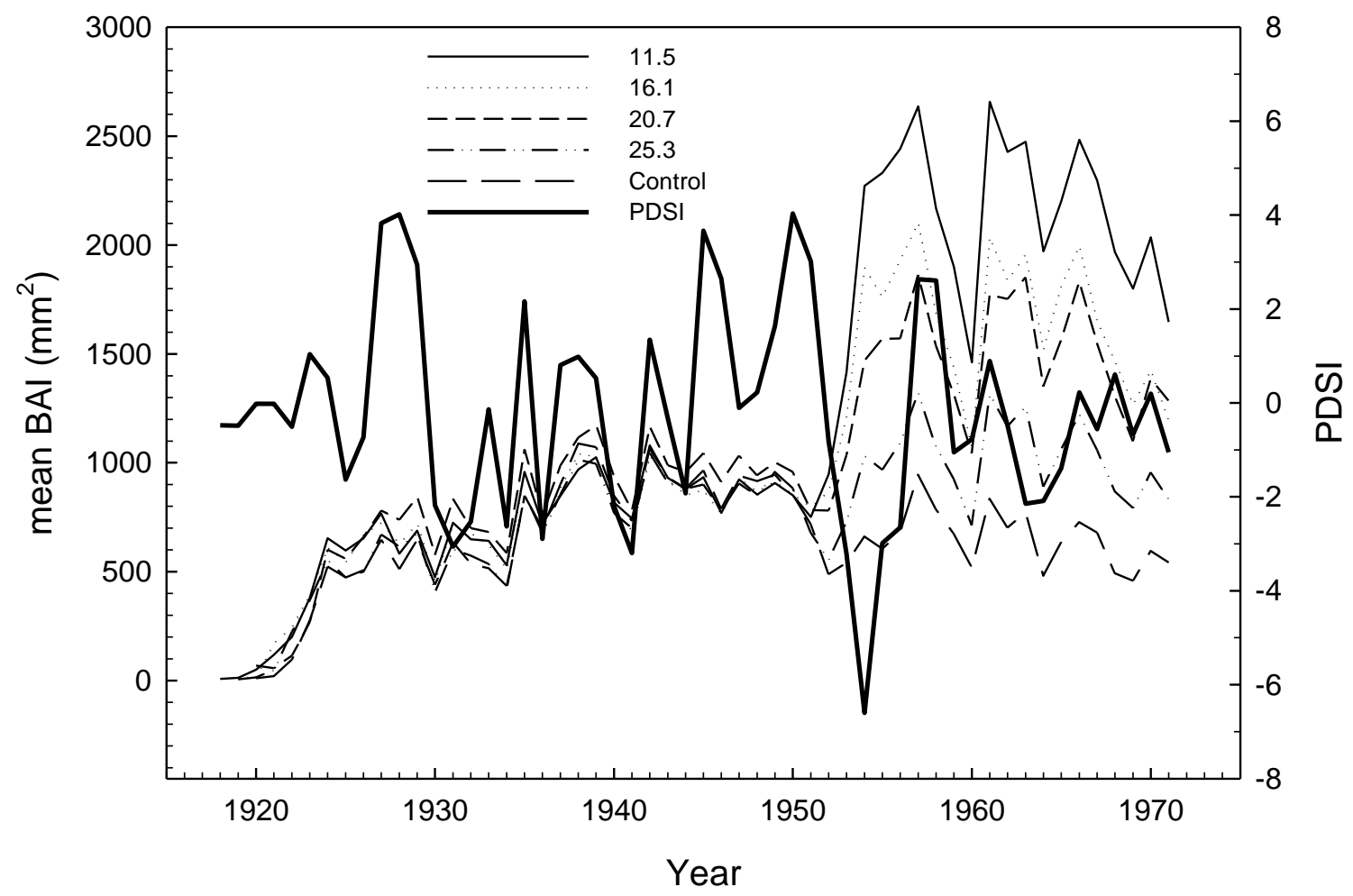

Figure 3.3: Basal area increment (BAI $\left.\mathrm{mm}^{2}\right)$ and Palmer Drought Severity Index (PDSI). BAI from 1918 through 1971 overlaid with PDSI averaged for Feb-Aug of each year. Note the very low PDSI value in 1954.

\section{Influence of Thinning and Drought}

Although the change was not significantly different from zero, the 1952-56 drought did cause a decrease in growth in the control treatment compared to predrought conditions (Figure 3.4). Decreased growth rates in the control were maintained through time following the drought as average BAI post-drought (1957-1971) remained visually lower than pre-drought (1931-1951) BAI. The 25.3 $\mathrm{m}^{2} /$ ha treatment also did not show a significant change in growth. The 11.5, 16.1, and $20.7 \mathrm{~m}^{2} /$ ha treatments showed a significant increase in growth posttreatment (during the drought). The changes in growth from pre- to post-drought and thinning were significantly different among treatments for each pair-wise 
comparison (Table 3.3). Similarly, variance increased post-treatment in all treatment densities except the control. Pre-treatment variance was not significantly different among treatment densities. However, the post-treatment variance of the $11.5 \mathrm{~m}^{2} /$ ha was significantly greater than all other treatment densities (Table 3.4). Coefficient of variation, a metric used to better illustrate dispersion around a mean, was highest in the control stands (Table 3.4).

One-tailed t-tests showed that net BAI pre-treatment was not significantly greater than zero for any treatment density. Post treatment, one tailed t-tests showed that all treatment densities had greater than net zero growth.

Pre-treatment one-way ANOVA and Tukey's HSD pairwise comparisons showed that net BAI of the $20.7 \mathrm{~m}^{2} /$ ha was significantly greater than the other treatments. Post-treatment one-way ANOVA and Tukey's HSD pairwise comparisons showed net BAI was significantly different among treatment densities where the $11.5 \mathrm{~m}^{2} /$ ha had the highest net $\mathrm{BAI}$, the 16.1 and $20.7 \mathrm{~m}^{2} / \mathrm{ha}$ were not significantly different, and the $25.3 \mathrm{~m}^{2} /$ ha had the lowest net BAI (Figure 3.5).

Table 3.3. Drought influence on BAI and response to thinning paired $t$ test and ANOVA results

\begin{tabular}{|c|c|c|c|c|c|}
\hline $\begin{array}{l}\text { Treatment } \\
\text { Density } \\
\text { (m²/ha) }\end{array}$ & $\begin{array}{c}\text { Pre- } \\
\text { Drought } \\
\text { BAl } \\
\left(\mathrm{mm}^{2}\right)\end{array}$ & $\begin{array}{c}\text { Drought } \\
\text { BAI }\left(\mathrm{mm}^{2}\right)\end{array}$ & $\begin{array}{l}\text { Change in } \\
\mathrm{BAI}\left(\mathrm{mm}^{2}\right)\end{array}$ & $\begin{array}{c}\text { Paired } \\
\text { T P- } \\
\text { value }\end{array}$ & $\begin{array}{l}\text { Tukey's } \\
\text { Pairwise }\end{array}$ \\
\hline 11.5 & 855.0310 & 1877.5930 & 1022.5620 & 0.0019 & a \\
\hline 16.1 & 872.3370 & 1533.8590 & 661.5220 & 0.0127 & $b$ \\
\hline 20.7 & 946.4050 & 1288.1000 & 341.6950 & 0.0158 & c \\
\hline 25.3 & 847.7070 & 873.6050 & 25.8980 & 0.6703 & $d$ \\
\hline Control & 877.2570 & 604.0020 & -273.2550 & 0.0585 & e \\
\hline
\end{tabular}


Table 3.4. Drought influence on plot level variance and response to thinning paired t-test and ANOVA results

\begin{tabular}{|c|c|c|c|c|c|c|}
\hline $\begin{array}{c}\text { Treatment } \\
\text { Density } \\
\left(\mathrm{m}^{2} / \mathrm{ha}\right)\end{array}$ & $\begin{array}{c}\text { Pre-Drought } \\
\text { Variance }\left(\mathrm{mm}^{2}\right)\end{array}$ & $\begin{array}{l}\text { Drought } \\
\text { Variance } \\
\left(\mathrm{mm}^{2}\right)\end{array}$ & $\begin{array}{l}\text { Change in } \\
\text { Variance } \\
\left(\mathrm{mm}^{2}\right)\end{array}$ & $\begin{array}{c}\text { Paired } \\
\text { T P- } \\
\text { value }\end{array}$ & $\begin{array}{c}\text { Coefficient } \\
\text { of } \\
\text { Variation }\end{array}$ & $\begin{array}{l}\text { Tukey's } \\
\text { Pairwise }\end{array}$ \\
\hline 11.5 & 104412.9870 & 557938.2018 & 453525.2148 & 0.0370 & 0.3640 & a \\
\hline 16.1 & 102341.1395 & 305744.8918 & 203403.7523 & 0.0485 & 0.3520 & $b$ \\
\hline 20.7 & 110316.5168 & 282847.3213 & 172530.8045 & 0.0054 & 0.3820 & $b$ \\
\hline 25.3 & 80821.8930 & 146503.0253 & 65681.1323 & 0.0253 & 0.3910 & $b$ \\
\hline Control & 99797.7906 & 84621.4310 & -15176.3596 & 0.0605 & 0.4800 & $b$ \\
\hline
\end{tabular}

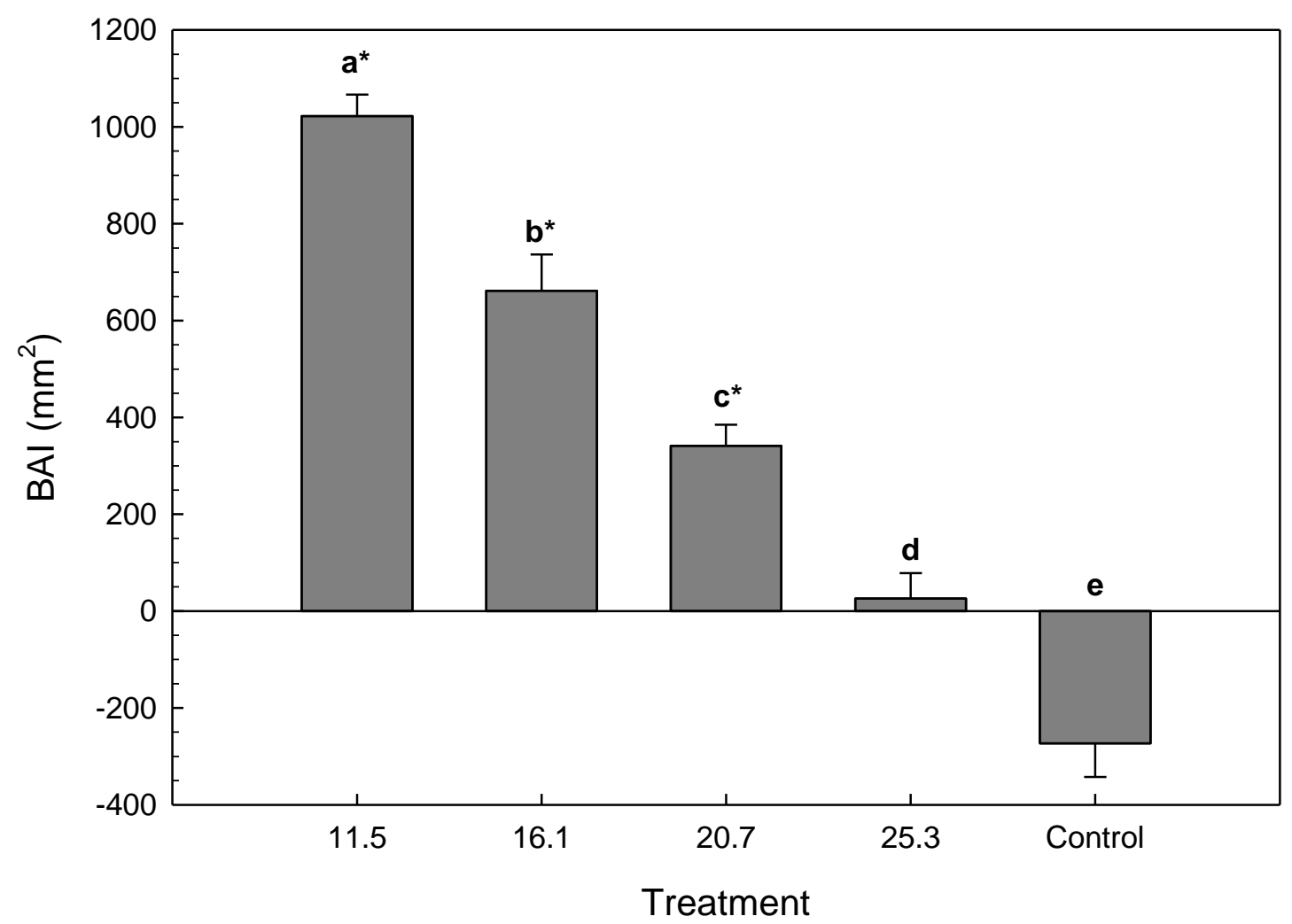

Figure 3.4: Change in growth (BAl) pre- drought to during-drought by treatment. Letters of significance represent one-way ANOVA results post-treatment. * designates paired t-tests showing a significant change in growth rates during the 1952-1956 drought. 


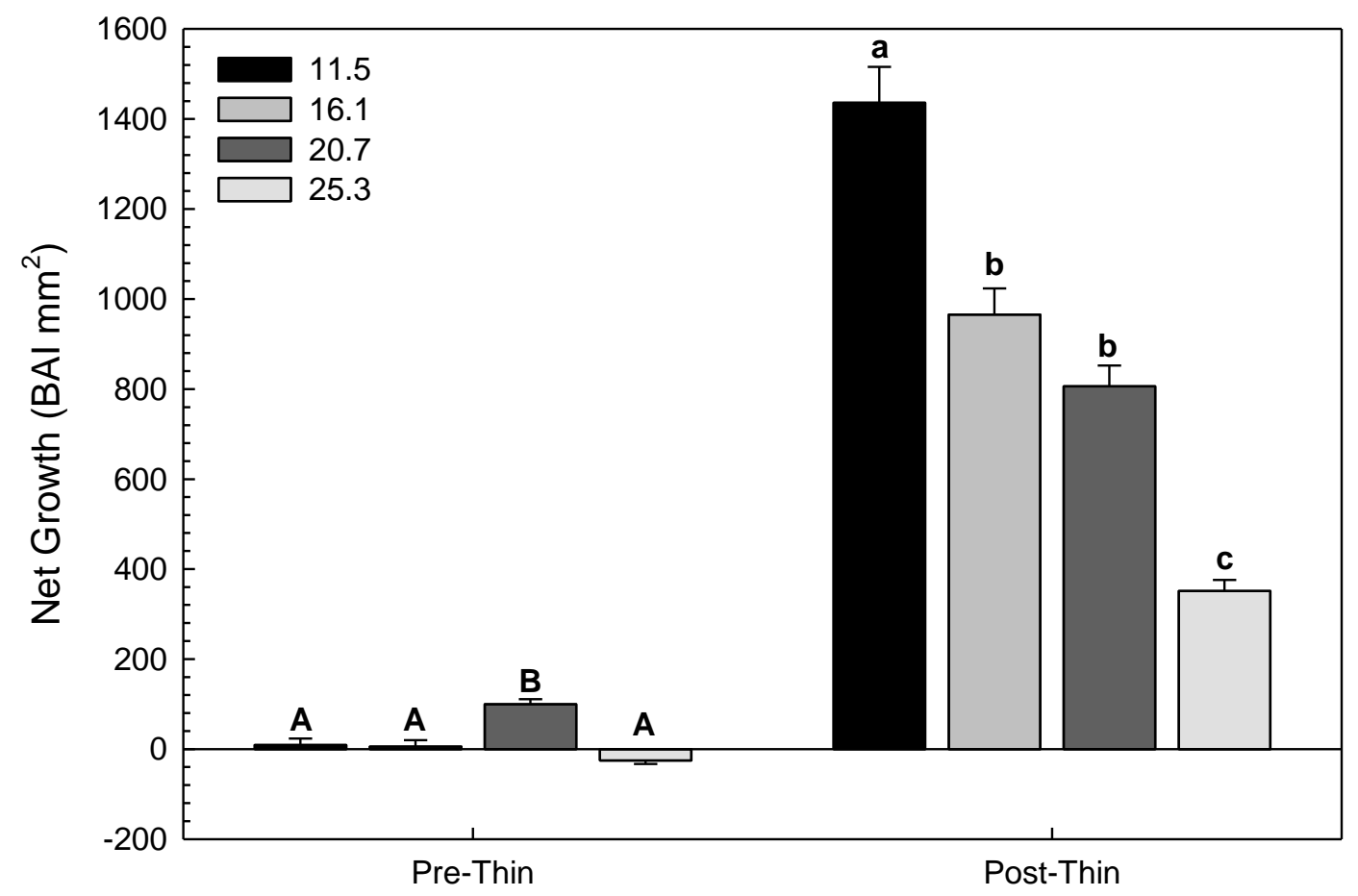

Figure 3.5: Net BAI. Growth of thinned stands after removing control stand growth to reduce most of the influence of climate. Uppercase letters represent significant differences among treatments in one-way ANOVA results at 0.05 significance level pre-treatment (1931-1951). Lowercase letters indicate siginficant differences among treatments based on one-way ANOVA results at 0.05 significance level post-treatment (1952-1971). 


\section{Discussion}

Increasing growing space through thinning has been considered as a possible technique for encouraging stand-level and individual tree adaptation to drought (D'Amato et al., 2013; Keyser and Brown, 2014; Kohler et al., 2010). The use of dendrochronological techniques to date and measure yearly tree ringwidths has aided in determining climate and disturbance histories and has been shown to be useful for understanding fine scale, individual tree response to management (D'Amato et al., 2013; Laurent et al., 2003).

\section{Drought Response}

Drought, an unpredictable yet expected consequence of climate change, has been shown to decrease forest productivity and increase tree stress and mortality, particularly in water-limited ecosystems (Bigler et al., 2007; D'Amato et al., 2013; Fritts, 1962; Gea-Izquierdo et al., 2011). Our results support those of previous studies that found that lower stand densities resulted in increased BAI during and immediately after a drought (D'Amato et al., 2013; Kohler et al., 2010; Laurent et al., 2003). The control stand, which represented an unmanaged, overstocked condition, showed a decrease in BAI during the 1950s drought and then maintained lower average BAI post-drought (1957-1971) compared with pre-drought (1931-1951) BAI.

\section{Thinning Influence}

It is well-established that thinning encourages increased tree growth, but few studies have examined how thinning interacts with both biological (previous growth rates) and climatological (PDSI) influences on growth. Immediately prior 
to thinning, stands were fully stocked (100\%) and did not show any significant correlation with previous years' growth but did show significant positive correlation with same-year PDSI. These results may suggest that tree growth was primarily controlled by climate and limited water availability. Following thinning, growth in the lower density stands $\left(11.5,16.1,20.7 \mathrm{~m}^{2} / \mathrm{ha}\right)$ was positively correlated with the previous year's growth suggesting that the removal of trees increased resource availability on the site, benefitting growth and resource allocation in the same year and in the following year. Also, post-thin PDSI, lagged by $-1,-2$, and -3 years showed a significant negative correlation with BAI (BAI increased as PDSI decreased). Typically, a negative lagged correlation between climate and growth (PDSI increases while BAI continues to decrease) would suggest that a drought event decreased root mass and needle area of trees, which continued to negatively influence growth beyond the drought year. However, the negative lagged correlation observed in this study showed decreasing PDSI with increasing BAI. This growth response may be due to trees in thinned stands increasing root mass and crown size following the thinning prior to the most severe drought years in 1953 and 1954. A similar response in the control stands may be due to a minor release initiated by understory hardwood control measures taken at the onset of the study in 1952. Further information beyond the scope of this study is required to determine what other factors are influencing this specific negative correlation.

Although it is difficult to separate growth response to the 1952 thinning from the 1952-1956 drought, the reduction in growth caused by the drought in the 
uncut control stands was easily identifiable. Interestingly, the $25.3 \mathrm{~m}^{2} /$ ha density treatment was thinned so that average BAI during the drought did not significantly change compared to pre-drought BAI. This result is most likely due to the stand being thinned to a level where available growing space and, therefore, site resources were sufficient to maintain productivity during the drought (Appendix: Figure A-6).

Previous studies have sought to determine how long a thinning event will continue to positively influence growth rates (D'Amato et al., 2013; Keyser and Brown, 2014; Kohler et al., 2010). While this study may be limited in ability to answer that question due to repeated thinnings and changes made to the study design in the 1970s, it offered some relevant observations. First, BAl began to decline in all treatments after 1957. All treatments, except the $11.5 \mathrm{~m}^{2} / \mathrm{ha}$, became $\left(16.1 \mathrm{~m}^{2} / \mathrm{ha}\right)$ or remained $\left(20.7\right.$ and $\left.25.3 \mathrm{~m}^{2} / \mathrm{ha}\right)$ fully stocked after 1954 suggesting that growth began to slow as trees filled all available growing space. Keyser and Brown (2014) observed growth declines beginning 11 years after thinning, and this study showed declines in growth after only 6 years with 1960 having the lowest BAI post-thin.

In the Ozarks, the shortleaf pine growing season begins in early to midApril (Brinkman and Smith, 1968). Fritts (1976) suggests that extreme cold prior to the start of the growing season may delay or slow spring growth. The narrow growth ring in 1960 was most likely caused by the coldest March on record in Missouri, with an average temperature of $-1.8^{\circ} \mathrm{C}$ and multiple state monthly snowfall records broken (Missouri Climate Center, 2017). The cold temperatures 
in March 1960 may have been enough to delay the shortleaf pine growing season, causing a narrow growth ring to form that year in all stands, regardless of thinning density. While the decline in growth in 1960 may appear to be extreme, it is important to note that growth in all thinned stands was maintained well above 1952 drought growth rates. If we consider the extreme cold in March 1960 as an additional climatic stressor, the thinned stands were more resistant to stress 8 years after thinning compared to the control, suggesting that thinning increased resistance to climate related disturbances.

Drought, the focus of this study, is one of many climate change induced disturbances expected to increase in frequency and severity in the Missouri Ozarks. Although it is important to take all potential causes of disturbance into account, assessing adaptability of thinned shortleaf pine stands to other disturbances including wind, insects and disease, and wildfire is beyond the scope of this study. Future shortleaf pine studies should consider how stand density influences tree level response to each of these disturbances to determine potential management trade-offs associated with managing shortleaf pine for increased climate change adaptability. 


\section{Conclusion}

A shortleaf pine chronology was developed for the Missouri Ozarks to answer questions relating to stand density, management, and climate-related growth response. Dendrochronology offers more detailed information for determining the extent of the effects of thinning on radial growth compared to periodic inventories and supplies valuable information regarding previous management, time taken to recover from a water deficit, and time taken to return to pre-thin growth rates. This study supported previous findings that reported increased tree-level tolerance to drought events in lower density stands (Kohler et al., 2010; Laurent et al., 2003). Our study also demonstrated that thinning altered the relationship between radial tree growth and PDSI such that current year water availability is no longer immediately influencing radial growth. Using this study to determine management methods and stand density thresholds that promote shortleaf pine climate adaptability through increased resistance and resilience may benefit future management and restoration efforts in the Missouri Ozarks. 


\section{CHAPTER IV}

\section{CONCLUSIONS}

As climate change-related objectives become more prominent in forest management, it is important to understand how traditional forest management techniques influence climate change mitigation and adaptation potential. In the Missouri Ozarks, little research has addressed the effects of long-term density management on climate change objectives. Our study offers further understanding into the impacts of stand density on current interests regarding climate change.

First, I tested the effects of long-term density management on forest carbon dynamics and related metrics in natural shortleaf pine and oak-hickory stands in the Missouri Ozarks. This study confirmed previous findings concerning climate change mitigation that suggest higher density, fully stocked stands store more aboveground carbon through time compared to lower density stands.

Findings also illustrated trade-offs associated with stand- and individual tree-level carbon dynamics, where lower density stands produce merchantable sawlogs earlier than more dense stands, but at the cost of lower total aboveground stored carbon. Concerning carbon sequestration rates, although there were few clear patterns in stand and individual tree-level carbon sequestration rates, our results did not support previous studies that reported significant age-related decline in stand productivity. In fact, individual trees increased carbon sequestration rates through time. 
Second, I developed a shortleaf pine chronology for the Missouri Ozarks to answer climate adaptation questions relating to stand density, management, and climate-related growth response. Our study supported previous findings that reported increased tree-level tolerance to drought events in lower density stands and found that thinning altered the relationship between radial tree growth and PDSI so that current year water availability was no longer immediately influencing radial growth.

Although long-term studies are inherently difficult to maintain due to changes in staff, interests, and funding sources, they supply invaluable information regarding long-term forest response to management. Our study illustrates the importance of maintaining long-term data sets for use in addressing traditional and emerging objectives alike. 


\section{Literature Cited}

1976 Progress Report: The Effects of Stand Density on Growth, Quality, and Total Wood Production of Even-Aged Oak Stands.

Adams, M.; Loughry, L.; Plaugher, L, comps. (2004). Experimental Forests and Ranges of the USDA Forest Service. Gen. Tech. Rep. NE-321. Newtown Square, PS: U.S. Department of Agriculture, Forest Service, Northeastern Research Station. 178 p.

Adams, H. D., et al. (2009). "Temperature sensitivity of drought-induced tree mortality portends increased regional die-off under global-change-type drought." Proc Natl Acad Sci U S A 106(17): 7063-7066.

Allen, C. D., et al. (2010). "A global overview of drought and heat-induced tree mortality reveals emerging climate change risks for forests." Forest Ecology and Management 259(4): 660-684.

Anning, A. K. and B. C. McCarthy (2013). "Long-Term Effects of Prescribed Fire and Thinning on Residual Tree Growth in Mixed-Oak Forests of Southern Ohio." Ecosystems 16(8): 1473-1486.

Ayres, M. P. and M. J. Lombardero (2000). "Assessing the consequences of global change for forest disturbance from herbivores and pathogens." Science of The Total Environment 262(3): 263-286.

Behan, R.W. (1990). Multiresource Forest Management: A paradigmatic challenge to professional forestry. Journal of Forestry 88: 12-18

Bigler, C., et al. (2007). "Drought Induces Lagged Tree Mortality in a Subalpine Forest in the Rocky Mountains." Oikos 116(12): 1983-1994.

Birdsey, R. A. (1992). "Carbon storage and accumulation in united states forest ecosystems." USDA Forest Service GTR WO 059.

Blizzard, E.M.; Larsen, D.R; Dey, D.C.; Kabrick, J.M.; Gwaze, D. (2007). “The state of mixed shortleaf pine-upland oak management in Missouri. In: Kabrick, J.M.; Dey, D.C.; Gwaze, D., eds. Shortleaf Pine Restoration and Ecology in the Ozarks: Proceedings of a Symposium; 2006 November 7-9; Springfield, MO. Gen. Tech. Rep/ NRS-P-15. Newtown Square, PA: U.S. Department of Agriculture, Forest Service, Northern Research Station: 153-157.

Bradford, J. B. and A. W. D'Amato (2011). "Recognizing trade-offs in multiobjective land management." Frontiers in Ecology and the Environment 10(4): 210-216.

Bragg, D. C. (2013). Results of a long-term thinning study in some natural, evenaged pine stands of the Midsouth. 15th biennial southern silvicultural research conference, Asheville, NC, U.S. Department of Agriculture, Forest Service, Southern Research Station. 
Brandt, L. A. et al. (2014). "Central Hardwoods Ecosystem Vulnerability Assessment and Synthesis." USFS GTR NRS-124.

Breshears, D. D., et al. (2009). "Tree die-off in response to global change-type drought: mortality insights from a decade of plant water potential measurements." Frontiers in Ecology and the Environment 7(4): 185-189.

Brinkman, K. A. (1961). "Columbia Supplement to the Basic Work Plan Entitled: The Effects of Stand Density on Growth, Quality, and Total Wood Production in Even-Aged Hardwoods Stands."

Brinkman, K. A., Rogers, N.F., Gingrich, S.F. (1962). "Effect of Stocking Density on Growth of Shortleaf Pine Stands in Missouri." USDA Forest Service.

Brinkman, K. A. and N. F. Rogers (1967). Timber management guide for shortleaf pine and oak-pine types in Missouri. [Saint Paul, Minn.], North Central Forest Experiment Station, Forest Service, U.S. Dept. of Agriculture.

Brinkman, K. A., et al. (1965). "Shortleaf Pine in Missouri, Stand Density Affects Yield." Central States Forest Experiment Station, Columbus, OH. U.S. Forest Service Research Paper CS-14.

Brinkman, K., Smith, R (1968). "Managing Shortleaf Pine in Missouri."

Bruhn, J.N.; Dey, D.C.; Kromroy, K.K.; Mihail, J.D.; Kabrick, J.M.; Wetteroff, J.J., Jr. (2005). "Armillaria root disease affects oak coppice regeneration in upland Missouri Ozark Forests. In: Manka, Malgorzata; Lakomy, Piotr, eds. Proceedings of the $11^{\text {th }}$ International Conference on Root and Butt Rots, Root and Butt Rots of Forest Trees. The August Cieszkowski Agricultural University: Poznan, Poland. 279-285.

Burton, J. I., et al. (2013). "Management trade-off between aboveground carbon storage and understory plant species richness in temperate forests." Ecological Applications 23(6): 1297-1310.

Cain, M. D. and M. G. Shelton (2003). "Effects of alternative thinning regimes and prescribed burning in natural, even-aged loblolly-shortleaf pine stands: 25 Year results." Southern Journal of Applied Forestry 27(1): 18.

Canadell, J. G., et al. (2007). "Contributions to accelerating atmospheric $\mathrm{CO}^{2}$ growth from economic activity, carbon intensity, and efficiency of natural sinks." Proceedings of the National Academy of Sciences 104(47): 1886618870.

Canadell, J. G. and M. R. Raupach (2008). "Managing forests for climate change mitigation." Science 320(5882): 1456-1457.

Canham, C. D., et al. (2001). "Interspecific variation in susceptibility to windthrow as a function of tree size and storm severity for northern temperate tree species." Canadian Journal of Forest Research 31(1): 1-10. 
Carmean, W. H., Hahn, J.T., Jacobs, R.D. (1989). "Site index curves for forest tree species in the eastern united states." USDA Forest Service GTR NC128.

Cescatti, A. and E. Piutti (1998). "Silvicultural alternatives, competition regime and sensitivity to climate in a European beech forest." Forest Ecology and Management 102(2-3): 213-223.

Chmura, D. J., et al. (2011). "Forest responses to climate change in the northwestern United States: Ecophysiological foundations for adaptive management." Forest Ecology and Management 261(7): 1121-1142.

Chojnacky, D. C., Heath, L.S., Jenkins, J.C. (2013). "Updated generalized biomass equations for north american tree species." Forestry.

Dai, A. (2016, 19 Apr 2016). "The Climate Data Guide: Palmer Drought Severity Index (PDSI)." from https://climatedataguide.ucar.edu/climatedata/palmer-drought-severity-index-pdsi.

Dale, M.E., Sander, I.L. (1959). The Effects of Stand Density on Growth, Quality, and Total Wood Production in Even-Aged Hardwood Stands. Berea, KY. USDA Forest Service Southern Research Station.

Dale, V. H., et al. (2001). "Climate Change and Forest Disturbances." BioScience 51(9): 723-734.

D'Amato, A. W., et al. (2010). "Growth, yield, and structure of extended rotation Pinus resinosa stands in Minnesota, USA." Canadian Journal of Forest Research 40(5): 1000-1010.

D'Amato, A. W., et al. (2011). "Forest management for mitigation and adaptation to climate change: Insights from long-term silviculture experiments." Forest Ecology and Management 262(5): 803-816.

D'Amato, A. W., et al. (2013). "Effects of thinning on drought vulnerability and climate response in north temperate forest ecosystems." Ecological Applications 23(8): 1735-1742.

Davis, S. C., et al. (2009). "Forest carbon sequestration changes in response to timber harvest." Forest Ecology and Management 258(9): 2101-2109.

DeRose, R. J. and J. N. Long (2014). "Resistance and Resilience: A Conceptual Framework for Silviculture." Forest Science 60(6): 1205-1212.

Devi, L. S. and P. S. Yadava (2015). "Carbon stock and rate of carbon sequestration in Dipterocarpus forests of Manipur, Northeast India." Journal of Forestry Research 26(2): 315-322.

Duveneck, M. J., et al. (2014). "Effects of alternative forest management on biomass and species diversity in the face of climate change in the northern Great Lakes region (USA)." Canadian Journal of Forest Research 44(7): 700-710. 
Dwyer, J. P., Kabrick, J.M., Wetteroff, J. (2007). "Do Improvement Harvests Mitigate Oak Decline in Missouri Ozark Forests." Northern Journal of Applied Forestry 24(2).

Easterling, D. R., et al. (2000). "Climate Extremes: Observations, Modeling, and Impacts." Science 289(5487): 2068-2074.

Eisen, K., Barker-Plotkin, A. (2015). "Forty years of forest measurements support steadily increasing aboveground biomass in a maturing, Quercusdominant northeastern forest." Journal of the Torrey Botanical Society 142(2): 97-112.

Elliott, K. J., et al. (2012). "Restoration of shortleaf pine (Pinus echinata)hardwood ecosystems severely impacted by the southern pine beetle (Dendroctonus frontalis)." Forest Ecology and Management 274: 181-200.

Estes, E. T. (1970). "Dendrochronology of Black Oak (Quercus velutina Lam.), White Oak (Quercus alba L.), and Shortleaf Pine (Pinus echinata Mill.) in the Central Mississippi Valley." Ecological Monographs 40(3): 295-316.

Fahey, T. J., et al. (2010). "Forest carbon storage: ecology, management, and policy." Frontiers in Ecology and the Environment 8(5): 245-252.

Farrar, R. M., P.A. Murphy (1987). "Taper Functions for Predicting Product Volumes in Natural Shortleaf Pines." USDA Forest Service GTR Research Paper(SO-234).

Floyd, M. L., et al. (2009). "Relationship of stand characteristics to droughtinduced mortality in three Southwestern piñon-juniper woodlands." Ecological Applications 19(5): 1223-1230.

Foster, J. R., et al. (2014). "Looking for age-related growth decline in natural forests: unexpected biomass patterns from tree rings and simulated mortality." Oecologia(1).

Fritts, H. C. (1962). "The Relation of Growth Ring Widths in American Beech and White Oak to Variations in Climate." Tree-Ring Bulletin 1(2): 2-10.

Fritts, H. C. (1976). Tree Rings and Climate. Caldwell, NJ, The Blackburn Press.

Fu, L., et al. (2015). "Spatial and temporal dynamics of forest aboveground carbon stocks in response to climate and environmental changes." Journal of Soils and Sediments 15(2): 249-259.

Gea-Izquierdo, G., et al. (2011). "Tree-rings reflect the impact of climate change on Quercus ilex L. along a temperature gradient in Spain over the last 100 years." Forest Ecology and Management 262(9): 1807-1816.

Gevorkiantz, S. R., Olsen, L.P. (1955). Composite Volume Tables for Timber and Their Application in the Lake States. U. F. Service. U.S. Government Printing Office, United States Department of Agriculture Lake States Experiment Station. 
Gilmore, D. W., et al. (2005). "Thinning Red Pine Plantations and the Langsaeter Hypothesis: A Northern Minnesota Case Study." Northern Journal of Applied Forestry 22(1): 19-26.

Gingrich, S. F. (1961). United States Government Memorandum: Personal Communication. K. A. Brinkman. Columbia, MO: 2.

Gingrich, S.F., et al. (1965). "Shortleaf Pine in Missouri, Two Methods of Thinning. Cent. States Forest Experiment Sta., Columbus, Ohio. U.S. Forest Service Research Paper CS-16.

Gingrich, S. F. (1967). "Measuring and Evaluating Stocking and Stand Density in Upland Hardwood Forests in the Central States." Forest Science 13(1).

Grigal, D. F. and L. F. Ohmann (1992). "Carbon Storage in Upland Forests of the Lake States." Soil Science Society of America Journal 56(3): 935-943.

Guldin, J.M.; Poole, E.A.; Heitzman, E.; Kabrick, J.M.; Muzika, R. (2006). Ground Truth Assessments of Forests Affected by Oak Decline and Red Oak Borer in the Interior Highlands of Arkansas, Oklahoma, and Missouri: preliminary results from overstory analysis. Gen. Tech. Rep. SRS-92. Asheville, NC: U.S. Department of Agriculture, Forest Service, Southern Research Station. Pp 415-419.

Guldin, J. M. (2007). "Restoration and Management of Shortleaf Pine in Pure and Mixed Stands--Science, Empirical Observation, and the Wishful Application of Generalities."

Guldin, J. M., et al. (2008). Pioneer Forest. a half century of sustainable unevenaged forest management in the Missouri Ozarks. [electronic resource], Asheville, NC: U.S. Dept. of Agriculture, Forest Service, Southern Research Station, [2008].

Guyette, R. P., et al. (2014). "Future fire probability modeling with climate change data and physical chemistry." Forest Science 60(5): 862-870.

Hanson, P. J. and J. F. Weltzin (2000). "Drought disturbance from climate change: response of United States forests." Science of The Total Environment 262(3): 205-220.

Hanson, P. J., et al. (2001). "A six-year study of sapling and large-tree growth and mortality responses to natural and induced variability in precipitation and throughfall." Tree Physiology 21(6): 345-358.

Harmon, M. E. and B. Marks (2002). "Effects of silvicultural practices on carbon stores in Douglas-fir - western hemlock forests in the Pacific Northwest, U.S.A.: results from a simulation model." Canadian Journal of Forest Research 32(5): 863-877.

Harmon, M. E., et al. (2009). "Effects of partial harvest on the carbon stores in douglas-fir/western hemlock forests: A simulation study." Ecosystems 12(5): 777-791. 
Heitzman, E.; Muzika, R.; Kabrick, J.; Guldin, J.M. (2004). Assessment of Oak Decline in Missouri, Arkansas, and Oklahoma. In: Yaussy, D.A.; Hix, D.M.; Long, R.P.; Goebel, P. C., eds. Proceedings, $14^{\text {th }}$ Central Hardwood Forest Conference; 2004 March 16-19; Wooster, OH. Gen. Tech. Rep. NE-316. Newtown Square, PA; U.S. Department of Agriculture, Forest Service, Northeastern Research Station; 510.

Holmes, R. L. (1983). "Computer-assisted quality control in tree-ring dating and measurements." Tree-Ring Bulletin 43: 69-78.

Hoover, C. and S. Stout (2007). "The Carbon Consequences of Thinning Techniques: Stand Structure Makes a Difference." Journal of Forestry 105(5): 266-270.

Husch, B., Beers, T.W., Kershaw, J.A. (2003). Forest Mensuration. Hoboken, NJ, John Wiley \& Sons, Inc.

IPCC, (2007). "Climate Change 2007: Working Group II: Impacts, Adaptation and Vulnerability." IPCC Fourth Assessment Report: Climate Change 2007. 2017, from https://www.ipcc.ch/publications_and_data/ar4/wg2/en/ch17s17-3.html.

IPCC, (2014). Climate Change 2014: Synthesis Report. Contribution of Working Groups I, II and III to the Fifth Assessment Report of the Intergovernmental Panel on Climate Change [Core Writing Team, R.K. Pachauri and L.A. Meyer (eds.)]. IPCC, Geneva, Switzerland, 151 pp.

Jain, T. B., Graham, R.T., Adams, D. (2010). Carbon Concentrations and Carbon Pool Distributions in Dry. Moist, and Cold Mid-Aged Forests of the Rocky Mountains, USDA Forest Service.

Janowiak, M. K., et al. (2014). "A Practical Approach for Translating Climate Change Adaptation Principles into Forest Management Actions." Journal of Forestry 112(5): 424-433.

Jenkins, J. C., Chojnacky, D.C., Heath, L.S., Birdsey, R.A. (2003). "Nationalscale biomass estimators for united states tree species." Forest Science 49(1).

Jensen, Randy G.; Kabrick, John M. (2008). Comparing single-tree selection, group selection, and clearcutting for regenerating oaks and pines in the Missouri Ozarks. In: Jacobs, Douglass F.; Michler, Charles H., eds. 2008. Proceedings, 16th Central Hardwood Forest Conference; 2008 April 8-9; West Lafayette, IN. Gen. Tech. Rep. NRS-P-24. Newtown Square, PA: U.S. Department of Agriculture, Forest Service, Northern Research Station: 38-49.

Johnson, P. S., Shifley, S.R., Rogers, R. (2009). The Ecology and Silviculture of Oaks. Cambridge, MA, CABI. 
Kabrick, John M.; Shifley, Stephen R.; Jensen, Randy G.; Fan, Zhaofei; Larsen, David R. (2004). Factors Associated with Oak Mortality in Missouri Ozark Forests. In: Yaussy, Daniel A.; Hix, David M.; Long, Robert P.; Goebel, P. Charles, eds. Proceedings, 14th Central Hardwood Forest Conference; 2004 March 16 19; Wooster, OH. Gen. Tech. Rep. NE-316. Newtown Square, PA: U.S. Department of Agriculture, Forest Service, Northeastern Research Station: 27-35.

Kabrick, J. M., et al. (2008). "The role of environmental factors in oak decline and mortality in the Ozark Highlands." Forest Ecology and Management 255(56): 1409-1417.

Kabrick, J. M., et al. (2017). "Managing Hardwood-Softwood Mixtures for Future Forests in Eastern North America: Assessing Suitability to Projected Climate Change." Journal of Forestry 000(000).

Keyser, T. L., Brown, P.M. (2014). "Climate-growth Relationships for YellowPoplar Across Structural and Site Quality Gradients in the Southern Appalachian Mountains." Forest Ecology and Management 329: 158-165.

Kirilenko, A. P. and R. A. Sedjo (2007). "Climate change impacts on forestry." Proceedings of the National Academy of Sciences 104(50): 19697-19702.

Kohler, M., et al. (2010). "Can drought tolerance of Norway spruce (Picea abies (L.) Karst.) be increased through thinning?" European Journal of Forest Research 129(6):1109-1118.

Larsen, D. R., et al. (1997). "Oak regeneration and overstory density in the Missouri Ozarks." Canadian Journal of Forest Research 27: 869-875.

Larsen, D. R. Loewenstein, E.F.; Johnson, P.S. (1999). Sustaining recruitment of oak reproduction in uneven-aged stands in the Ozark Highlands. St. Paul, MN, U.S. Dept. of Agriculture, Forest Service, North Central Forest Experiment Station. General Technical Report NC-203.

Laurent, M., et al. (2003). "Effects of different thinning intensities on drought response in Norway spruce (Picea abies (L.) Karst.)." Forest Ecology and Management 183(1-3): 47-60.

Lawler, J. J., et al. (2010). "Resource management in a changing and uncertain climate." Frontiers in Ecology and the Environment 8(1): 35-43.

Lawson ER. (1990). Pinus echninata Mill. Shortleaf Pine. In Silvics of North America; Volume 1, Conifers: 316-326. Burns RM, Honkala BH, technical coordinators. U.S. Department of Agriculture, Forest Service Handbook 654. Washington, DC.

Lee, Christopher A.; Dey, Daniel C.; Muzika, Rose-Marie (2016). Oak stumpsprout vigor and Armillaria infection after clearcutting in southeastern Missouri, USA. Forest Ecology and Management. 374: 211-219. 
Loewenstein, E. F., Johnson, P.S., Garett, H.E. (2000). "Age and Diamter Structure of an Uneven-aged Oak Forest." Canadian Journal of Forest Research 30.

Loewenstein, E. F. (2005). "Conversion of uniform broadleaved stands to an uneven-aged structure." Forest Ecology and Management 215(1-3): 103112.

Logan, J. A., et al. (2003). "Assessing the Impacts of Global Warming on Forest Pest Dynamics." Frontiers in Ecology and the Environment 1(3): 130-137.

Magruder, M., et al. (2013). "Thinning increases climatic resilience of red pine." Canadian Journal of Forest Research 43(9): 878-889.

Malmsheimer, R. W., et al. (2008). "Forest Management Solutions for Mitigating Climate Change in the United States." Journal of Forestry 106(3): 115171.

Martinez-Vilalta, J., et al. (2012). "Stand- and tree-level determinants of the drought response of Scots pine radial growth." Oecologia 168(3): 877-888.

McQuilkin, R.A. (1974). Site index prediction table for black, scarlet, and white oaks in southeastern Missouri. Res. Pap. NC-108. St. Paul, MN: U.S. Department of Agriculture, Forest Service, North Central Forest Experiment Station. 8 p.

Millar, C. I., et al. (2007). "Climate change and forests of the future: managing in the face of uncertainty." Ecol Appl 17(8): 2145-2151.

Missouri Climate Center. (2017). "Significant Weather Events of the Century for Missouri." 2017, from http://climate.missouri.edu/sigwxmo.php.

Mohan, J. E., et al. (2009). "Composition and carbon dynamics of forests in northeastern North America in a future, warmer world." Canadian Journal of Forest Research 39(2): 213-230.

Muzika, R.-M. Guyette., Richard P. (2004). A Dendrochronological Analysis of Red Oak Borer Abundance. Gen. Tech. Rep. M. A. Spetich. Asheville, NC, U.S. Department of Agriculture, Forest Service, Southern Research Station. SRS-73: 102-105.

Nace, R. L., Pluhowski, E.J. (1965). Drought of the 1950's with Special Reference to the Midcontinent. Washington, D.C., US Department of the Interior USGS.

Nash, A.J. (1963). A method of classifying shortleaf pine sites in Missouri. Res. Bull. 824. Columbia, MO: Missouri Agricultural Experiment Station. 53 p.

NCDC (2016). "NCDC Climate Data Online Missouri Division 5." Retrieved July 24, 2016, from https://www7.ncdc.noaa.gov/CDO/cdodivisionalselect.cmd. 
Nigh, T.A., Schroeder, W.A. (2002). Atlas of Missouri Ecoregions. Missouri Department of Conservation, Jefferson City, MO.

Nowak, J. T., et al. (2015). "Southern Pine Beetle Infestations in Relation to Forest Stand Conditions, Previous Thinning, and Prescribed Burning: Evaluation of the Southern Pine Beetle Prevention Program." Journal of Forestry 113(5): 454-462.

Oswalt, C. M. (2013). "Broad Scale Inventory of Shortleaf Pine." 2016, from http://shortleafpine.net/why-shortleaf/fia-data.

Paquette, A. and C. Messier (2011). "The effect of biodiversity on tree productivity: from temperate to boreal forests." Global Ecology and Biogeography 20(1): 170-180.

Piva, R. J. Treiman, T.B. (2015). Forests of Missouri, 2014. Resource Update FS-40. Newtown Square, PA: U.S. Department of Agriculture, Forest Service, Northern Research Station.

Puettmann, K. J., Coates, K. D., \& Messier, C. C. (2009). A critique of silviculture: Managing for complexity. Washington, DC: Island Press.

Puettmann, K. J. (2011). "Silvicultural Challenges and Options in the Context of Global Change: "Simple" Fixes and Opportunities for New Management Approaches." Journal of Forestry 109(6): 321-331.

Powers, M. D., et al. (2010). "Thinning method and intensity influence long-term mortality trends in a red pine forest." Forest Ecology and Management 260(7): 1138-1148.

Prasad, A.M., L.R. Iverson, S. Matthews, M. Peters. (2007). A Climate Change Atlas for 134 Forest Tree Species of the Eastern United States [database]. http://www.nrs.fs.fed.us/atlas/tree/tree_atlas.html, Northern Research Station, USDA Forest Service, Delaware, Ohio.

Rogers, N.F., Liming, F.G. (1951). Work Plan: A Study on Degrees of Stocking and Methods of Thinning Stands of Shortleaf Pine (Pine Stocking Study). USDA Forest Service.

Rogers, N.F., and Brinkman, K.A. (1965). "Shortleaf Pine in Missouri, Understory Hardwoods Retard Growth. Central States Forest Experiment Station, Columbus, OH. U.S. Forest Service Research Paper CS-15.

Rogers, N.F. (1969). "A Study on Degrees of Stocking and Methods of Thinning Stands of Shortleaf Pine: Pine Stocking Study. A Proposal for the Modification of the Design and Thinning Schedules. USDA Forest Service.

Rogers, R. (1982). Guides for Thinning Shortleaf Pine. Second Southern Silvicultural Research Conference, Atlanta, GA.

Rogers, R. (1990). "White Oak." Silvics of North America. 2016, from https://www.na.fs.fed.us/pubs/silvics_manual/volume_2/quercus/alba.htm. 
Roach, B. A., Gingrich, S.F. (1968). Even-Aged Silviculture for Upland Central Hardwoods. N. F. E. Station. Washington, D.C., USDA Forest Service.

Sander, I. L. (1990). "Black Oak." Silvics of North America. 2016, from https://www.na.fs.fed.us/pubs/silvics_manual/volume_2/quercus/velutina.h tm.

Schaedel, M. S., et al. (2017). "Early Forest Thinning Changes Aboveground Carbon Distribution Among Pools, But Not Total Amount." Forest Ecology and Management 389: 187-198.

Seidel, K. W. (1963). The Effects of Stand Density on Growth, Quality, and Total Wood Production in Even-Aged Hardwood Stands (Oak Stocking Study): Establishment Report, USDA Forest Service: Northern Research Station.

Shifley, S. R., et al. (2006). "Oak mortality risk factors and mortality estimation." Forest Ecology and Management 229(1-3): 16-26.

Shores, E. F., et al. (1999). Ozark-Ouachita Highlands Assessment: Terrestrial Vegetation and Wildlife. F. S. U.S. Department of Agriculture. 035.

Smith, D. M., Larson, B.C., Kelty, M.J., Ashton, P.M (1997). The Practice of Silviculture, John Wiley \& Sons, Inc.

Speer, J. H. (1971). Fundamentals of Tree-ring Research. Tuscon, AZ, University of Arizona Press.

Stambaugh, M. C. a. G., R.P. (2004). "Long-Term Growth and Climate Response of Shortleaf Pine at the Missouri Ozark Forest Ecosystem Project." Proceedings of the 14th Central Hardwood Forest Conference GTR-NE316.

Stambaugh, M. C., et al. (2009). "Fire, Drought, and Human History near the Western Terminus of the Cross Timbers, Wichita Mountains, Oklahoma, USA." Fire Ecology 5(2): 51-65.

Stambaugh, M. C., Guyette, R.P., McMurry, E.R., Cook, E.R., Meko, D.M., Lupo, A.R. (2011). "Drought duration and frequency in the U.S. Corn Belt during the last millennium (AD 992-2004)." Agricultural and Forest Meteorology 151(2): 154-162.

Stephenson, N. L., et al. (2014). "Rate of tree carbon accumulation increases continuously with tree size." Nature 507(7490): 90-93.

USDA Forest Service. (2011). Timber Volume Estimator Handbook Chapter 50 Application. Timber Volume Estimator Handbook. Milwaukee, WI, Eastern Region. FSH 2409.12A: 15.

USDA Forest Service. (2016). "Carbon Sequestration." 2016. 
Varmola, M. and H. Salminen (2004). "Timing and intensity of precommercial thinning in Pinus sylvestris stands." Scandinavian Journal of Forest Research.

Voelker, S. L., et al. (2008). "Individual Tree and Stand Level Influences on the Growth, Vigor, and Decline of Red Oaks in the Ozarks." Forest Science 54(1): 8-20.

Walker, B., et al. (2004). "Resilience, adaptability and transformability in socialecological systems." Ecology and society 9(2): 5.

Walker, Laurence C. and Wiant, Harry V. Jr, "Forestry Bulletin No. 9: Silviculture of Shortleaf Pine" (1966). Forestry Bulletins No. 1-25, 1957-1972. Book 8.

Wang, T., et al. (2006). "Use of response functions in selecting lodgepole pine populations for future climates." Global Change Biology 12(12): 24042416.

Wang, W. J., et al. (2013). "Modeling the Effects of Harvest Alternatives on Mitigating Oak Decline in a Central Hardwood Forest Landscape." PLoS ONE 8(6).

Will, R., Stewart, J., Lynch, T., Turton, D., Maggard, A., Lilly, C., Atkinson, K. (2014). "Strategic assessment for shortleaf pine." USDA Forest Service Strategic Assessment.

Yuhua, T. and R. A. Williams (2013). "Carbon Stocks and Sequestration Rates in Oak-Hickory Forests of Ohio, USA." Journal of Resources and Ecology 4(2): 115-124.

Zeide, B. (2001). "Thinning and growth: A full turnaround." Journal of Forestry 99(1): 20-25. 


\section{Appendix}
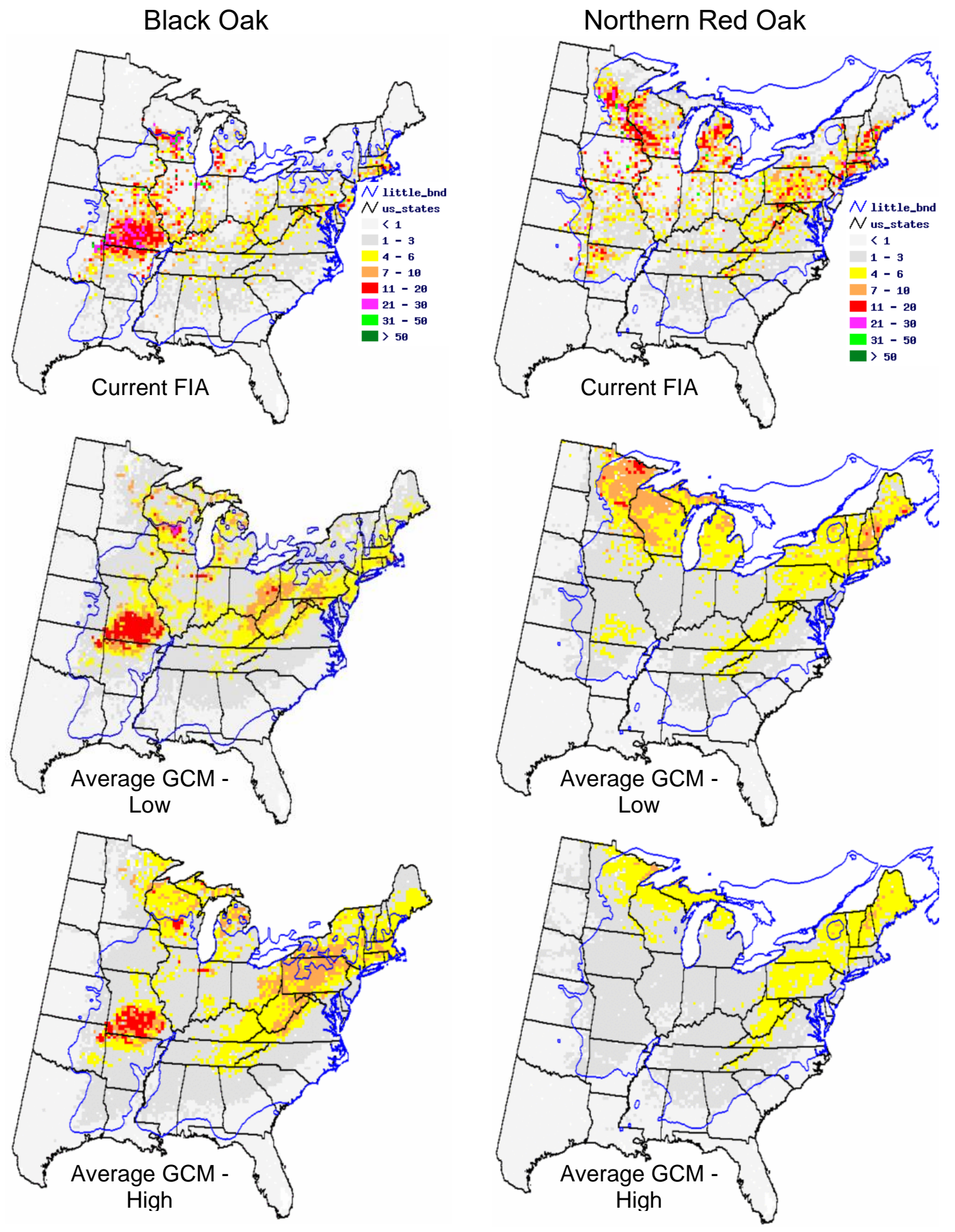

Figure A-1. Current range and projected High and Low emissions scenarios showing range of suitable habitat and importance values for black oak and northern red oak to 2100 averaged across three commonly referenced general circulation models (GCMs). (Prasad et al., 2007) 

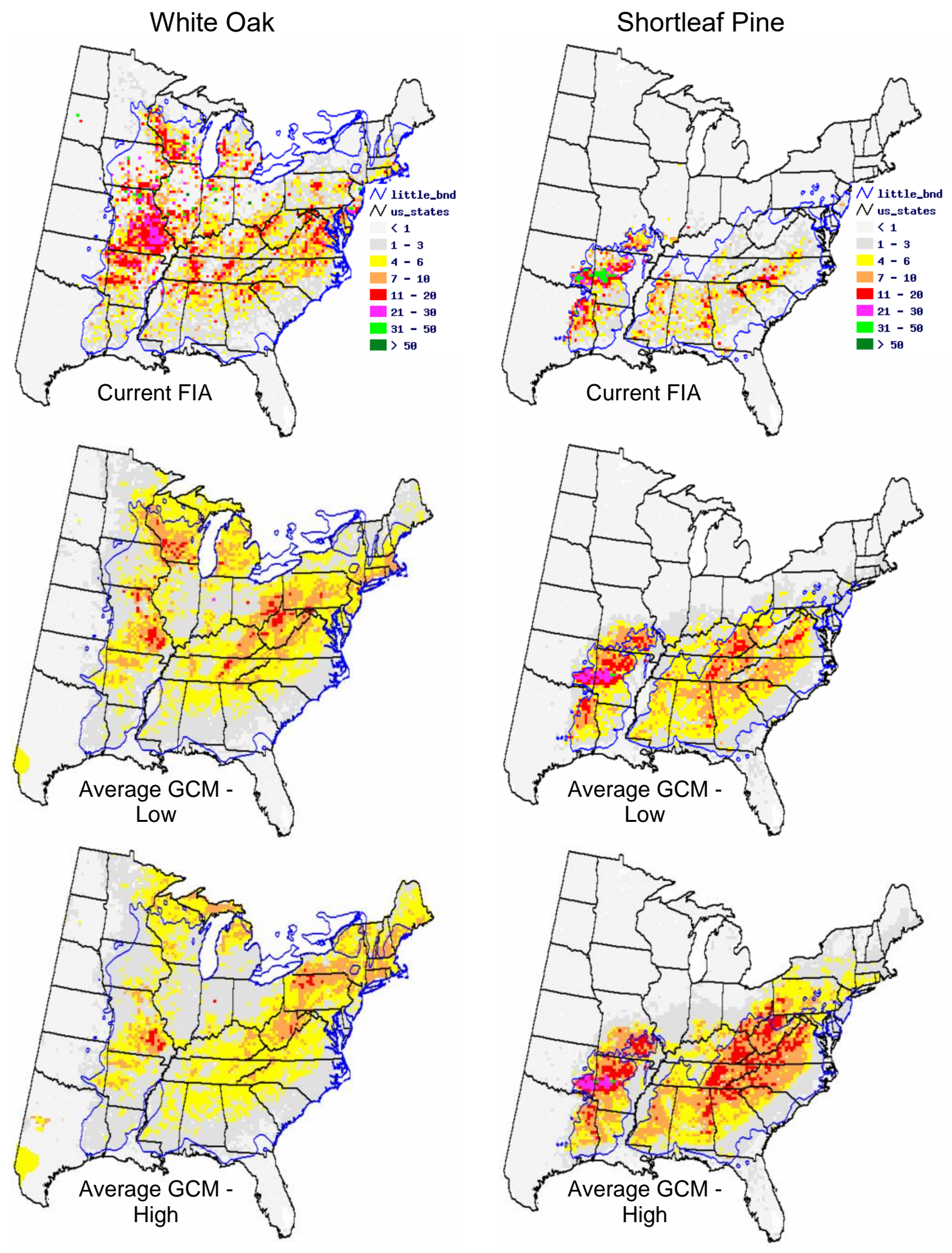

Figure A-2. Current range and projected High and Low emissions scenarios showing range of suitable habitat and importance values for white oak and shortleaf pine to 2100 averaged across three commonly referenced general circulation models (GCMs). (Prasad et al., 2007) 
Table A-1. PSS Inventory and Treatment Schedule

\begin{tabular}{|c|c|c|c|c|c|c|c|c|c|c|c|c|c|c|c|}
\hline \multirow{2}{*}{$\begin{array}{c}1952 \\
\text { Treatment }\end{array}$} & \multirow{2}{*}{ Plot } & \multicolumn{14}{|c|}{ Year } \\
\hline & & 1952 & 1956 & 1960 & 1965 & 1971 & 1972 & 1976 & 1980 & 1985 & 1990 & 1995 & 2000 & 2007 & 2015 \\
\hline \multirow{3}{*}{11.5} & 134 & 0 & & 0 & & & 0 & & & & & & & & \\
\hline & 137 & 0 & & 0 & & & + & & & & & + & & & \\
\hline & 146 & 0 & & 0 & & & + & & & & & + & & & \\
\hline \multirow{12}{*}{16.1} & 125 & 0 & & 0 & & & 0 & & & & & & & & \\
\hline & 126 & 0 & & 0 & & & 0 & & & + & & + & & & \\
\hline & 127 & 0 & & 0 & & & 0 & & & & & + & & & \\
\hline & 129 & 0 & & 0 & & & $\square$ & & & & & & & + & \\
\hline & 130 & 0 & & 0 & & & $*$ & & & & & & & & \\
\hline & 132 & 0 & & 0 & & & 0 & & & & & + & & & \\
\hline & 138 & 0 & & 0 & & & $*$ & & & & & & & & \\
\hline & 143 & 0 & & 0 & & & 0 & & & & & + & & & \\
\hline & 144 & 0 & & 0 & & & + & & & + & & + & & & \\
\hline & 147 & 0 & & 0 & & & $*$ & & & & & & & & \\
\hline & 148 & 0 & & 0 & & & 0 & & & & & + & & & \\
\hline & 150 & 0 & & 0 & & & $*$ & & & & & & & & \\
\hline \multirow{3}{*}{20.7} & 139 & 0 & & 0 & & & $\square$ & & & 0 & & 0 & & + & \\
\hline & 151 & 0 & & 0 & & & + & & & + & & & & + & \\
\hline & 153 & 0 & & 0 & & & 0 & & & + & & + & & & \\
\hline \multirow{6}{*}{25.3} & 131 & 0 & & 0 & & & $\square$ & & & & & $\square$ & & & \\
\hline & 133 & 0 & & 口 & & & $\square$ & & & & & $\square$ & & & \\
\hline & 135 & 0 & & 0 & & & 0 & & & 0 & & 0 & & & \\
\hline & 136 & 0 & & $\square$ & & & $\square$ & & & & & $\square$ & & + & \\
\hline & 142 & 0 & & 0 & & & $\square$ & & & & & $\square$ & & & \\
\hline & 145 & 0 & & $\square$ & & & $\square$ & & & $\square$ & & 口 & & + & \\
\hline \multirow{6}{*}{ C } & 128 & & & & & & $\square$ & & & & & & & & \\
\hline & 140 & & & & & & & & & & & & & & \\
\hline & 141 & & & & & & & & & & & & & & \\
\hline & 149 & & & & & & $\square$ & & & & & & & & \\
\hline & 152 & & & & & & $\square$ & & & & & & & & \\
\hline & 154 & & & & & & $\square$ & & & & & & & & \\
\hline
\end{tabular}

\section{Plot inventoried}

$\diamond$ Plot thinned to original density assignment

$\checkmark$ Plot thinned to lower density than original assignment

+ Plot thinned to higher density than original assignment

*Plot removed from study 


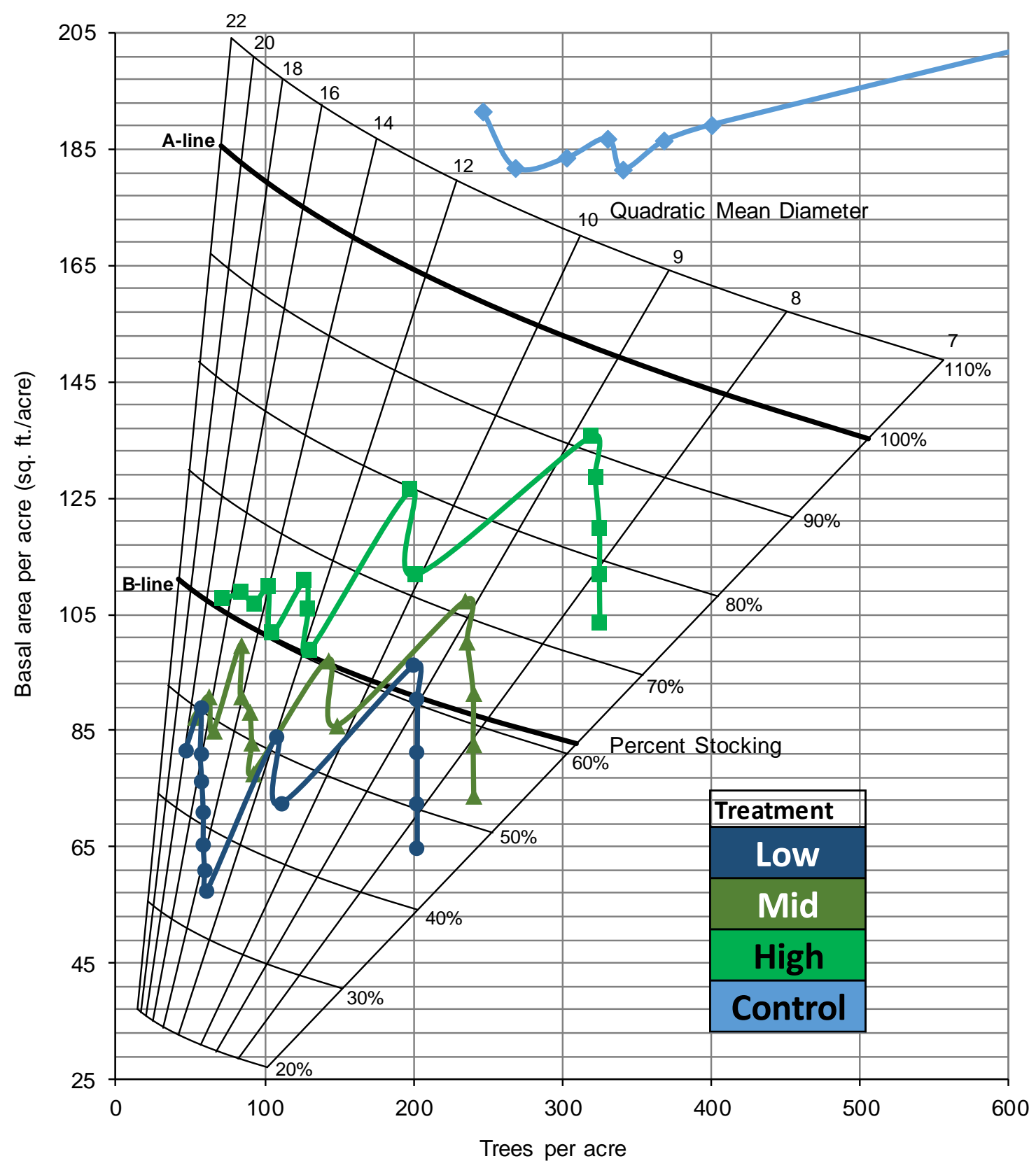

Figure A-3. Pine Stocking Study (Chapter 2) Gingrich stocking diagram (1952-2015) from Rogers (1982) developed for MS Excel by Dr. David Larsen, University of Missouri. Stocking chart is in English units. 


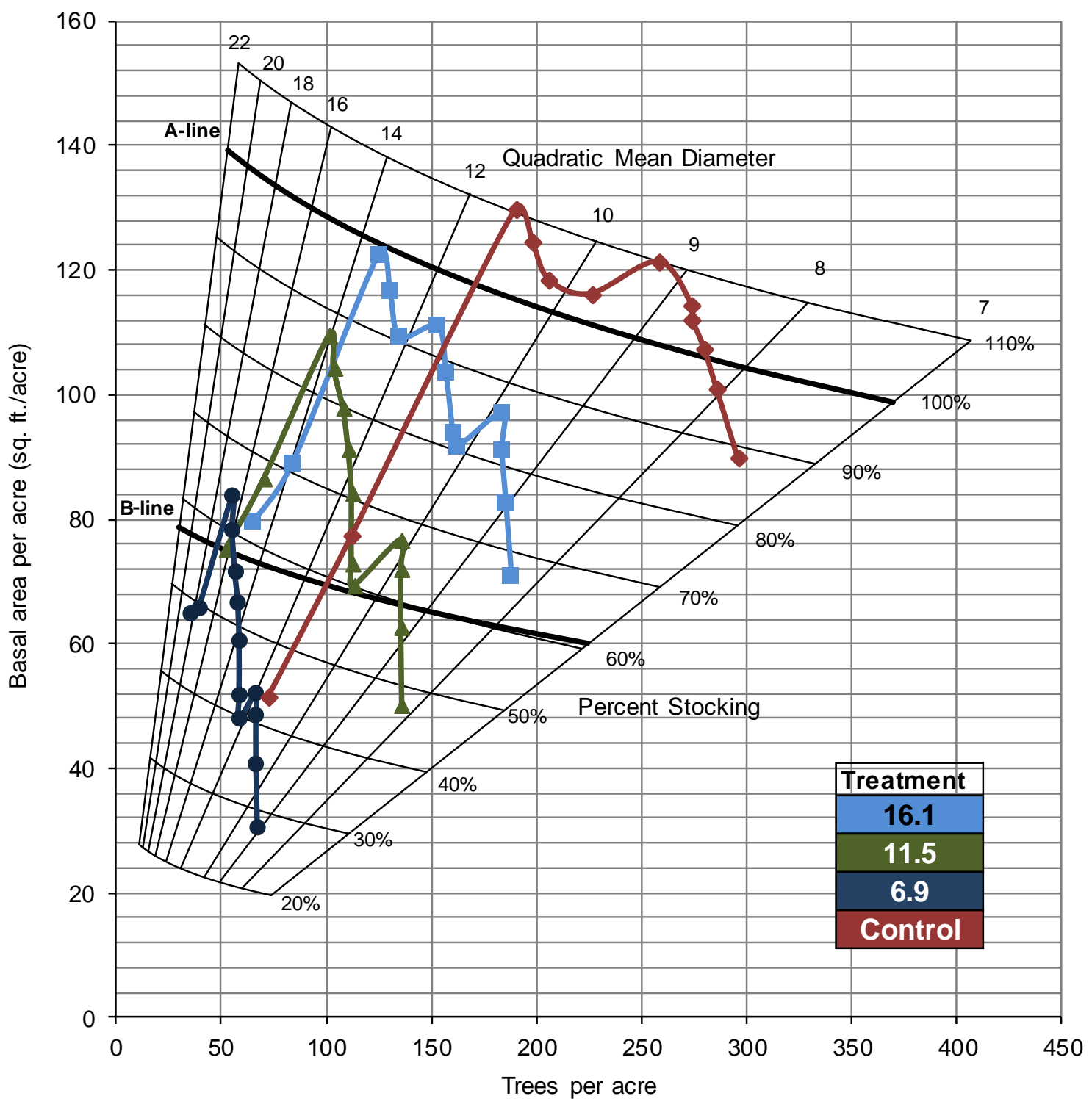

Figure A-4. Oak Stocking Study Gingrich stocking diagram (1961-2015) developed for MS Excel by Dr. David Larsen, University of Missouri. Stocking chart is in English units. 


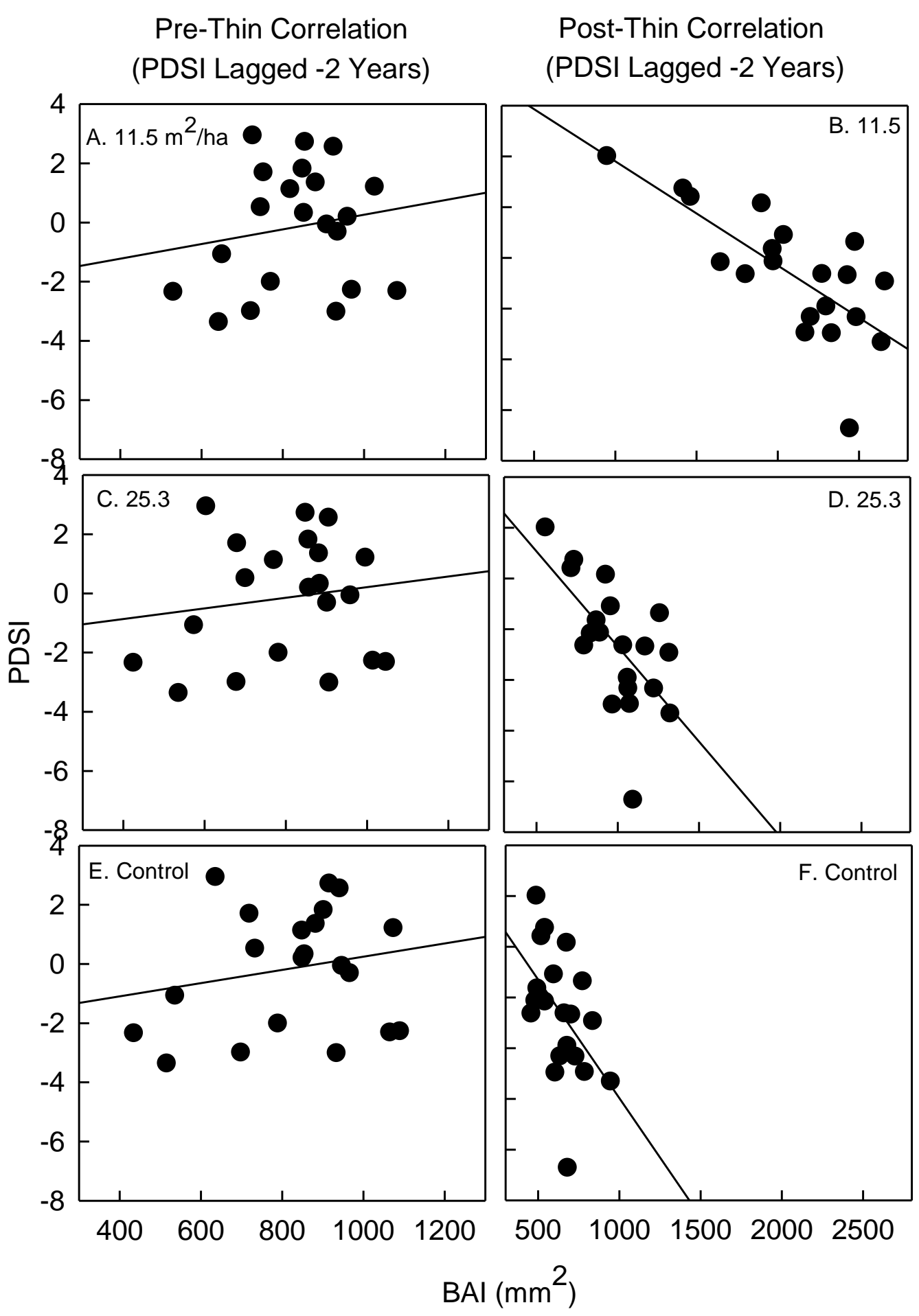

Figure A-5. Subset of Pre- and Post- Thin Pearson correlations between BAI, PDSI, and PDSI lagged -2 years in the 11.5, 25.3, and control treatments as an example of the switch from positive to negative PDSI correlation. 


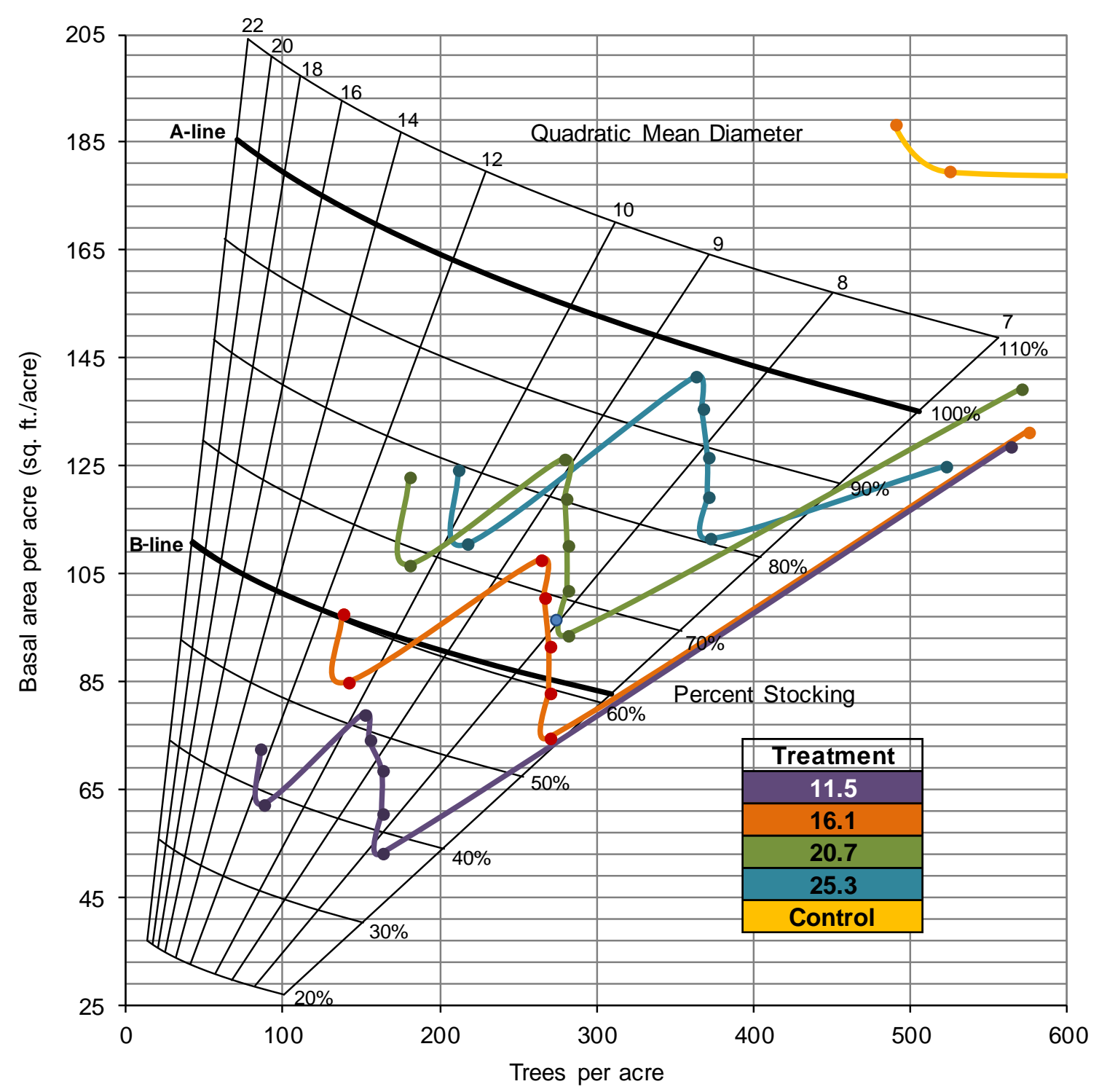

Figure A-6. Pine Stocking Study (Chapter 3) original treatment densities (1950-1971) Gingrich stocking diagram from Rogers (1982) developed for MS Excel by Dr. David Larsen, University of Missouri. Stocking chart is in English units. 